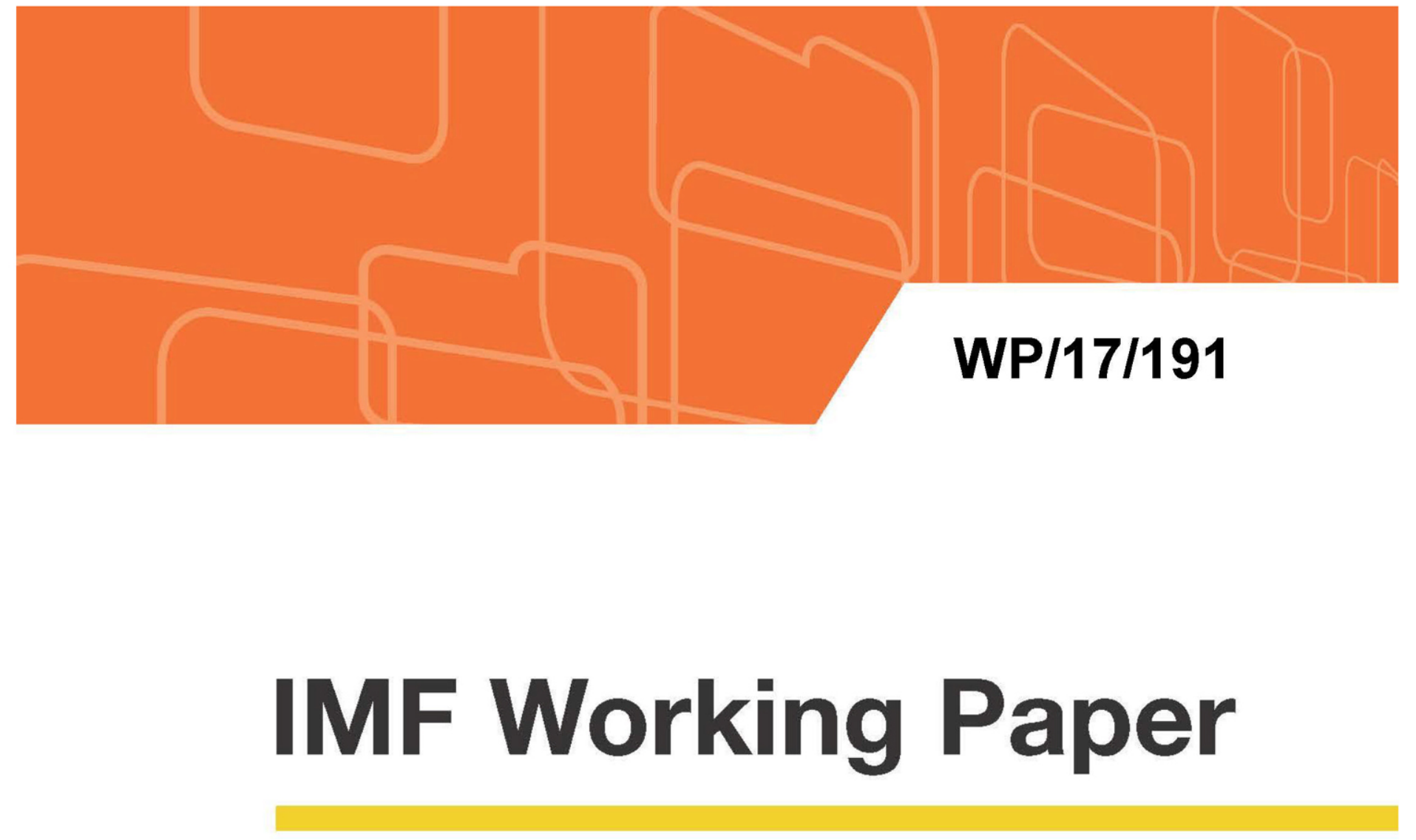

\title{
Emissions and Growth: Trends and Cycles in a Globalized World
}

by Gail Cohen, Joao Jalles, Prakash Loungani, and Ricardo Marto

IMF Working Papers describe research in progress by the authors and are published to elicit comments and to encourage debate. The views expressed in IMF Working Papers are those of the authors and do not necessarily represent the views of the IMF, its Executive Board, or IMF management. 


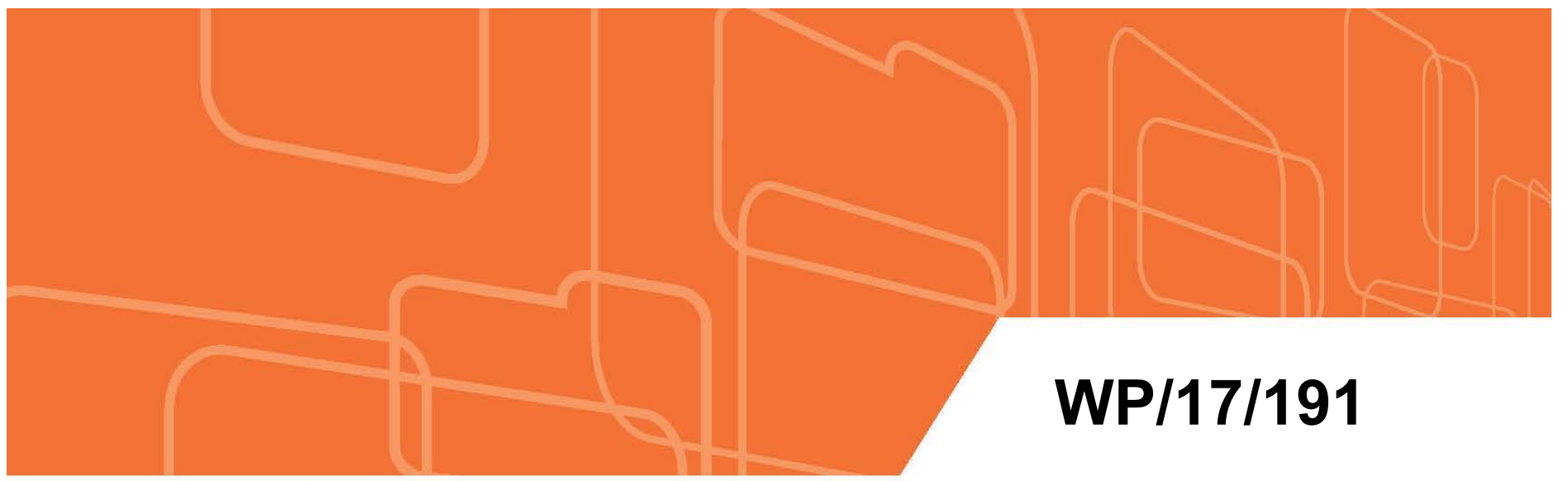

\section{IMF Working Paper}

\section{Emissions and Growth: Trends and Cycles in a Globalized World}

by Gail Cohen, Joao Jalles, Prakash Loungani, and Ricardo Marto

IMF Working Papers describe research in progress by the authors and are published to elicit comments and to encourage debate. The views expressed in IMF Working Papers are those of the authors and do not necessarily represent the views of the IMF, its Executive Board, or IMF management.

$$
\text { I N T E R N A T I O N A L M O N E T A R Y F U N D }
$$




\title{
IMF Working Paper
}

\author{
Research Department and Fiscal Department
}

\author{
Emissions and Growth: Trends and Cycles in a Globalized World \\ Prepared by Gail Cohen, Joao Jalles, Prakash Loungani, and Ricardo Marto
}

Authorized for distribution by Prakash Loungani

August 2017

\begin{abstract}
IMF Working Papers describe research in progress by the author(s) and are published to elicit comments and to encourage debate. The views expressed in IMF Working Papers are those of the author(s) and do not necessarily represent the views of the IMF, its Executive Board, or IMF management, or U.K. DFID.
\end{abstract}

\begin{abstract}
Recent discussions of the extent of decoupling between greenhouse gas (GHG) emissions and real gross domestic product (GDP) provide mixed evidence and have generated much debate. We show that to get a clear picture of decoupling it is important to distinguish cycles from trends: there is an Environmental Okun's Law (a cyclical relationship between emissions and real GDP) that often obscures the trend relationship between emissions and real GDP. We show that, once the cyclical relationship is accounted for, the trends show evidence of decoupling in richer nations - particularly in European countries, but not yet in emerging markets. The picture changes somewhat, however, if we take into consideration the effects of international trade, that is, if we distinguish between production-based and consumption-based emissions. Once we add in their net emission transfers, the evidence for decoupling among the richer countries gets weaker. The good news is that countries with underlying policy frameworks more supportive of renewable energy and supportive of climate change tend to have greater decoupling between trend emissions and trend GDP, and for both production- and consumption-based emissions.
\end{abstract}

JEL Classification Numbers: E32, O44, Q43, Q54, Q56.

Keywords: Emissions, Environmental Okun's Law, Environmental Kuznets Curve.

Authors’ E-Mail Addresses: gcohen@nas.edu, jjalles@imf.org, ploungani@imf.org, rmarto@imf.org.

\footnotetext{
* Authors are grateful to Ottmar Edenhofer, Marina Mendes Tavares, Adele Morris, Willi Semmler, and seminar participants at the Mercator Research Institute on Global Commons and Climate Change and the IMF for their useful comments, suggestions, and advice. The opinions expressed herein are those of the authors and do not necessarily reflect those of the IMF, its member states or its policy. This working paper is part of a research project financed by the U.K.'s Department of International Development (DFID) to support macroeconomic research on Low Income Countries. This paper should not be reported as representing the view of the IMF or of DFID. The views expressed in this paper are those of the authors and do not necessarily represent those of the IMF, or of IMF policy, or of DFID.
} 


\section{Contents}

Page

1. Introduction $\quad \underline{3}$

2. Empirical Approach $\quad \underline{5}$

$\begin{array}{lll}\text { 3. Data } & \underline{7}\end{array}$

4. Trends and Cycles $\quad 1 \underline{1}$

4.1. Is there an Environmental Okun's Law? . . . . . . . . . . . . . . . 12

4.2. Do Kuznets elasticities reflect a low-carbon transition? . . . . . . . . . . . . . $1 \underline{6}$

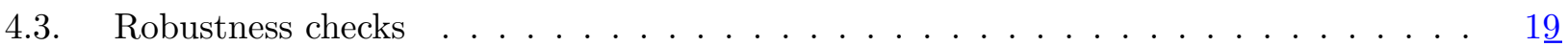

5. Globalization and Emissions $2 \underline{1}$

5.1. Trade matters for emissions . . . . . . . . . . . . . . . . . 21

5.2. Revisiting Okun and Kuznets elasticities . . . . . . . . . . . . . . 24

6. Explaining Cross-Country Differences $\quad 2 \underline{7}$

$\begin{array}{lr}\text { 7. Conclusion } & 3 \underline{2}\end{array}$

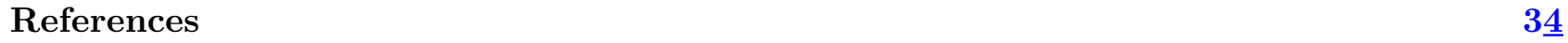

$\begin{array}{ll}\text { Appendix } & 3 \underline{7}\end{array}$

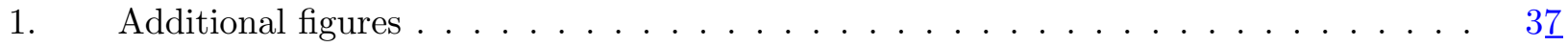

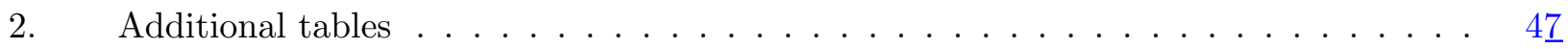

Figures

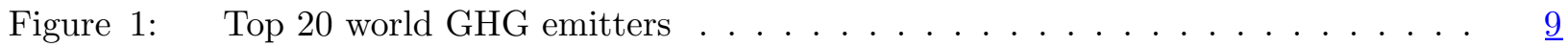

Figure 2: Trends and cycles in some advanced economies . . . . . . . . . . . . . . 12

Figure 3: Trends and cycles in some emerging economies . . . . . . . . . . . . . . . . . . .

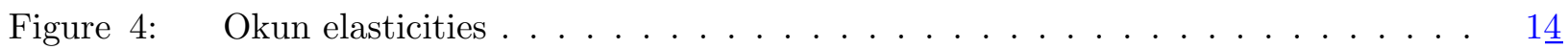

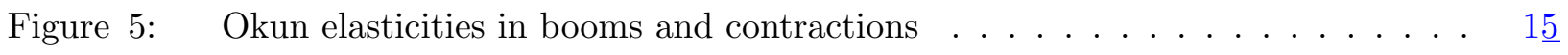

Figure 6: Time-varying Okun elasticities $\left(\mathrm{CO}_{2}\right.$ emissions $) \ldots \ldots \ldots \ldots$

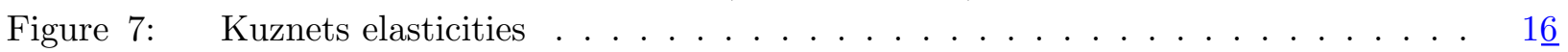

Figure 8: Time-varying Okun estimates (production-based GHG emissions) . . . . . 19

Figure 9: Okun elasticities: Production vs. consumption . . . . . . . . . . $2 \underline{5}$

Figure 10: Time-varying Okun estimates (consumption-based GHG emissions) . . . . . $2 \underline{6}$

Figure 11: Kuznets elasticities: Production vs. consumption . . . . . . . . . . 2 2 Z

Figure 12: The EKC revisited: Kuznets elasticities and real GDP per capita . . . . . . $2 \underline{8}$

Figure 13: Kuznets elasticities and Sectoral value added . . . . . . . . . . $3 \underline{0}$ 
Figure 14: Kuznets elasticities and Policy framework . . . . . . . . . . . $\underline{31}$

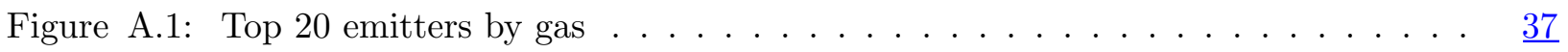

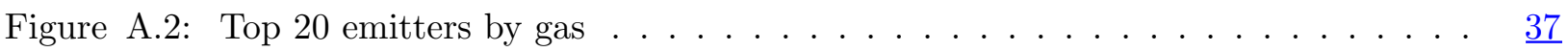

Figure A.3: Elasticity of emissions growth with respect to GDP growth . . . . . . . $\underline{38}$

Figure A.4: Variance decomposition of emissions . . . . . . . . . . . $\underline{38}$

Figure A.5: Production-based Okun elasticities around the world . . . . . . . . . $\underline{39}$

Figure A.6: Production-based Kuznets elasticities around the world . . . . . . . . . . $\underline{39}$

Figure A.7: Production-based Kuznets residuals . . . . . . . . . . . . . . $\underline{40}$

Figure A.8: Production-based Kuznets residuals for longer time series . . . . . . . . . $\underline{40}$

Figure A.9: Comparing OLS estimates with Bayesian estimates for production-based emissions ........................... 41

Figure A.10: Comparing HP estimates with Hamilton, Baxter-King, and Christiano-Fitzgerald estimates for production-based emissions . . . . . . . . . . 41

Figure A.11: Trends and cycles in some advanced economies (production-based vs. consumption-

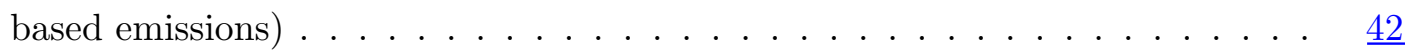

Figure A.12: Trends and cycles in some emerging economies (production-based vs. consumption-

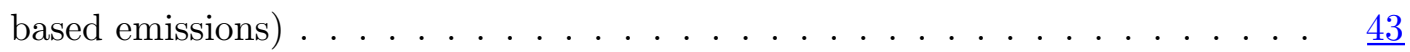

Figure A.13: Consumption-based Okun elasticities around the world . . . . . . . . . $\underline{44}$

Figure A.14: Consumption-based Kuznets residuals . . . . . . . . . . . . . . . . $\underline{44}$

Figure A.15: Consumption-based Kuznets elasticities around the world . . . . . . . . . $\underline{45}$

Figure A.16: Kuznets elasticities and real GDP per capita . . . . . . . . . . . . . $\underline{45}$

Figure A.17: Kuznets' y-intercepts and real GDP per capita . . . . . . . . . . . . . $\underline{46}$

Figure A.18: Kuznets y-intercepts: Production- vs. consumption-based . . . . . . . . $\underline{46}$

\section{Tables}

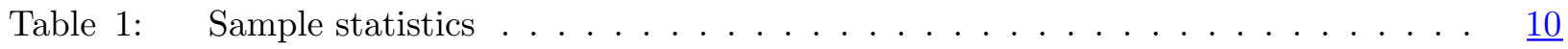

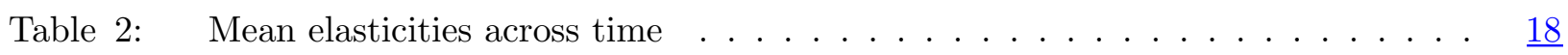

Table 3: Contrasting OLS and Bayesian estimates, HP and Hamilton filtering methods . $\underline{20}$

Table 4: Okun and Kuznets correlations for top 20 emitters . . . . . . . . . . 21

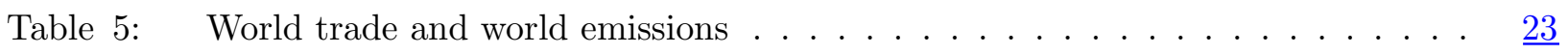

Table 6: Real GDP growth in trading partners and emissions . . . . . . . . . . $\underline{24}$

Table B.1: Augmented Dickey-Fuller test for unit root . . . . . . . . . . . . . $\underline{47}^{4}$

Table B.2: Augmented Dickey-Fuller test for unit root . . . . . . . . . . . . $\underline{48}$

Table B.3: Contrasting elasticities with LULUCF and $\mathrm{CO}_{2} \ldots \ldots \ldots \ldots$

Table B.4: Contrasting elasticities with longer time series . . . . . . . . . $\underline{51}$

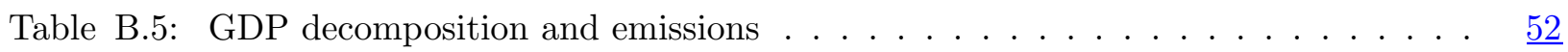

Table B.6: GDP decomposition, regional trade, and emissions . . . . . . . . . . $\underline{53}$

Table B.7: GDP decomposition, sectoral trade, and emissions . . . . . . . . . . $\underline{54}$

Table B.8: Augmented Dickey-Fuller test for unit root . . . . . . . . . $\underline{55}$

Table B.9: Economic structure and time-varying production-based Okun elasticities . . . . $\underline{56}$

Table B.10: Economic structure and time-varying consumption-based Okun elasticities . . . $\underline{56}$ 


\section{Introduction}

There are conflicting claims on whether emissions and economic activity have decoupled. Part of the debate arises from a failure to distinguish business cycles from trends: there is an Environmental Okun's Law (a cyclical relationship between emissions and real GDP) that often obscures the Environmental Kuznets Curve (the trend relationship between emissions and real GDP). By decomposing emissions and real GDP into their trend and cyclical components, we show that once the cyclical relationship is accounted for, the trends reveal evidence of decoupling in richer nations, particularly in European countries, but not yet in emerging markets. We then apply the framework to take into account the effects of international trade, that is, we distinguish between production-based and consumption-based emissions. Accounting for the emissions embodied in a country's net emission transfers does make some difference to the results. Specifically, the evidence for decoupling for the richer nations gets weaker, including for many European countries.

Okun's Law (after Okun, 1962) describes how labor market indicators, such as employment and unemployment, respond to cyclical movements in output, after accounting for the trend behavior in these variables. By analogy, we estimate an Environmental Okun's Law which describes the cyclical relationship between emissions and output, after accounting for the trend behavior in the two. The 'Okun elasticity' is the percent change in emissions (relative to trend) in response to a 1 percent change in real GDP (relative to trend). Similarly, we refer to the responsiveness of the trend component of emissions to the trend components of output as the Kuznets elasticity for the country. Kuznets famously conjectured that these elasticities would change as countries got richer: they would initially be strongly positive but beyond a certain threshold for average incomes they would start to decline and tend toward zero. When looking at a group of countries at different levels of per capita GDP, this traces out the so-called Environmental Kuznets Curve (EKC; see Grossman and Krueger (1991 and 1995)), a relationship that comes through quite clearly in our results once we control for cyclical fluctuations.

To estimate the cyclical and structural relationships between emissions and GDP, we use data for the top 20 world emitters for the period between 1990 and 2012. This sample is the focus of our work and most of the results are based on it. We supplement this sample with longer time series starting in 1850 for 16 countries and also present a brief summary of results for a much larger group of 161 countries. ${ }^{1}$ We use a broad measure of emissions that includes, in addition to $\mathrm{CO}_{2}$, methane $\left(\mathrm{CH}_{4}\right)$, nitrous oxide $\left(\mathrm{N}_{2} \mathrm{O}\right)$, and fluorinated gases to capture developments in key sectors, such as agriculture. In addition to documenting the relationship between GDP growth and environmental quality over time, we carry out a panel investigation of some of the factors that may explain the cross-country variation in the Kuznets and Okun elasticities.

Few studies have addressed all these issues for a large group of countries in one simple but comprehensive framework, which is the gap this paper aims to fill. Doda (2014) analyzes the heterogeneity in cyclical properties of $\mathrm{CO}_{2}$ emissions for a panel of countries and provides evidence of the higher volatility of cyclical emissions relative to GDP. Heutel (2012) discusses the higher volatility and pro-

\footnotetext{
${ }^{1} \mathrm{~A}$ detailed discussion of the results from the 161-country data set will be in a separate paper (ongoing).
} 
cyclicality of emissions for the United States, while Sheldon (2017) shows that emissions in the U.S. fall more sharply when GDP declines than they rise when GDP increases. York (2012), on the other hand, demonstrates that the response of emissions to an increase in income is greater during economic expansions. Burke et al. (2015) look at $\mathrm{CO}_{2}$ emissions and value added growth rates and concludes that as per capita GDP increases emissions growth rates decline. The literature analyzing the long term relationship between emissions and output has tested for unit roots and cointegration. Pao and Tsai (2010), for instance, show that for a panel of BRICs over the 1971-2005 period, $\mathrm{CO}_{2}$ long run elasticities with respect to real GDP are very disparate, with positive and significant values for India and China, insignificant for Brazil, and negative and significant for Russia. Anjum et al. (2014) reformulate the EKC in terms of long-run growth rates and find smaller elasticities of emissions with respect to income than Stern (2010), which uses mean emissions and mean income.

This paper is also related to the incipient literature on consumption-based emissions and their relevance for curbing the effects of climate change. Although some advanced economies have managed to stabilize their emissions, some studies argue that this was achieved at the expense of a rise of carbon-intensive imports from developing economies after outsourcing production to those countries. Davis and Caldeira (2010) find that $23 \%$ of global $\mathrm{CO}_{2}$ emissions were embodied in exports from China and other emerging markets to more advanced economies in 2004, while Peters et al. (2011) argue that net emissions from trade from developing to developed countries increased fourfold between 2000 and 2008 - exceeding Kyoto Protocol targets. Peters and Hertwich (2008) as well as Aichele and Felbermayr (2012) concur and show that the Kyoto Protocol had a limited effect on world emissions, with little variation in countries' carbon footprints despite reductions in production-based emissions. Pan et al. (2008) study China's consumption-based emissions and suggest that the current institutional framework, which favors the production-based accounting of emissions, has encouraged carbon leakages through trade. On the other hand, consumption-based emissions are not the panacea. These may fail to account for different degrees of trade specialization as Jakob et al. (2013) pointed out. Kander et al. (2015) propose an improvement to consumption-based emissions that take into account technology differences in export sectors and Jakob et al. (2014) suggest that climate policy should focus on a few highly traded, emission-intensive industries to reduce carbon leakages.

The contribution of this paper is therefore threefold. First, it aims to provide a thorough account of how production-based emissions-output elasticities have evolved across the largest world GHG emitters, distinguishing cyclical fluctuations from structural trends. Second, it aims to shed light on how globalization is related to emissions, highlighting the importance of trade in understanding real changes in these elasticities. Finally, the paper relates the production- and consumption-based elasticities to key characteristics, documenting cross-countries differences in terms of income per capita, economic structure, and policies.

The remainder of the paper is organized as follows. Section II discusses the paper's empirical approach and Section III presents the data used. Section IV presents our baseline estimates of the Okun and Kuznets elasticities. Section V discusses how trade affects emissions and revisits our estimates of the elasticities after accounting for international trade. Section VI explores explanations for crosscountry differences in elasticities based on differences in climate policies and economic structures. The conclusion and policy implications of our findings are discussed in Section VII.

CInternational Monetary Fund. Not for Redistribution 


\section{Empirical Approach}

\section{Framework}

To understand empirically the relationship between emissions and real GDP, we first consider the following specification

$$
\Delta e_{t}=\alpha+\omega \Delta y_{t}+u_{t}
$$

where $\Delta e_{t}$ and $\Delta y_{t}$ are the growth rates of emissions and real GDP, respectively. We then depart from this specification to distinguish cycles from trends to shed light on the recent decoupling phenomena seen in several advanced economies. Okun (1962) documented a strong cyclical relationship between the unemployment rate and real GDP - the so-called Okun's Law, a "sturdy empirical regularity" (Blinder, 1997). For our own purposes, we adapt this law as one that relates detrended real GDP and emissions, that we label as the Environmental Okun's Law, or, more formally

$$
e_{t}^{c}=\beta^{\mathrm{okun}} y_{t}^{c}+\varepsilon_{t}^{c},
$$

where $e_{t}^{c}$ and $y_{t}^{c}$ are the cyclical components of the log of emissions and log of real output, respectively, and $\beta^{\text {okun }}$ is the Environmental Okun's elasticity. We also consider the long-term relationship between emissions and real GDP by analyzing their respective trends. The Kuznets estimate, $\beta^{\text {kuznets }}$, relates trend real GDP, $y_{t}^{\tau}$, with trend emissions, $e_{t}^{\tau}$, such that

$$
e_{t}^{\tau}=\gamma+\beta^{\text {kuznets }} y_{t}^{\tau}+\varepsilon_{t}^{\tau}
$$

By estimating the cross-country long-run emissions elasticity with respect to real GDP, we are able to study whether richer economies - as measured by their income per capita - tend to have a lower level of environmental degradation (as measured by emissions) and whether the path to high income status configures a period of magnified emissions. We estimate the model with an intercept $(\gamma)$, expecting countries to be endowed with relatively different initial conditions and, therefore, with some inherent historical level of emissions.

To extract the cyclical and trend components ( $c_{t}$ and $\tau_{t}$, respectively) of real GDP and emissions, we employ the commonly used Hodrick-Prescott (HP, 1981, 1997) filter. This filter minimizes the following function

$$
\min _{\tau_{t}}\left\{\sum_{t=1}^{T}\left(y_{t}-\tau_{t}\right)^{2}+\lambda \sum_{t=1}^{T}\left[\left(\tau_{t}-\tau_{t-1}\right)-\left(\tau_{t-1}-\tau_{t-2}\right)\right]^{2}\right\},
$$

where $\lambda$ is the smoothing parameter set at 100, as common practice when employing annual data. ${ }^{2}$ The criticisms surrounding the use of the HP filter, in particular in the context of a large sample of very heterogeneous countries, are well-known (see Harvey and Jaeger, 1993; Cogley and Nason, 1995; Hamilton, 2017). We therefore also compare the cyclical and trend series with the ones proposed by

\footnotetext{
${ }^{2}$ Ravn and Uhlig (2002) suggest a smoothing parameter of 6.25 for annual data, which is more congruent with a smoothing parameter of 1600 applied to quarterly data and has commonly been applied to advanced economies' time series. The greater the value of $\lambda$, the larger is the penalty on variations of the trend's growth rate (i.e. the sum of the squares of the trend's second differences).
} 
Hamilton (2017) as an alternative filtering method. For that purpose, we estimate

$$
y_{t+h}=\beta_{0}+\sum_{j=0}^{k} \beta_{j+1} y_{t-j}+u_{t+h},
$$

where as before $y_{t}=\tau_{t}+c_{t}$. The non-stationary part of the regression provides the cyclical component

$$
c_{t}=\hat{u}_{t}
$$

while the trend is given by

$$
\tau_{t}=\hat{\beta}_{0}+\sum_{j=0}^{k} \hat{\beta}_{j+1} y_{t-h-j} .
$$

Hamilton (2017) suggests that $h$ and $k$ should be chosen such that the residuals from equation (5) are stationary and points that for a broad array of processes, the fourth differences of a series are indeed stationary. In that regard, we choose $h=2$ and $k=3$, which is line with the dynamics seen in both emissions and GDP. ${ }^{3}$

\section{Estimation}

Equations (1), (2), and (3) are estimated using ordinary least squares (OLS) for each country in our dataset with at least 21 observations of both real GDP and emissions.

As a robustness check, we also estimate these equations through Bayesian maximum likelihood. Bayesian methods are useful to estimate the relationship at hand because they allow to combine assumptions on the prior distribution of $\beta^{\text {okun }}$ and $\beta^{\text {kuznets }}$ (let it be called $p\left(\beta^{j}\right)$ for $j=$ okun, kuznets) with information extracted from the data (the likelihood function $\mathcal{L}\left(y^{\text {data }} \mid \beta^{j}\right)$ ), which mitigates the effect of small sample sizes given well-informed priors. The posterior distributions of our Okun and Kuznets coefficients $\left(p\left(\beta^{j} \mid y^{\text {data }}\right)\right)$ are proportional to the likelihood and their prior distributions, i.e.

$$
p\left(\beta^{j} \mid y^{\text {data }}\right) \propto \mathcal{L}\left(y^{\text {data }} \mid \beta^{j}\right) p\left(\beta^{j}\right),
$$

approximated with Markov Chain Monte Carlo simulation methods. Posterior estimates are based on 25,000 random draws from 3 Markov chains, discarding the initial 5,000 draws. The draws are generated following a random-walk Metropolis-Hastings with an acceptance rate between 20 and 30\%. We assume a normally-distributed likelihood function with unknown variance (i.e. with a non-informative Jeffreys prior). Our priors are informed by the EKC relationship, assuming $\beta^{j}$ behaves disparately across different income groups, i.e. we assume emissions elasticity to output for low income countries to fluctuate around 0 , since these countries are expected to be at an early stage of their development process; with mean 0.5 for advanced economies, as the EKC argues that richer countries have reached a level of development that allows them to pollute less; and with prior mean of 1 for the emerging

\footnotetext{
${ }^{3}$ We cross-checked our findings using alternative filtering methods, such as the Baxter-King and the ChristianoFitzgerald Random Walk. Other methods exist such as the one explored in Chang et al. (2015), who develop a Bayesian reduced-rank method to split the series.
} 
economies, which are supposed to be the more intense emitters. Our priors follow a normal distribution (preferred for non-bounded parameters) and standard deviations are set at 1 for all countries.

Another contribution of this paper is considering that the regression coefficients of equation (2) may vary over time, that is

$$
e_{t}^{c}=\beta_{t}^{\text {okun }} y_{t}^{c}+\varepsilon_{t}^{c}
$$

where $\beta_{t}^{\text {okun }}$ follows a random walk, i.e. assumed to change slowly and unsystematically over time, and in expectation equal to its historical value. The change of the coefficient is denoted by $\nu_{t}$, which is assumed to be normally distributed with mean zero and variance $\sigma^{2}$, such that

$$
\beta_{t}^{\text {okun }}=\beta_{t-1}^{\text {okun }}+\nu_{t}
$$

Equations (9) and (10) are jointly estimated using the Varying-Coefficient model proposed by Schlicht $(1985,1988)$, where $\hat{\beta}_{t}^{\text {okun }}$ is obtained by minimizing $\sum_{t=1}^{T}\left(\varepsilon_{t}^{c}\right)^{2}+\sum_{t=2}^{T} \nu_{t}^{2}$ and the covariance matrix $\sum_{\nu \nu}$ is assumed to be diagonal. ${ }^{4}$ As discussed by Aghion and Marinescu (2008), this method has several advantages compared to other methods to compute time-varying coefficients such as rolling windows and Gaussian methods. First, it allows using all observations in the sample to estimate the Environmental Okun coefficient in each year-which by construction is not possible in the rolling windows approach. Second, changes in the Environmental Okun coefficient in a given year come from innovations in the same year, rather than from shocks occurring in neighboring years. Third, it reduces reverse causality problems when the Environmental Okun coefficient is used as explanatory variable as it depends on the past.

\section{Data}

We use various sources of data to conduct the empirical analysis. Most of the analysis covers data ranging from 1990 through 2012 for 161 advanced, emerging market and developing economies. We pay particular attention to the top 20 largest GHG emitters and when warranted, we use data that goes as far back as 1850. We distinguish between production-based emissions and consumption-based emissions, and look beyond $\mathrm{CO}_{2}$ emissions since $26 \%$ of emissions do not derive from $\mathrm{CO}_{2}$ and it may underestimate economic activity in major agricultural producers.

\section{Production- and consumption-based emissions}

We use data aggregated by the World Resources Institute (WRI), which includes GHG emissions by gas and economic sectors. GHG emissions rely on a gas aggregation method that includes carbon dioxide $\left(\mathrm{CO}_{2}\right)$ and non- $\mathrm{CO}_{2}$ emissions, such as methane $\left(\mathrm{CH}_{4}\right)$, nitrous oxide $\left(\mathrm{N}_{2} \mathrm{O}\right)$, and fluorinated gases (F-gases), converted based on their 100-year Global Warming Potential (GWP-100) according to the IPCC's $2^{\text {nd }}$ Assessment Report.

\footnotetext{
${ }^{4}$ Equations (9) and (10) generalize equation (2), which is obtained as a special case when the variance of the disturbance in the coefficient $\sum_{\nu \nu}$ is zero.
} 
$\mathrm{CO}_{2}$ emissions from fossil fuel combustion and cement manufacture are taken from the International Energy Agency (IEA) for the 34 OECD's industrialized countries and 101 developing economies), the Carbon Dioxide Information Analysis Center (CDIAC) for 50 countries that lack IEA data (cover mostly cement production and up to 2011), and the U.S. Energy Information Administration (USEIA), which complements the CDIAC's 2012 emissions for the 50 countries that lack IEA data. $\mathrm{CH}_{4}$ and $\mathrm{N}_{2} \mathrm{O}$ are taken from U.S. Environmental Protection Agency (US-EPA), which provides data on emissions from industrial processes and waste, and from the Food and Agriculture Organization (FAO), which includes data on agriculture emissions. F-gas emissions are provided by the US-EPA and fall within the industrial processes sector. We also use data going back to 1850 from the CDIAC on $\mathrm{CO}_{2}$ emissions from fossil fuel combustion (available for some 15 countries from 1850 and 35 countries from 1900).

Emissions by sector regroup agriculture, energy, industrial processes, and waste emissions. Agriculture emissions are made of $\mathrm{CH}_{4}$ and $\mathrm{N}_{2} \mathrm{O}$ (data from FAO) and energy emissions are composed of $\mathrm{CO}_{2}$ from fuel combustion (IEA) and of $\mathrm{CH}_{4}$ and $\mathrm{N}_{2} \mathrm{O}$ from fugitive emissions (US-EPA). Industrial processes include $\mathrm{CO}_{2}$ from cement production (CDIAC) and other related emissions (US-EPA), and waste emissions are produced by $\mathrm{CH}_{4}$ and $\mathrm{N}_{2} \mathrm{O}$ from landfills and human sewage (US-EPA). In contrast with the literature, we favor GHG emissions for being a more comprehensive measure of emissions and a clearer depiction of economic activity. For instance, major agricultural producers (such as Brazil, Indonesia, Mexico, and Australia) emit almost as much methane as carbon dioxide (with $\mathrm{CH}_{4}$ representing 31 to 79 percent of $\mathrm{CO}_{2}$ emissions). We do not include GHG emissions from Land-use and Land-use Change and Forestry (LULUCF) in our baseline results, given the discrepancies between FAO data and what countries report to the UNFCCC. ${ }^{5}$

The twenty largest GHG emitters contribute with 74 percent to the world total level of emissions and account for 63 percent of the world population and 77 percent of global GDP (Figure 1). Between 1991 and 2013, the world's real GDP growth and the world's GHG emissions are correlated, with a correlation coefficient of 0.9. Although advanced economies emit more GHG than emerging markets, the largest emitters are found in the latter group. The average advanced economy emits annually 473 million metric tons of $\mathrm{CO}_{2}$ equivalent $\left(\mathrm{MtCO}_{2} \mathrm{e}\right)$, more than twice as much the average emerging market economy and almost 15 times more than the average low income economy. China, the U.S., India, Russia, and Japan are the largest GHG emitters - these five countries emit more 3.7 billion metric tons of $\mathrm{CO}_{2}$ e (i.e. $20 \%$ more) annually than the remaining 180 countries for which data is available (Table 1). The major source of emissions from these countries is the energy sector, followed by agriculture, which are mostly expelled in the form of $\mathrm{CO}_{2}$ and $\mathrm{CH}_{4}$ (Figures A.1 and A.2 in the Appendix).

To compute our consumption-based emissions we require a measure of emissions embodied in international trade. We use the Eora multi-region input-output (MRIO) database, which provides data on both production and consumption emissions. ${ }^{6}$ The database matches emissions with input-

\footnotetext{
${ }^{5}$ Our results are robust even with the inclusion of LULUCF, except for some large territories where deforestation and reforestation represent an important fraction of emissions (namely Brazil, Canada, Japan, and Russia).

${ }^{6}$ The database is free of charge for academic purposes. Additional details can be found in Lenzen et al (2012) and (2013).
} 
output tables covering more than 15,000 sectors and 170 countries of our original dataset. Productionbased emissions are based on EDGAR (Emissions Database for Global Atmospheric Research) and FAO. EDGAR's $\mathrm{CO}_{2}, \mathrm{CH}_{4}$, and $\mathrm{N}_{2} \mathrm{O}$ emissions are calculated based on the energy balance statistics of the IEA, which is the same source of emissions as for the WRI dataset, agriculture emissions follow FAO, and the remaining emissions combine alternative sources. In light of some differences in production emissions from Eora and our original emissions time series, we use the difference between Eora's consumption and production emissions, capturing emissions derived from international trade and added it to our production-based emissions for each country and year.

The twenty largest consumption-based GHG emitters look very similar to our initial group, with China, the U.S., and India leading world emissions (Japan and Russia inverted their positions and are now $4^{\text {th }}$ and $5^{\text {th }}$, respectively). Two countries (South Africa and Ukraine) dropped below the top 20-but remained among the largest 23 world emitters - and were replaced by Spain and Poland (these countries were previously ranked $22^{\text {nd }}$ and $21^{\text {st }}$, respectively). Our original twenty largest GHG emitters represent 78 percent of the world's consumption-based emissions, emitting an average 33,289 $\mathrm{MtCO}_{2} \mathrm{e}$ every year. The countries for which trade contributed the largest decrease in emissions when comparing production and consumption-based are mostly advanced economies (with the U.S., Japan, the U.K., France, and Germany leading the gains), while most African countries together with China and Russia have considerably lower consumption than production-based emissions (after China and Russia, the Central African Republic, Ethiopia, Ghana, Nigeria, and India have the largest negative difference between emissions). Moreover, several countries have had negative consumptionbased emissions over the past 20 years. These are mostly African countries (more than 25 countries) and some East Asian (Cambodia, Laos, and Myanmar) and Eastern European (Belarus, Latvia, and Moldova) economies. ${ }^{7}$

Figure 1: Top 20 world GHG emitters

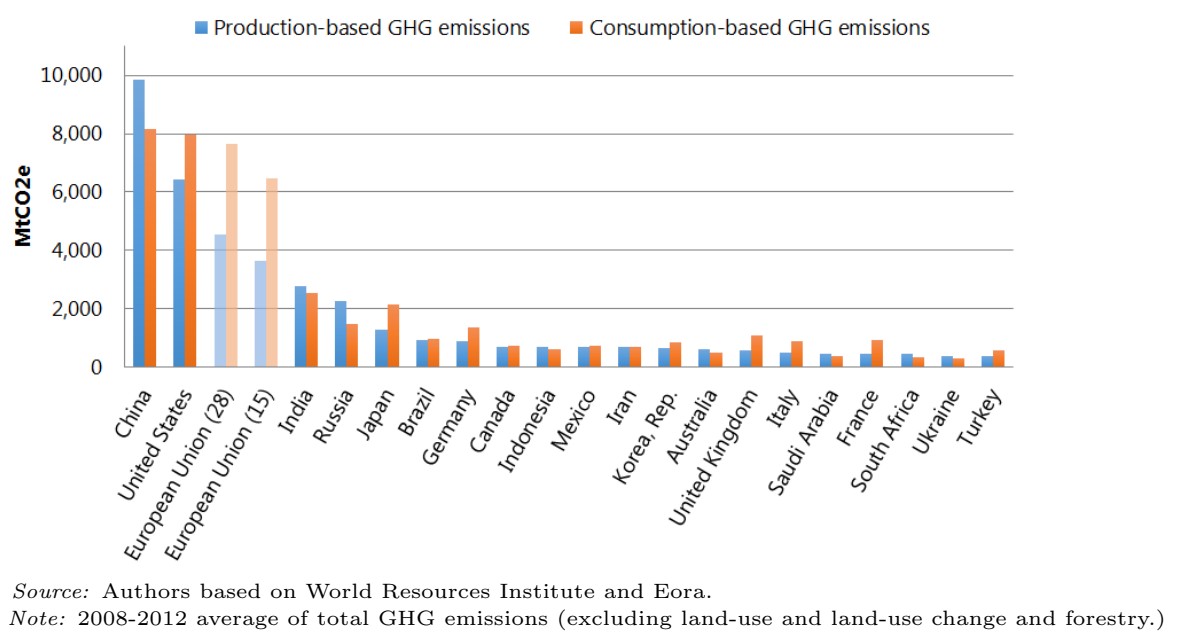

${ }^{7}$ Countries with several years of negative emissions were dropped from our sample. 
Table 1: Sample statistics

\begin{tabular}{|c|c|c|c|c|c|}
\hline VARIABLE & Obs. & Mean & Std. Dev. & Min & Max. \\
\hline \multicolumn{6}{|c|}{ Advanced economies (29 countries, 1990-2012) } \\
\hline \multirow[t]{2}{*}{ GHG emissions } & 667 & 473.4 & $1,182.2$ & 2.7 & $6,865.2$ \\
\hline & 667 & 636.7 & $1,433.6$ & -13.4 & $8,897.5$ \\
\hline \multirow[t]{2}{*}{$\mathrm{CO}_{2}$ emissions } & 667 & 391.9 & 995.0 & 1.8 & $5,830.5$ \\
\hline & 667 & 456.3 & $1,110.9$ & 2.1 & $6,918.6$ \\
\hline \multicolumn{6}{|c|}{ Emerging markets (79 countries, 1990-2012) } \\
\hline \multirow[t]{2}{*}{ GHG emissions } & 1,817 & 233.8 & 803.4 & 0.1 & $10,975.5$ \\
\hline & 1,725 & 208.7 & 670.3 & -169.3 & $9,337.2$ \\
\hline \multirow[t]{2}{*}{$\mathrm{CO}_{2}$ emissions } & 1,817 & 164.0 & 635.6 & 0 & $9,312.5$ \\
\hline & 1,725 & 147.7 & 523.4 & -7.5 & $7,683.3$ \\
\hline \multicolumn{6}{|c|}{ Low income countries (53 countries, 1990-2012) } \\
\hline \multirow[t]{2}{*}{ GHG emissions } & 1,217 & 32.3 & 51.4 & 0.0 & 296.7 \\
\hline & 1,125 & -6.7 & 99.8 & $-1,474.2$ & 245.0 \\
\hline \multirow[t]{2}{*}{$\mathrm{CO}_{2}$ emissions } & 1,217 & 8.8 & 22.7 & 0.0 & 173.1 \\
\hline & 1,125 & 9.0 & 20.2 & -0.9 & 176.4 \\
\hline
\end{tabular}

\section{Other macroeconomic and environmental variables}

Real GDP (in national currency) and real GDP growth are retrieved from the latest update of the IMFs World Economic Outlook (WEO) database, which covers 189 countries starting in 1980. For the analysis with longer time series (starting 1850 through 2009), we use real GDP (in 1990 international dollars) from the Maddison-Project. Sectoral value added are taken from the World Bank World Development Indicators, in constant 2005 US\$, constant local currency, and in \% of GDP. ${ }^{8}$ Trade value and volumes are taken from the IMF WEO (for World's real exports/imports and export/import volumes at country level) and the IMF Direction of Trade Statistics and UN Comtrade databases (detailed data by product and country of export/import) aggregated by region and sector at the 1 and 2-digit level. The latter includes more than 10 million observations recording yearly transactions between 184 countries and for 96 sectors. For each country, the exports and imports series were deflated using the IMF's GDP deflator index.

Our measures of environmental policy aim to capture cross-country differences in climate change policies. Unfortunately, most of the indices available have a short timespan or are not freely available to the public. For our analysis, we considered four indices: (i) the Germanwatch's Climate Change Performance Index (CCPI); (ii) the World Bank's Country Policy and Institutional Assessment (CPIA) Environmental Sustainability index; (iii) the World Energy Council's Energy Trilemma Index (ETI); and (iv) EY's Renewable Energy Attractiveness Index (RECAI).

\footnotetext{
${ }^{8}$ Agriculture value added corresponds to ISIC divisions 1-5 (forestry, hunting, and fishing, as well as cultivation of crops and livestock production), Industry value added to ISIC divisions 10-45 with Manufacturing represented by divisions 1537 (also includes mining, construction, electricity, water, and gas), and Services value added correspond to ISIC divisions 50-99 (wholesale and retail trade, transport, and government, financial, professional, and personal services).
} 
The CCPI compares the climate protection performance of 58 countries, the largest world emitters, starting in 2006. It is based on fifteen indicators classified into five categories: Emissions level (with a weight of 30\%), Development of emissions (30\%), Efficiency (10\%), Renewable energies (10\%), and Climate policy (20\%). Since the CCPI includes $\mathrm{CO}_{2}$ emissions from fuel combustion from the IEA and from deforestation from FAO (accounting for about 30\%), we rely on three alternative measures to overcome endogeneity issues. The CPIA rates 82 developing economies (none of the top 20 world emitters) on their policy and institutions for environmental sustainability starting in 2005. The ratings are attributed by World Bank staff and reflect a variety of indicators, observations, and judgments capturing the extent to which environmental policies foster the protection and sustainable use of natural resources and the management of pollution. The ETI ranks 130 countries since 2011 on their ability to provide sustainable energy using four dimensions: Energy security (with a weight of 30\%), Energy equity (accessibility and affordability; 30\%), Environmental sustainability (30\%), and the Country context (10\%). As in the CCPI, emissions are included in the ETI (accounting for about $10 \%$ ). The RECAI measures the attractiveness of 40 countries (advanced and emerging economies) for companies interested in investing in renewable energies. Available since 2003 but redefined in 2016, the index is organized around five pillars: Macro context, Energy imperative (security, supply, and affordability), Policy enablement, Project delivery (access, infrastructure, and financing), and Technology potential.

\section{Trends and Cycles}

We first look at the what the literature has focused on: the relationship between emissions growth and real GDP growth (i.e. equation (1)). Figure A.3 in the Appendix presents these elasticities for the 20 largest GHG emitters, with coefficients ranging from 0.34 (for India) to 1.25 (for Korea). We argue that assessing the decoupling based on these estimates ( $\omega$ below) is misleading since they capture both changes in economic activity associated with the phase of the business cycle the country finds itself in as well as structural changes that makes an economy less carbon-dependent because

$$
\Delta e_{t} \equiv \Delta e_{t}^{c}+\Delta e_{t}^{\tau}=\alpha+\omega\left(\Delta y_{t}^{c}+\Delta y_{t}^{\tau}\right)+u_{t} \equiv \alpha+\omega \Delta y_{t}+u_{t}
$$

and therefore rewriting equation (11) using (2) and (3) would show that $\omega=\frac{\beta^{\text {okun }} \Delta y_{t}^{c}+\beta^{\text {kuznets }} \Delta y_{t}^{\tau}}{\Delta y_{t}}$.

Given this, we focus on the filtered series and assess how the relationship between emissions and output in trends and cycles have evolved. On one hand, cyclical emissions appear to trail cyclical output fairly well across most countries, with peaks and troughs matching well (Figures 2 and 3 below). On the other hand and despite the cyclical relationship, we see a delinking between trend production-based emissions and trend real GDP for some advanced economies, while for emerging economies trend components still comove. We can assess whether the variance in the time series is due to the trend or cyclical components by decomposing the variance of GHG emissions (in logarithm) as

$$
\operatorname{Var}\left(e_{t}\right)=\operatorname{Var}\left(e_{t}^{c}\right)+\operatorname{Var}\left(e_{t}^{\tau}\right)+2 \operatorname{Cov}\left(e_{t}^{c}, e_{t}^{\tau}\right) .
$$


Figure A.4 shows the relative contribution of each component to the variance of GHG emissions for the 20 largest emitters. Most of the variance in emissions are captured by the variance in trend emissions. For few countries, the variance of cyclical emissions still help explain some of the variance in GHG emissions - more than 20 percent for France, Italy, and Japan. Other countries have the covariance between trend and cyclical series explain some of the variance in emissions (France, Italy, Russia, and the U.S.), but overall this term has little explanatory power.

Figure 2: Trends and cycles in some advanced economies
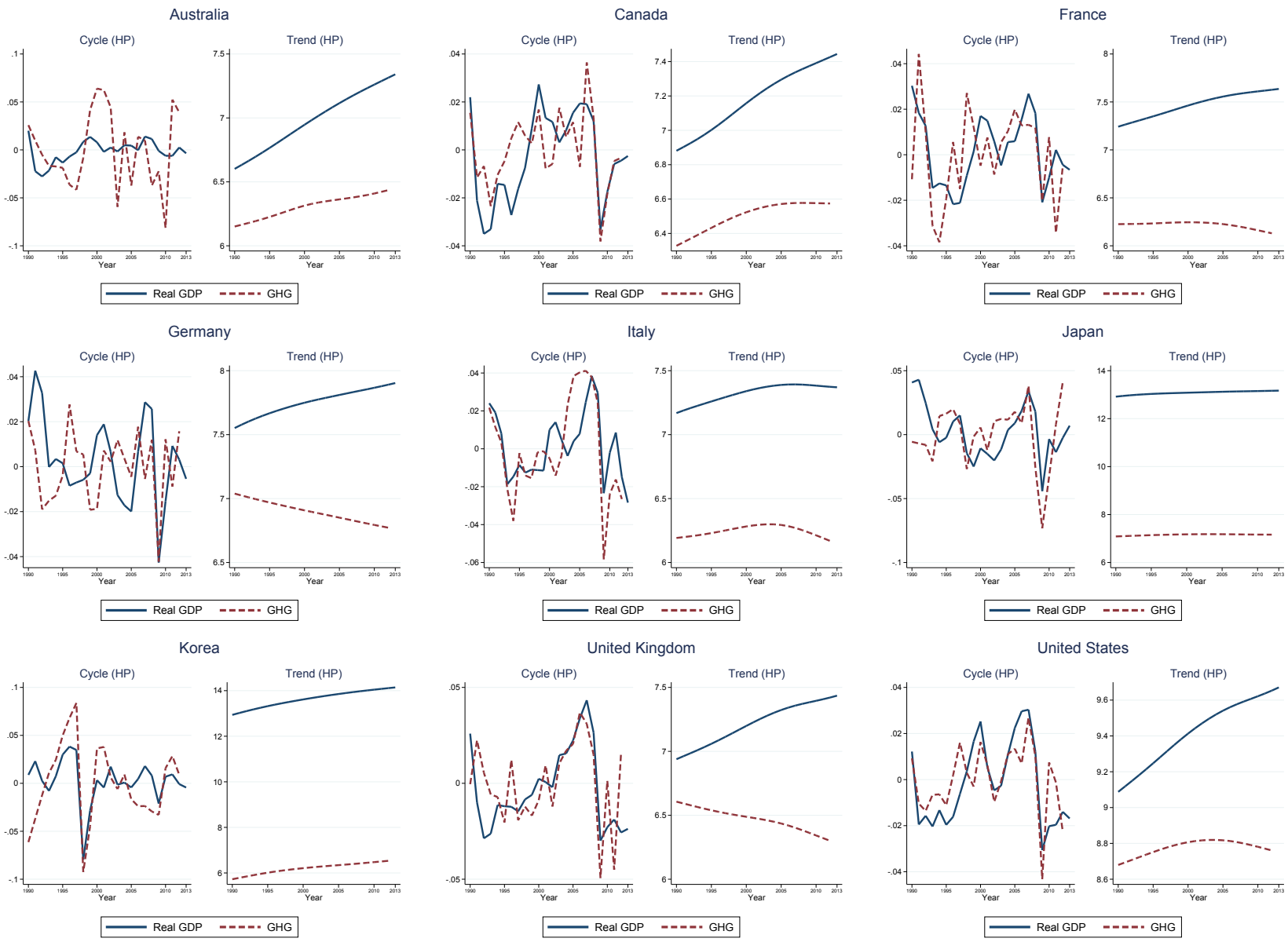

\subsection{Is there an Environmental Okun's Law?}

Emissions, like real GDP, move in cycles. Our results suggest that there is a strong cyclical relationship between emissions and real GDP (of 0.6 on average for each income group). Therefore, emissions could temporarily be low simply because the economy is in a downswing phase of its business cycle, or temporarily high during a boom period. Figure 4 shows the difference between coefficients $\hat{\omega}$ from equation (1) and $\hat{\beta}^{\text {okun }}$ from equation (2) for the top emitters. We see notable differences for large economies such as Brazil, Canada, India, and the U.S., which would suggest shifts in the 
Figure 3: Trends and cycles in some emerging economies
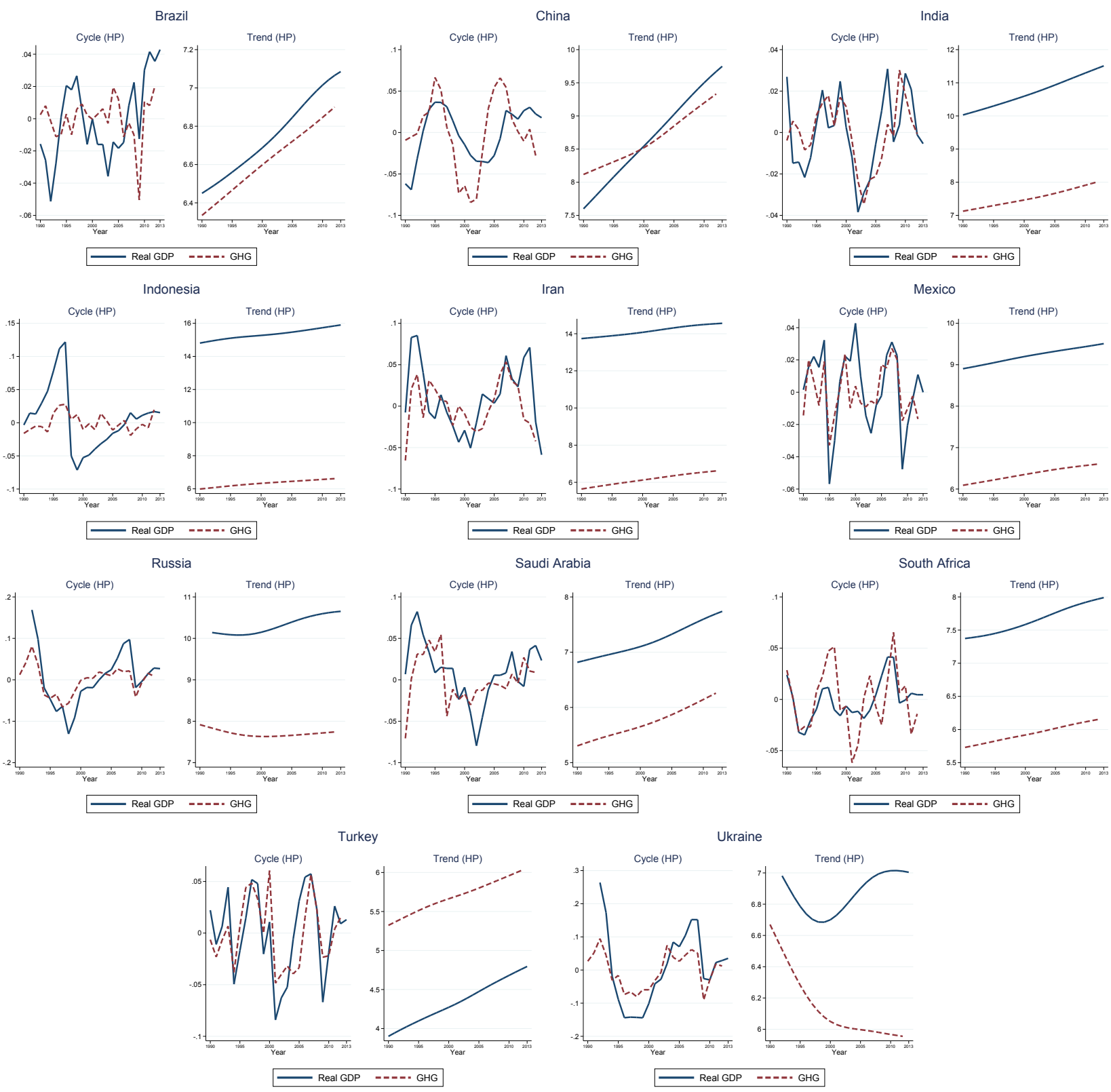

relationship between trends and cycles.

Figure A.5 in the Appendix presents the Okun estimates for the extended sample of 161 countries. The mean for the entire sample is 0.6 and is statistically significant for 78 countries. GHG emissions are highly procyclical ( $\beta^{\text {okun }}>1$ ) in Spain, Luxembourg, Korea, and Italy, but only countercyclical in the Netherlands $\left(\beta^{\text {okun }}=-0.4\right.$ ). The Netherlands is in fact the only country in the entire sample for which emissions are negatively correlated with GDP both within the business cycle and in the trend relationship, which could be related to the low carbon intensity of their major productive sectors and 
Figure 4: Okun elasticities

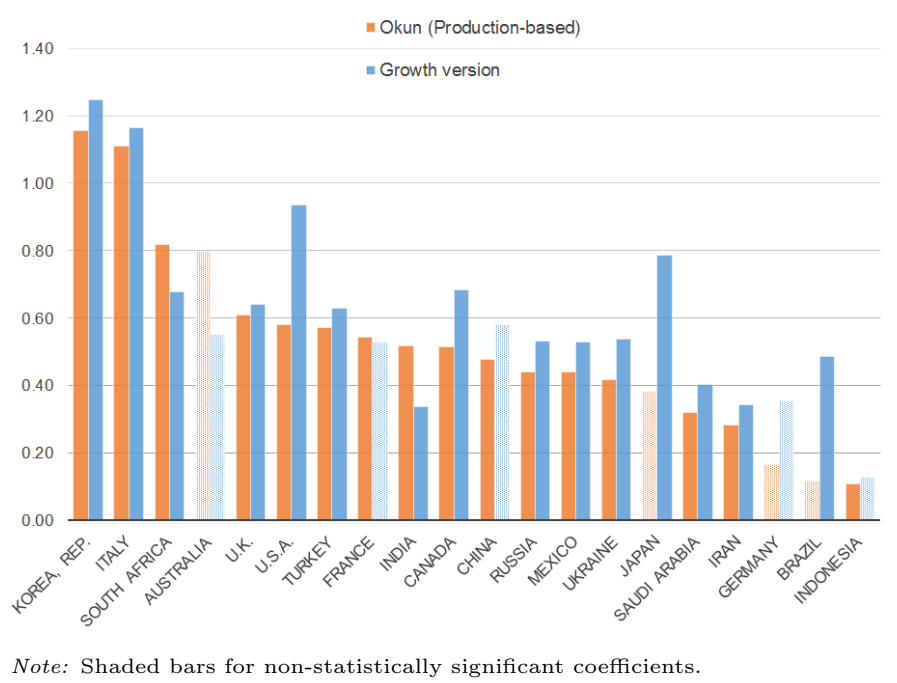

a de facto decoupling between emissions and output. Of the 86 emerging countries in the sample, 55 percent have Okun estimates different from 0 and from these almost $2 / 3$ have estimates above 0.5. The mean Okun for these countries is 0.62 (the median is 0.58), with Fiji and Jamaica as outliers with estimates above 1.5. Much fewer low income countries have statistically significant Okun estimates. Emissions in LICs tend to be procyclical with a mean Okun coefficient across 15 countries of 0.57 (the median is 0.5). Nepal, the Kyrgyz Rep., and Haiti present estimates close or above unity.

We also contrast the effect of output on emissions in periods of boom versus periods of contraction by estimating

$$
e_{t}^{c}=\beta^{\text {okun, boom }} y_{t}^{c \text {, boom }}+\beta^{\text {okun, bust }} y_{t}^{c, \text { bust }}+\varepsilon_{t}^{c},
$$

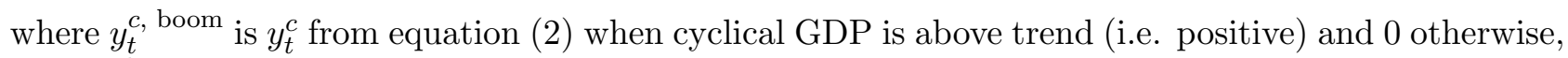
and $y_{t}^{c \text {, bust }}$ is given by $y_{t}^{c}$ when it is below trend (i.e. negative) and 0 otherwise. Figure 5 shows the average effect for the top 20 countries grouped by country income group and geographic region. Our results indicate that on average advanced economies tend to experience sharper reductions in cyclical emissions when the economy is in a contractionary phase than the other economies (with the exception of Australia). By contrast, commodity exporters (which also include Australia) tend to emit more when their economies are in an expansionary phase - which reflects the nature of their productive sectors. Despite these differences, the magnitude of the effect of output on emissions contrasting periods of boom and contraction is not very large. This result is in line with Sheldon (2017), who reports that for the U.S. the emissions-output elasticity is greater in recessions than in booms, and Burke et al. (2015), who found a lower emissions-output elasticity (using the growth version equation (1)) over long contractions and no significant differences in elasticities during expansions or contractions.

Finally, we explore the longer time series available. Emissions data is available for most of our 20 largest world emitters starting in 1850 for $\mathrm{CO}_{2}$, with some gaps during World War II that were linearly interpolated. Table B.4 in the Appendix reports these elasticities and compares them with 
Figure 5: Okun elasticities in booms and contractions

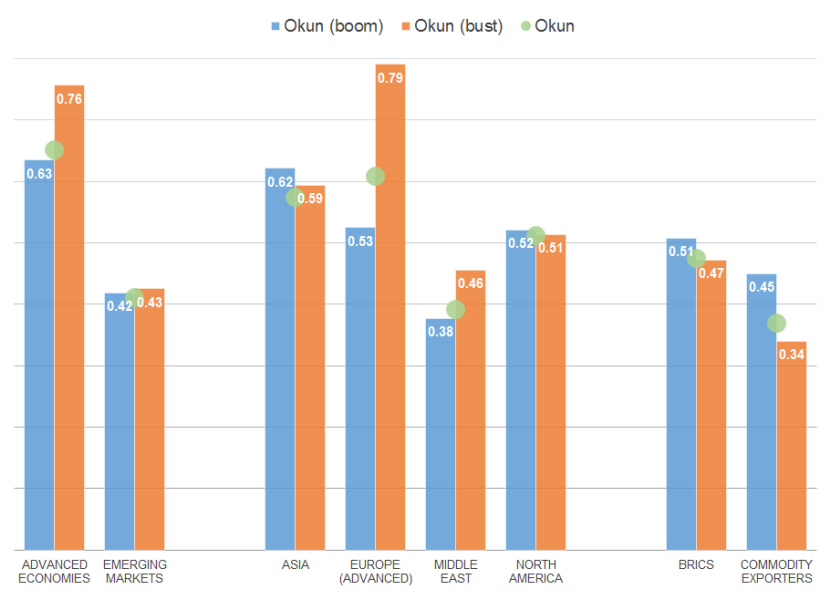

the Okun and Kuznets estimates for $\mathrm{CO}_{2}$ emissions up to 2009. Estimates over the business cycle show less improvement over time, with several countries presenting similar Okun coefficients (Australia and France) or even a worsening of the elasticities (India, Korea, Mexico, South Africa, Turkey, the U.K., and the U.S.) relative to the 1990-2009 period. The time-varying Okun elasticities show that some countries have made significant improvements in decoupling their cyclical GDP from cyclical emissions. For instance, Brazil, Canada, and Indonesia experienced a major decline in their Okun coefficient before stabilizing (between 1920 and 1960 for Brazil, 1880 and 1920 for Canada, and 18901950 for Indonesia). Other countries show a deterioration over the past decades, with growth becoming more carbon-intensive over time. This is the case of India (starting in 1910) and Turkey (over the 1940-1980 period). Also, in some cases the time-varying estimates added very little information, with countries like Australia, Korea, and the U.K. presenting fairly constant Okun elasticities over time. More interestingly, World War II seems to have a turning point for countries like Germany, Italy, and the U.S. (Figure 6). While Germany and Italy intensified their emissions-output elasticity in the years culminating to the end of the war, the U.S. experienced the reverse effect with the Okun elasticity dropping from 1 in the first decades of the $20^{\text {th }}$ century to an elasticity of 0.3 by 1945 .

We also contrast the Okun elasticities in periods of booms and contractions using the longer time series. There is considerable heterogeneity across countries estimates, but as previously the Okun elasticity when the economy contracts is greater than during expansions (with some exceptions such as China and Germany). China, in particular, records the largest difference between $\beta^{\text {okun, boom }}$ and $\beta^{\text {okun, bust }}$, with emissions growing by a factor of 2 during booms and 0.5 during contractions. As above, BRICS and commodity exporters have larger Okun elasticities during expansions than during contractions ( 0.8 and 0.9 during booms and 0.7 and 0.8 during busts, respectively), while the average effect in advanced economies is larger during contractions than during expansions (1.2 and 1.1). 
Figure 6: Time-varying Okun elasticities $\left(\mathrm{CO}_{2}\right.$ emissions)
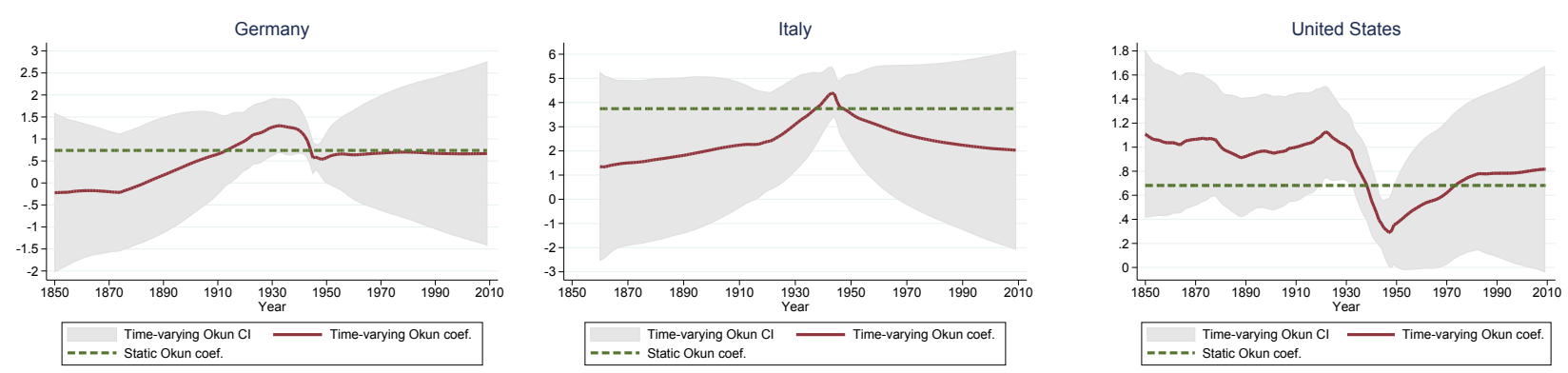

\subsection{Do Kuznets elasticities reflect a low-carbon transition?}

Advanced economies have managed to transition to a low-carbon path with trend real GDP and trend emissions moving in opposite directions. Among the top 20 largest GHG emitters, advanced economies present an average long-term emissions-to-output elasticity of 0.1, while BRICS and commodity exporters have Kuznets coefficients at a much higher level, ranging from 0.6 to 0.7 (Figure 7). Output in richer economies (namely in Germany, Denmark, U.K., Sweden, Finland, Netherlands, and Switzerland) tends to be correlated with a decrease in GHG emissions and for most advanced economies Kuznets coefficients are smaller than their Okun counterparts, suggesting that emissions are far more cyclical than structural in nature.

Figure 7: Kuznets elasticities

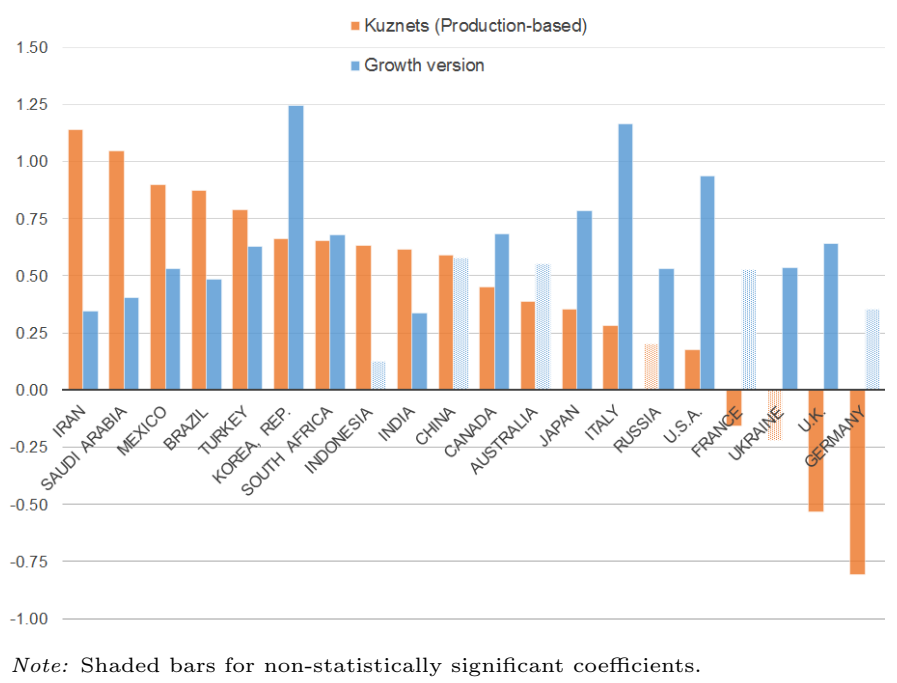

Figure A.6 in the Appendix presents the Kuznets coefficients for the extended sample of 161 countries. The mean Kuznets and Okun coefficients for the entire sample are very similar at 0.6 (with the median Kuznets (0.6) slightly above the median Okun) and estimates tend be statistically significant for the vast majority of countries (150 countries). Kuznets' support is wider than the 
distribution of Okun elasticities, but coefficients are concentrated around the mean and more skewed to the right than Okun. Advanced economies present the lowest mean Kuznets (0.14 and median of 0.23 ) and are the only group of countries for which the mean Kuznets is lower than the mean Okun (0.6). There is nonetheless heterogeneity within the 28 advanced countries. Output in richer economies tends to be correlated with a decrease in GHG emissions, while Greece, Portugal, and Spain are at the other end of the spectrum with estimates above 0.4 (Israel has the highest Kuznets estimate at 0.75). Surprisingly, the U.S. has a relatively low Kuznets coefficient of 0.18 .

Several emerging markets and low income countries have Kuznets above 1, in particular, oil producers (such as Libya, Oman, Iran, and Saudi Arabia) and small island states (such as Haiti, Kiribati, Seychelles, Tonga, Antigua and Barbuda, St. Kitts and Nevis, Maldives, and Mauritius). After power plants, oil and natural gas production is a major source of GHG emissions. The heavy reliance on these sectors justify such high Kuznets estimates in oil producing countries. Among the highest emitters per capita, small island states tend to have "dirty" energy matrices that rely heavily on fossil fuels. This dependence helps explain the predominance of extreme Kuznets coefficients. The mean and median of the statistically significant Kuznets coefficients (72 emerging countries) are 0.70 and 0.72 , respectively. More than 73 percent of emerging markets show a strong correlation of GHG emissions and GDP (Kuznets estimates above 0.5), while mostly eastern European countries (Romania, Hungary, and Poland) have a negative long-run emissions-output relationship. The mean Kuznets estimate for the 50 low income countries for which it is statistically meaningful is 0.72 (the median is 0.56 ), pushed by heavy outliers (Kiribati and Haiti with coefficients above 3) and several African countries with coefficients greater than unity (Togo, CAR, Ethiopia, Congo Rep., Benin, and Niger).

Using the longer time series, we find that several countries have made important strides in reducing their carbon-intensity, with the Kuznets elasticities for the 1990-2009 period much smaller than the ones implied by the longer time series. For instance, Germany and the U.K. reversed their trend $\mathrm{CO}_{2}$-GDP elasticity over the years. In contrast, a few countries have maintained relatively similar trend relationships for more than 100 years (Brazil, Japan, Mexico, South Africa, Turkey). We also assess how Okun and Kuznets elasticities have changed across time by splitting the time series into four key periods: (i) the Second Industrial Revolution (from 1870 to 1913), (ii) the war-interwar period (1914-1945), (iii) post-WWII period (1946-1982), and (iv) the Great Moderation (1983-2007), by estimating equations (2) and (3) for the four different subsamples. Table 2 summarizes the mean Okun and Kuznets elasticities across the different periods, considering all countries with more than 20 years of observations per period.

The differences in mean elasticities across periods are striking. Although the Second Industrial Revolution was a phase of rapid industrialization with advancements in manufacturing and the expansion of railroad networks, we see very little correlation between GDP and emissions at both the cyclical and trend level: the vast majority of countries have Kuznets estimates lower than 0.1 and Okun coefficients of 0. Despite the war efforts, the 1914-1945 period is not different from the previous period with coefficients of similar magnitude. The post-WWII period brought carbon intensity to a new level. The rapid growth in energy demand-mostly for oil-help explain the sudden increase in elasticities. Most of the 20 largest emitters have Kuznets estimates greater than 1 and the largest (China, India, and Korea) have coefficients greater than 1.5. At the cyclical level, the mean Okun 
coefficient of about 0.6 is greater for the 20 largest emitters than for the entire sample of countries. Although Asian economies tended to have larger Kuznets elasticities during that period, emissions at the cyclical level are more responsive to growth in European countries with France, Germany, and Italy (and Japan) presenting the largest Okun elasticities (above 1.3). Kuznets elasticities have reduced significantly during the Great Moderation, averaging 0.7 for the largest emitters and 0.9 for the entire sample. The Kyoto protocol and the slowdown in energy consumption, in particular of coal until 2001, may have played a role - China's Kuznets coefficient more than halved relative to the previous period. For the first time, several countries have managed to see a decoupling between trend emissions and trend GDP, with Denmark, Germany, the U.K. presenting negative elasticities. Surprisingly, the U.S. went from a Kuznets coefficient of 0.7 during the 1946-1982 period to 0.4 during the Great Moderation-despite maintaining an Okun elasticity of 0.7 across both periods.

Table 2: Mean elasticities across time

\begin{tabular}{|c|c|c|c|c|}
\hline VARIABLE & $\begin{array}{l}\text { Second Industrial Revolution } \\
\qquad(1870-1913)\end{array}$ & $\begin{array}{l}\text { War-Interwar } \\
(1914-1945)\end{array}$ & $\begin{array}{l}\text { post-WWII } \\
(1946-1982)\end{array}$ & $\begin{array}{c}\text { Great Moderation } \\
\quad(1983-2007)\end{array}$ \\
\hline \multicolumn{5}{|c|}{20 largest emitters } \\
\hline Okun coefficient & -0.00 & -0.01 & 0.64 & 0.65 \\
\hline Kuznets coefficient & 0.01 & 0.04 & 1.11 & 0.66 \\
\hline \# countries & 9 & 13 & 16 & 16 \\
\hline \# obs. & 363 & 407 & 580 & 400 \\
\hline \multicolumn{5}{|c|}{ All countries } \\
\hline Okun coefficient & -0.00 & -0.00 & 0.47 & 0.90 \\
\hline Kuznets coefficient & -0.00 & 0.04 & 1.71 & 0.91 \\
\hline \# countries & 21 & 32 & 121 & 125 \\
\hline \# obs. & 883 & 998 & 4,122 & 3,124 \\
\hline
\end{tabular}

Since our trend components are non-stationary series, we assess whether there is a cointegrating relationship between trend emissions and trend GDP. For that purpose, we conduct a Dickey-Fuller (1979) test on the residuals of equation (3), $\hat{\varepsilon}_{t}^{\tau}$, by fitting the model

$$
\Delta \varepsilon_{t}^{\tau}=\theta+\delta \varepsilon_{t-1}^{\tau}+\zeta_{1} \Delta \varepsilon_{t-1}^{\tau}+\zeta_{2} \Delta \varepsilon_{t-2}^{\tau}+\zeta_{2} \Delta \varepsilon_{t-3}^{\tau}+\epsilon_{t}
$$

Figures A.7 and A.8 show $\hat{\varepsilon}_{t}^{\tau}$ for the top 20 world emitters for both our baseline dataset and the long time series, and Tables B.1 and B.2 report the test statistics and estimated coefficients for the Augmented Dickey-Fuller tests. The majority of the Kuznets residuals are stationary for the 1990-2012 time series and, with a few exceptions, we can reject the hypothesis that our Kuznets estimates are spurious correlations between emissions and GDP. The longer time series displays residuals fluctuating around 0 for most countries, despite the beginning of sample being characterized by larger residuals. In fact, several countries appear to have residuals more serially correlated when looking at the series prior to 1945, which could explain the large differences in the estimated coefficients for the first two periods. 


\subsection{Robustness checks}

Using Bayesian methods, we find very little prior dependence for our Okun and Kuznets coefficients (with a few exceptions, namely Djibouti, Ethiopia, and Haiti), which suggests that data was generally informative (Figure A.9). In particular, Table 3 compares the Okun and Kuznets elasticities derived from the OLS regression and the Bayesian maximum likelihood for the largest emitters. The estimates are very similar across both estimation methods with differences at the hundredths digits for reasonable priors. The time-varying Okun estimates unveil another interesting picture. Among the top 20 emitters, some key economies have seen their GHG emissions becoming more procyclical over the past years, such as Canada, Germany, Japan, Korea, and the U.K. (Figure 8).

Figure 8: Time-varying Okun estimates (production-based GHG emissions)
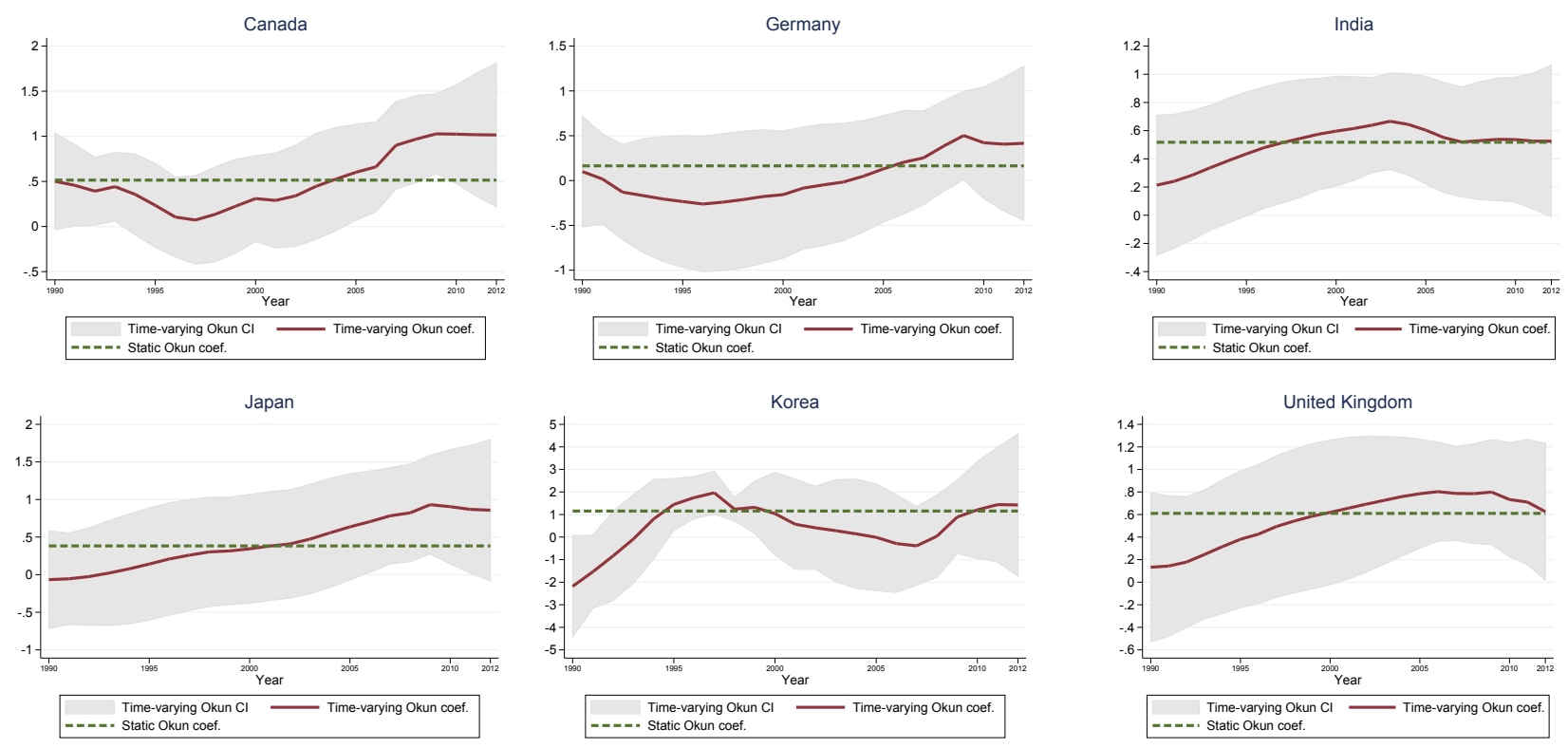

We also contrast the coefficients obtained from the Hamilton (2017) filtering method with the estimates obtained from using the HP filter. Table 3 shows these differences for the world largest emitters and Figure A.10 in the Appendix shows a scatter plot of these elasticities for the extended sample. The figure also contrasts the estimates from filtering the data using the Baxter-King (BK) and the Christiano-Fitzgerald (CF) filters. Kuznets estimates are fairly similar across the alternative filtering methods for most countries in our sample. Among the 20 largest emitters, some notable differences between the HP and Hamilton filters are the Kuznets estimates for Italy, Japan, and the U.S.. The Okun elasticities diverge more across countries and tend to be less precisely estimated than their HP counterparts - in particular for the BK and CF-filtered data. Australia, Italy, Japan, Saudi Arabia, and South Africa are the largest emitters for which the difference in Okun estimates is greater or lower by 3 tenths between the HP and the Hamilton-filtered time series.

Another robustness check conducted is using alternative measures of emissions. Table B.3 in the Appendix contrasts our baseline Okun and Kuznets coefficients with the emissions-output elasticities 
Table 3: Contrasting OLS and Bayesian estimates, HP and Hamilton filtering methods

\begin{tabular}{|c|c|c|c|c|c|c|c|}
\hline & \multicolumn{3}{|c|}{$(H P, O L S)$} & \multicolumn{2}{|c|}{ (HP, Bayesian) } & \multicolumn{2}{|c|}{ (Hamilton, OLS) } \\
\hline & (1) & $(2)$ & (3) & (4) & (5) & (6) & (7) \\
\hline COUNTRY & $\hat{\omega}$ & $\hat{\beta}^{\text {Okun }}$ & $\hat{\beta}^{\text {Kuznets }}$ & $\hat{\beta}^{\text {Okun }}$ & $\hat{\beta}^{\text {Kuznets }}$ & $\hat{\beta}^{\text {Okun }}$ & $\hat{\beta}^{\text {Kuznets }}$ \\
\hline \multicolumn{8}{|c|}{ Advanced economies } \\
\hline Australia & 0.551 & 0.798 & $0.386^{* * *}$ & 0.707 & 0.385 & 0.483 & $0.328^{* * *}$ \\
\hline Canada & $0.683^{* * *}$ & $0.514^{* * *}$ & $0.450^{* * *}$ & 0.512 & 0.452 & $0.325^{*}$ & $0.254^{* * *}$ \\
\hline France & 0.529 & $0.543^{* *}$ & $-0.159^{* * *}$ & 0.547 & -0.158 & 0.282 & -0.166 \\
\hline Germany & 0.353 & 0.164 & $-0.806^{* * *}$ & 0.176 & -0.805 & 0.090 & $-0.941^{* * *}$ \\
\hline Italy & $1.165^{* * *}$ & $1.110^{* * *}$ & $0.284^{* *}$ & 1.059 & 0.266 & $0.550^{* *}$ & -0.004 \\
\hline Japan & $0.786^{* * *}$ & 0.382 & $0.355^{* * *}$ & 0.393 & 0.356 & $0.758^{* * *}$ & 0.032 \\
\hline Korea, Republic & $1.247^{* * *}$ & $1.155^{* * *}$ & $0.662^{* * *}$ & 1.104 & 0.662 & $1.311^{* * *}$ & $0.543^{* * *}$ \\
\hline U.K. & $0.642^{* *}$ & $0.610^{* * *}$ & $-0.534^{* * *}$ & 0.603 & -0.532 & $0.733^{* * *}$ & $-0.540 * * *$ \\
\hline U.S.A. & $0.936^{* * *}$ & $0.581^{* * *}$ & $0.177^{* * *}$ & 0.584 & 0.179 & $0.442^{* * *}$ & 0.007 \\
\hline \multicolumn{8}{|c|}{ Emerging markets } \\
\hline Brazil & $0.487^{* * *}$ & 0.118 & $0.874^{* * *}$ & 0.136 & 0.877 & 0.138 & $0.810^{* * *}$ \\
\hline China & 0.580 & $0.478^{*}$ & $0.591 * * *$ & 0.514 & 0.591 & 0.483 & $0.681^{* * *}$ \\
\hline India & $0.336^{* *}$ & $0.518^{* * *}$ & $0.614^{* * *}$ & 0.526 & 0.614 & $0.521^{* * *}$ & $0.631^{* * *}$ \\
\hline Indonesia & 0.128 & $0.109 * *$ & $0.633^{* * *}$ & 0.110 & 0.631 & 0.078 & $0.515^{* * *}$ \\
\hline Iran & $0.344^{* *}$ & $0.283^{*}$ & $1.138^{* * *}$ & 0.300 & 1.136 & $0.204^{*}$ & $0.939 * * *$ \\
\hline Mexico & $0.530 * * *$ & $0.440^{* * *}$ & $0.897^{* * *}$ & 0.447 & 0.897 & $0.401^{* * *}$ & $0.841^{* * *}$ \\
\hline Russia & $0.531^{* * *}$ & $0.440^{* * *}$ & 0.020 & 0.444 & 0.025 & 0.183 & $0.145^{* * *}$ \\
\hline Saudi Arabia & $0.403^{*}$ & $0.319^{* *}$ & $1.046^{* * *}$ & 0.331 & 1.046 & -0.028 & $1.054^{* * *}$ \\
\hline South Africa & $0.678^{*}$ & $0.818^{* * *}$ & $0.653^{* * *}$ & 0.834 & 0.652 & 0.231 & $0.518^{* * *}$ \\
\hline Turkey & $0.630^{* * *}$ & $0.571^{* * *}$ & $0.791^{* * *}$ & 0.570 & 0.791 & $0.607^{* * *}$ & $0.716^{* * *}$ \\
\hline Ukraine & $0.537^{* * *}$ & $0.417^{* * *}$ & -0.219 & 0.418 & -0.060 & $0.466^{* * *}$ & -0.064 \\
\hline
\end{tabular}

Note: ${ }^{* * *} \mathrm{p}<0.01,{ }^{* *} \mathrm{p}<0.05,{ }^{*} \mathrm{p}<0.1$.

from using GHG emissions with LULUCF and only $\mathrm{CO}_{2}$. We find that accounting for deforestation emissions, the elasticities differ for large territorial countries such as Canada and India (for Okun estimates) and for Brazil, Canada, Japan, and Russia (for Kuznets estimates). Comparing our original estimates with the ones using $\mathrm{CO}_{2}$ emissions only, we see that emissions become more procyclical for the majority of countries, with the new Okun and Kuznets coefficients greater than our baseline estimates. There are few surprises nonetheless: Canada, Saudi Arabia, and the U.S. have long-term elasticities of $\mathrm{CO}_{2}$ emissions with respect to GDP that are very close to those derived from GHG emissions.

Finally, Table 4 summarizes the correlations of our original Okun and Kuznets elasticities with the alternative estimates discussed in this section. Regarding the growth version of the emissionsGDP relationship (equation (1)) and our baseline elasticities, the correlation coefficient between $\omega$ and $\beta^{\text {okun }}$ shows that there is a close linear relationship between these estimates, yet that linear relationship vanishes with the Kuznets elasticities. The alternative Kuznets coefficients are more closely related to the baseline Kuznets estimates than the growth version as shows column (2), with 
correlation coefficients close to 1 (with the exception of the consumption-based Kuznets and long $\mathrm{CO}_{2}$ time series Kuznets). The time-varying model presents a lower correlation coefficient for the Okun estimate since our baseline represents the average effect over the 1990-2012 period and for some countries there has been significant changes in the cyclical relationship as Figure 8 shows. On the other hand, the alternative filtering method shows that the linear relationship between coefficients is fairly close, while the alternative estimation method gives correlation coefficients close to 1 given the reasonable priors used.

Table 4: Okun and Kuznets correlations for top 20 emitters

\begin{tabular}{lcc}
\multicolumn{1}{c}{ VAR. } & $(1)$ & $(2)$ \\
& Okun & Kuznets \\
\hline Growth version & 0.821 & -0.058 \\
Time-varying (1990-2012) & 0.578 & 0.934 \\
Hamilton filtering & 0.683 & 0.970 \\
BK filtering & 0.579 & 0.977 \\
CF filtering & 0.563 & 0.769 \\
Bayesian estimation & 0.997 & 0.998 \\
Boom & 0.877 & - \\
Bust & 0.859 & - \\
Consumption-based GHG & 0.532 & 0.665 \\
$\mathrm{CO}_{2}$ (1990-2012) & 0.845 & 0.969 \\
$\mathrm{CO}_{2}$ (long time series) & 0.278 & 0.567 \\
$\mathrm{GHG}^{\prime}$ with LULUCF & 0.810 & 0.928 \\
\hline
\end{tabular}

\section{Globalization and Emissions}

\subsection{Trade matters for emissions}

We start this section by looking at the relationship between world emissions and world trade between 1990 and 2012. We find that an increase in real exports (or imports for that matter) is correlated with an increase in world emissions of about 0.1 for cyclical time series and of about 0.5 to 0.6 for trend components (Table 5). Furthermore, we pool all countries together and estimate equations (2) and (3) as a panel adding real GDP of country $i$ 's main trading partners (indexed by $p$ ) as a regressor

$$
e_{i, t}^{j}=\kappa+\vartheta_{i}+\delta_{t}+\beta^{j} y_{i, t}^{j}+\theta^{j} \sum_{p=1}^{n} w^{p} y_{i, t}^{p, j}+\epsilon_{i, t}^{j} \quad \text { for } j=c, \tau,
$$

where $w^{p}$ is the weight each partner $p$ has in country $i$ 's total exports $\left(w^{p}=x^{p} / \sum_{s=1}^{n} x^{s}\right)$ and $y_{t}^{p, j}$ is partner $p$ 's (cyclical or trend) real GDP. $\vartheta_{i}$ and $\delta_{t}$ represent country and time dummies capturing, respectively, the impact of unobserved country-specific factors and of common global shocks across 
the period; $\kappa$ is a constant term for the trend relationship. We find that real GDP growth in main trading partners helps explain growth in emissions at the individual country level: a 1 p.p. increase in a country's main trading partners real GDP growth is associated with a 0.3 p.p. increase in emissions growth (Table 6).

We then decompose country's $i$ 's GDP using the expenditure approach by estimating

$$
\Delta e_{i, t}=\kappa+\vartheta_{i}+\delta_{t}+\theta_{1} \Delta c_{i, t}+\theta_{2} \Delta I_{i, t}+\theta_{3} \Delta g_{i, t}+\theta_{4} \Delta x_{i, t}+\theta_{5} \Delta m_{i, t}+\epsilon_{i, t}
$$

and find that increasing exports of goods and services (in real terms) are associated with positive changes in GHG emissions (between 8 and 10 percent for a 1 percentage point increase depending on which model is considered (growth rates, cycles, or trends); Table B.5).

Using more disaggregated data from bilateral trade by product and partner (ongoing), aggregated at the 1-digit level of the Standard International Trade Classification (Rev.4) and by region of imports/exports, we estimate a panel regression using GDP's decomposition as before but adding the granularity of exports and imports by sector or region such that

$$
\begin{gathered}
\Delta e_{i, t}=\kappa+\vartheta_{i}+\delta_{t}+\theta_{1} \Delta c_{i, t}+\theta_{2} \Delta I_{i, t}+\theta_{3} \Delta g_{i, t}+\sum_{p=1}^{k} \theta_{4}^{p} w^{x, p} \Delta x_{i, t}^{g} \\
+\sum_{p=1}^{k} \theta_{5}^{p} w^{m, p} \Delta m_{i, t}^{g}+\theta_{6} \Delta x_{i, t}^{s}+\theta_{7} \Delta m_{i, t}^{s}+\epsilon_{i, t}
\end{gathered}
$$

where $e_{i, t}$ represents productions-based GHG emissions of country $i$ in year $t, c_{i, t}$ private consumption, $I_{i, t}$ private investment, and $x_{i, t}^{g}$ and $m_{i, t}^{g}$ are exports to/of and imports from/of region $p /$ product $p$, respectively, with superscript $g$ denoting trade in goods. Exports and imports are weighted by their relative share in total exports/imports, i.e. region/product $p$ 's weight is given by $w^{j, p}=j^{p} / \sum_{s=1}^{k} j^{s}$ for $j=x, m$ and for all $k$ regions/products. We also include trade in services as the difference between total exports/imports of goods and services from equation (16), and the sum of exports/imports by region or production, with $x_{i, t}^{s}$ and $m_{i, t}^{s}$ denoting trade in services.

Trading with certain regions of the world seem to entail greater carbon intensities (Table B.6 in the Appendix). An increase in the growth rate of imports from East Asia - which includes China, Japan, Korea, Mongolia, and Taiwan - is associated with an increase in emissions growth, suggesting that the goods imported from this region may be inputs for high carbon-intensive sectors domestically. By contrast, an increase in imports from Western Europe and North America is correlated with a reduction in production-based emissions, which could point that these goods are substitutes to more carbon-intensive goods produced domestically. That relationship is still statistically significant using the detrended time series. Imports from Latin America are also correlated with a decline in domestic emissions, while imports from Sub-Saharan African countries tend to be associated with a rise in emissions - but these effects are less precisely estimated for the specification in growth rates. Conversely, an increase in goods exported to East Asia, Latin America and the Pacific are associated with a statistically significant decline in production-based emissions. However, the sign of these effects 
is reversed when cyclical data is used and exports to Europe (both Eastern and Western) and North America also become significant.

Moreover, we find that an increase in the growth rate of exports of crude materials (SITC code 2) is associated with an increase in emissions growth, suggesting that producing these goods requires more carbon-intensive inputs (Table B.7 in the Appendix). The specification using detrended time series indicates that the exports of several other goods are significantly correlated with greater emissions, namely crude materials, mineral fuels, manufactured goods, machinery and transport equipments, and commodities (SITC codes 2, 3, 6, 7, 8, and 9, respectively ). On the other hand, importing chemicals, manufacturing goods, machinery, and commodities (SITC codes 5, 6, 7, and 9, respectively) is correlated with an increase in production-based emissions, which could highlight that these goods are inputs for more carbon-intensive production domestically. Nonetheless, these relationships loose significance using cyclical components. The import of animal and vegetable oils and fats is associated with a statistically significant reduction in emissions for the specifications in growth rates and its detrended version.

At the trend level, an increase in imports reduces emissions more than the equivalent increase in exports (for any types of goods and services and for any region), suggesting trade has played a role in reduced emissions. Nonetheless, our exercise does not capture technology transfers arising from trade, which have spurred improvements in energy efficiency and in the production of carbon-intensive goods. Though it is not the aim of this paper, using the Kaya identity, which relates emissions to the energy intensity of output and the carbon intensity of of energy, would point in that direction.

Table 5: World trade and world emissions

\begin{tabular}{|c|c|c|c|c|c|c|}
\hline & (1) & $(2)$ & (3) & $(4)$ & $(5)$ & (6) \\
\hline VARIABLE & $\Delta \mathrm{GHG}$ & $\Delta \mathrm{GHG}$ & GHG ${ }^{\text {cycle }}$ & GHG $^{\text {cycle }}$ & $\mathrm{GHG}^{\text {trend }}$ & $\mathrm{GHG}^{\text {trend }}$ \\
\hline$\Delta$ Real Exports & $\begin{array}{c}0.113^{* * *} \\
(0.030)\end{array}$ & & & & & \\
\hline$\Delta$ Real Imports & & $\begin{array}{c}0.108^{* * *} \\
(0.032)\end{array}$ & & & & \\
\hline Real Exports ${ }^{\text {cycle }}$ & & & $\begin{array}{c}0.107^{* * *} \\
(0.015)\end{array}$ & & & \\
\hline Real Imports ${ }^{\text {cycle }}$ & & & & $\begin{array}{c}0.099^{* * *} \\
(0.014)\end{array}$ & & \\
\hline Real Exports ${ }^{\text {trend }}$ & & & & & $\begin{array}{c}0.509^{* * *} \\
(0.020)\end{array}$ & \\
\hline Real Imports ${ }^{\text {trend }}$ & & & & & & $\begin{array}{c}0.644^{* * *} \\
(0.037)\end{array}$ \\
\hline Constant & & & & & $\begin{array}{c}-1.222^{* *} \\
(0.467)\end{array}$ & $\begin{array}{c}-4.299 * * * \\
(0.843)\end{array}$ \\
\hline Observations & 22 & 22 & 23 & 23 & 23 & 23 \\
\hline R-squared & 0.403 & 0.356 & 0.688 & 0.684 & 0.968 & 0.936 \\
\hline
\end{tabular}


Table 6: Real GDP growth in trading partners and emissions

\begin{tabular}{|c|c|c|c|c|c|c|}
\hline VARIABLE & $\begin{array}{c}(1) \\
\Delta \mathrm{GHG}\end{array}$ & $\begin{array}{c}(2) \\
\Delta \mathrm{GHG}\end{array}$ & $\begin{array}{c}(3) \\
\text { GHG }^{\text {cycle }}\end{array}$ & $\begin{array}{c}(4) \\
\text { GHG }^{\text {cycle }}\end{array}$ & $\begin{array}{c}(5) \\
\text { GHG }^{\text {trend }}\end{array}$ & $\begin{array}{c}(6) \\
\mathrm{GHG}^{\text {trend }}\end{array}$ \\
\hline \multirow[t]{2}{*}{$\Delta$ Real GDP } & $0.322^{* * *}$ & $0.302^{* * *}$ & & & & \\
\hline & $(0.022)$ & $(0.021)$ & & & & \\
\hline \multirow[t]{2}{*}{$\Delta$ Partners' real GDP } & & $0.328^{* *}$ & & & & \\
\hline & & $(0.162)$ & & & & \\
\hline \multirow[t]{2}{*}{ Real GDP cycle } & & & $0.295^{* * *}$ & $0.283^{* * *}$ & & \\
\hline & & & $(0.017)$ & $(0.016)$ & & \\
\hline \multirow[t]{2}{*}{ Partners' real GDPcycle } & & & & $0.282^{* *}$ & & \\
\hline & & & & $(0.122)$ & & \\
\hline \multirow[t]{2}{*}{ Real GDP ${ }^{\text {trend }}$} & & & & & $0.686^{* * *}$ & $0.689^{* * *}$ \\
\hline & & & & & $(0.013)$ & $(0.013)$ \\
\hline \multirow[t]{2}{*}{ Partners' real GDP trend } & & & & & & $0.901^{* * *}$ \\
\hline & & & & & & $(0.076)$ \\
\hline \multirow[t]{2}{*}{ Constant } & 0.006 & -0.002 & & & $2.321^{* * *}$ & $-2.220^{* * *}$ \\
\hline & $(0.016)$ & $(0.016)$ & & & $(0.118)$ & $(0.395)$ \\
\hline Country effects & Yes & Yes & Yes & Yes & Yes & Yes \\
\hline Time effects & Yes & Yes & Yes & Yes & Yes & Yes \\
\hline Observations & 3,705 & 3,554 & 3,880 & 3,721 & 3,880 & 3,721 \\
\hline R-squared & 0.186 & 0.203 & 0.097 & 0.105 & 0.996 & 0.996 \\
\hline
\end{tabular}

\subsection{Revisiting Okun and Kuznets elasticities}

Our results so far suggest that advanced economies have managed to transition to a low-carbon path but globalization may have played an important role. So far, we have looked at the relationship between output and emissions at the national level but understanding emissions transfers via trade would give a more accurate view of our Okun and Kuznets elasticities. Most advanced economies have become net importers of emissions since they tend to emit less in producing the goods and services they export than what their trading partners emit in producing the goods and services they import. In recent years, efforts have been made to develop a consumption-based accounting of emissions to incorporate emission transfers via international trade. ${ }^{9}$

Figures A.11 and A.12 contrast the cyclical and trend components of production-based and consumption-based GHG emissions for the 20 largest world emitters. The volatility in consumption-based emissions tends to be much higher at the cyclical frequency, while for some countries the trend component tends to be a linear transformation of the production-based emissions. Nonetheless, there a few interesting cases. For some countries trend components move in opposite directions (such as the U.K.) and in others trends have very different steepness (such as Australia and South Africa). Figure

\footnotetext{
${ }^{9}$ Davis and Caldeira (2010), Peters (2008), Peters and Hertwich (2008), Pan, Phillips, and Y. Chen (2008), Aichele and Felbermayr (2012).
} 
A.4 shows the variance decomposition of consumption-based emissions.

Revisiting our estimates using consumption-based emissions in equations (2) and (3) shows that both Okun and Kuznets coefficients differ greatly from our baseline estimates. The consumption-based cyclical data provide much greater elasticities over the business cycle, with consumption-based Okun estimates above unity for several of the 20 largest emitters (Figure 9). China is the only country for which consumption-based emissions are less procyclical than with production-based emissions (the same holds, but less precisely estimated, for Australia, Canada, and Japan). While the productionbased Okun elasticity averaged 0.52 for the top 20 emitters, the mean for the consumption-based data increases to 0.98 - primarily pushed by Brazil, Italy, and Korea.

Figure A.13 presents the consumption-based Okun elasticities for the extended sample of 116 countries (37 countries - mostly African - were excluded for having negative emissions). The mean for the entire sample is slightly higher than the one implied by the production-based data (0.8 as opposed to 0.6 ) but is also statistically significant for fewer countries (54). Although consumption-based GHG emissions tend to display similar levels of procyclicality across the different income groups (with a mean of 0.7 for emerging markets and 0.8 for advanced economies and low income countries), the variance in Okun elasticities is the largest for low income countries (with a median of 0.5 as opposed to 0.9 for advanced economies and 0.8 for emerging markets). The negative elasticities are found mostly in emerging economies (mostly Eastern European/Central Asian countries and Sub-Saharan Africa). In addition to Canada, Finland, Norway, and Singapore are the only advanced economies where when real GDP grows over the business cycle, cyclical emissions tend to decrease.

Figure 9: Okun elasticities: Production vs. consumption

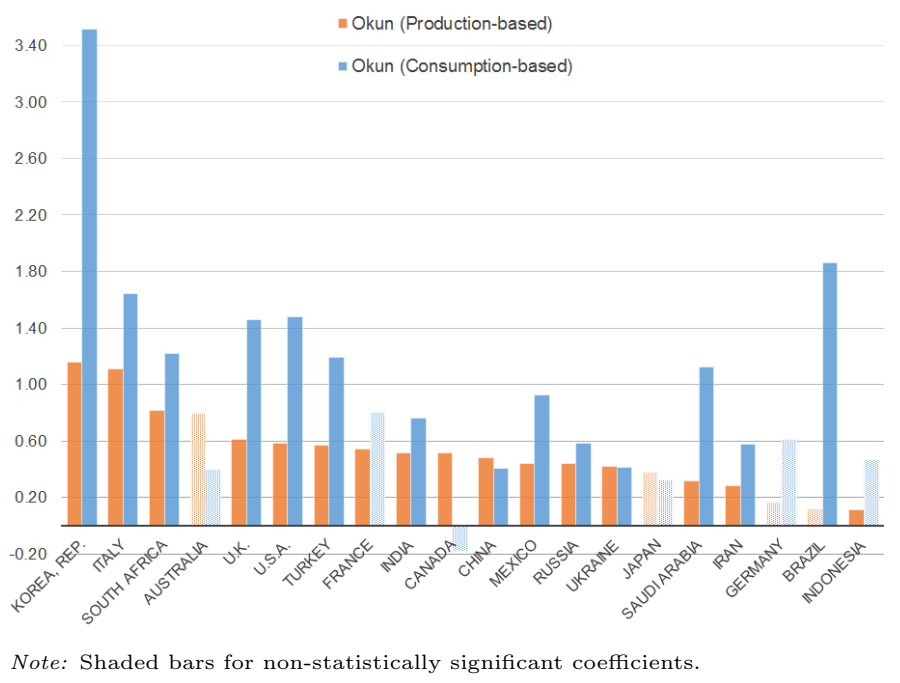

The time-varying Okun elasticities shows how in certain countries consumption-based emissions have become procyclical among the 20 largest emitters, though for several countries the time-varying Okun elasticities mirrors its static counterpart. Figure 10 contrasts both production- and consumptionbased time-varying Okun elasticities and the static consumption-based Okun coefficient for three selected cases. Japan's consumption-based elasticity has increased at a faster rate than its production- 
based Okun coefficient, which suggests that over the business cycle the country has been replacing its carbon emissions produced domestically by those from other countries. Mexico is the case of a country where consumption-based emissions have become less procyclical starting in the mid-1990s and have since then converging to its production-based coefficient, which could reflect the Tequila crisis of late 1994 that led to a readjustment of consumption following the peso's devaluation. The U.K.'s consumption-based Okun elasticity detached from its production-based counterpart with emissions becoming much more procyclical starting in 2004. In addition to Japan and the U.K., other advanced economies (such as Canada France, Italy, and the U.S.) have seen their consumption-based Okun elasticities consistently increase over time, while for countries like Brazil and Germany the Okun elasticities have decreased markedly since the global financial crisis.

Figure 10: Time-varying Okun estimates (consumption-based GHG emissions)
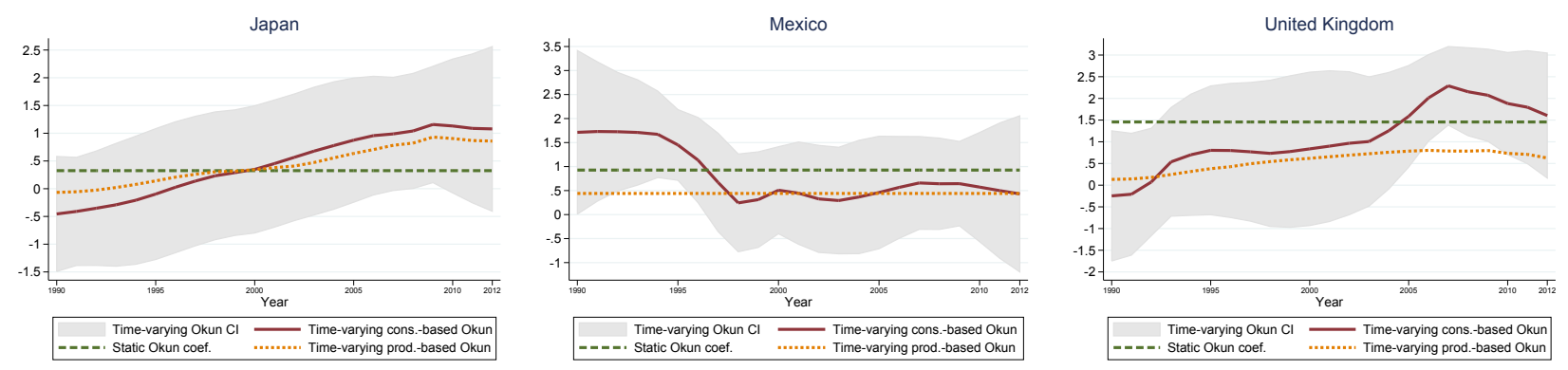

More important than analyzing cyclical components, consumption-based Kuznets elasticities can reveal whether countries have maintained consumption patterns that are carbon-intensive despite reducing their (production-based) emissions. We see notable differences in Kuznets coefficients among the 20 largest emitters - in particular those that had very low production-based elasticities - with the mean Kuznets for the top 20 emitters increasing from 0.40 to 0.64 (Figure 11). Countries that had negative estimates (such as France and the U.K.) now display Kuznets elasticities above 0.4, while Australia, Italy, and the U.S. have now coefficients close to 1 (for the first two) and of 0.6 (for the U.S.). Germany, on the other hand, does show a clear decoupling of both production-based and consumption-based trend emissions from trend GDP, with a coefficient of about -0.4 (as opposed to -0.8). Although China accounts for the largest difference between the two measures of emissions, it's Kuznets elasticity changed very little (from 0.59 to 0.58). Some other emerging markets in this group have also larger consumption-based Kuznets elasticities than production-based estimates (such as Brazil, Saudi Arabia, and Turkey) — which may suggest that when GDP increases, these countries tend to consume more imported carbon-intensive goods than they produce. ${ }^{10}$

Figure A.15 presents the Kuznets coefficients for the extended sample of 116 countries. The mean consumption-based Kuznets coefficients is close to the its production-based counterpart (0.6 and the same holds for the median (0.6)). However, we see less evidence of a decoupling at the trend level for advanced economies, with a mean Kuznets of 0.57 (much greater than the 0.14 implied by the production-based data) and a median of 0.56 (as opposed to 0.23). Almost all countries in this income

\footnotetext{
${ }^{10}$ As before, we test for a cointegrating relationship between trend emissions and trend GDP by estimating equation (14). Figure A.14 and Table B.8 report the results and as before for most countries the Kuznets residuals are stationary.
} 
group have larger consumption-based Kuznets elasticities, the exception being Israel, Korean, and New Zealand, while Germany is the only advanced economy with a statistically significant negative Kuznets coefficient (Iceland's Kuznets estimate negative but not statistically significant). This picture is reversed when looking at the 67 emerging economies. About 65 percent of these countries have lower consumption-based Kuznets coefficients and about 8 are negative. As before, the oil producers (Algeria, Iran, Saudi Arabia, U.A.E., among others) and small states (e.g. Guyana) are titling the mean upwards in this income group. In spite of this, the mean Kuznets coefficient for emerging markets still decreases from 0.70 to 0.53 . The low income countries stand in between the other two groups, but still have on average lower consumption-based elasticities than production-based coefficients (the mean is 0.65 ). The more expressive outliers are also found in this income group, with Haiti (as before) and Honduras among the most emission-intensive economies with Kuznets coefficients above 2.2.

Figure 11: Kuznets elasticities: Production vs. consumption

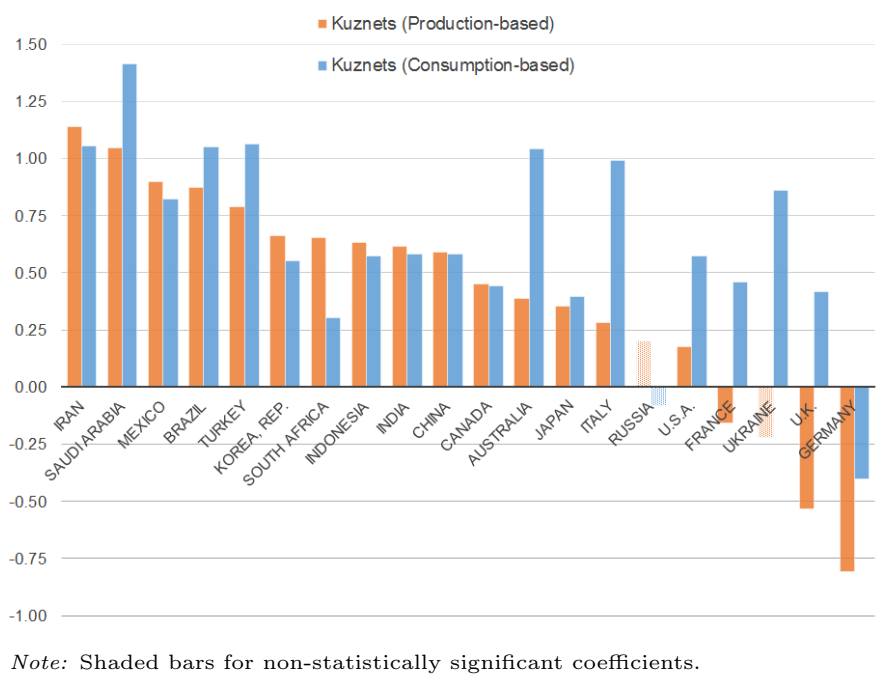

\section{Explaining Cross-Country Differences}

The literature that followed Grossman and Krueger (1991 and 1995) has aimed at estimating the EKC hypothesis for numerous countries and various indicators of environmental degradation. ${ }^{11}$ However, the link between levels of income and environmental degradation is rather inconclusive with disparate empirical estimates. Perman and Stern (2003) argued that the EKC does not exist and show that emissions rise with income, while Dasgupta et al. (2002) present evidence of emission's reductions in developing countries. Several empirical estimates and strategies exist for different types of countries and data, and each provide alternative interpretations of the hypothesis: Dinda and Coondoo (2006) used per capita CO2 emissions and GDP for 88 countries; Moomaw and Unruh (1997) for 16 OECD countries; Marrero (2010) for the EU; Ang (2007 and 2008) for France and Malaysia; Akbostanci et al.

\footnotetext{
${ }^{11}$ Originally for urban air pollution, the state of the oxygen regime in river basins, fecal contamination of river basins, and contamination of river basins by heavy metals, and more recently for $\mathrm{GHG}$ or $\mathrm{CO}_{2}$ emissions.
} 
(2009) for Turkey; Huang et al. (2008) used GHG emissions instead for a large number of countries; and Sulemana et al. (2016) show that the EKC hypothesis holds for CO2 and particulate matter emissions in African countries and that democracy is positively correlated with particulate matter emissions in those countries.

With our estimates in hand, we revisit the EKC hypothesis and establish the relationship between real GDP per capita (in PPP terms) and our Kuznets coefficients for both production- and consumption-based emissions for the top 20 largest GHG emitters (Figure 12 below and A.16 in the Appendix presents the results by region and income group). We find that there indeed exists an inverted U-shape relationship between production-based emissions and real GDP per capita. Richer and poorer countries alike (defined in income per capita terms) tend to have low emissions elasticities with respect to GDP, whereas countries in-between (mostly emerging economies) have larger Kuznets coefficients. However, that relationship becomes much weaker when accounting for international trade. In addition to looking at the slope of equation (3), we also contrast its y-intercept $(\gamma)$ to understand the weight of historical emissions, i.e. countries' emission endowments by 1990, a period prior to the accession of major economies to the World Trade Organization in the late 1990s and early 2000s (including China in 2001). Figure A.17 relates the y-intercepts derived from production- and consumption-based emissions with income per capita and shows that richer countries had lower (not higher, as one would expect) consumption-based y-intercepts than those implied by production-based emissions, which could reflect the greater importance trade has gained over time. ${ }^{12}$

Figure 12: The EKC revisited: Kuznets elasticities and real GDP per capita

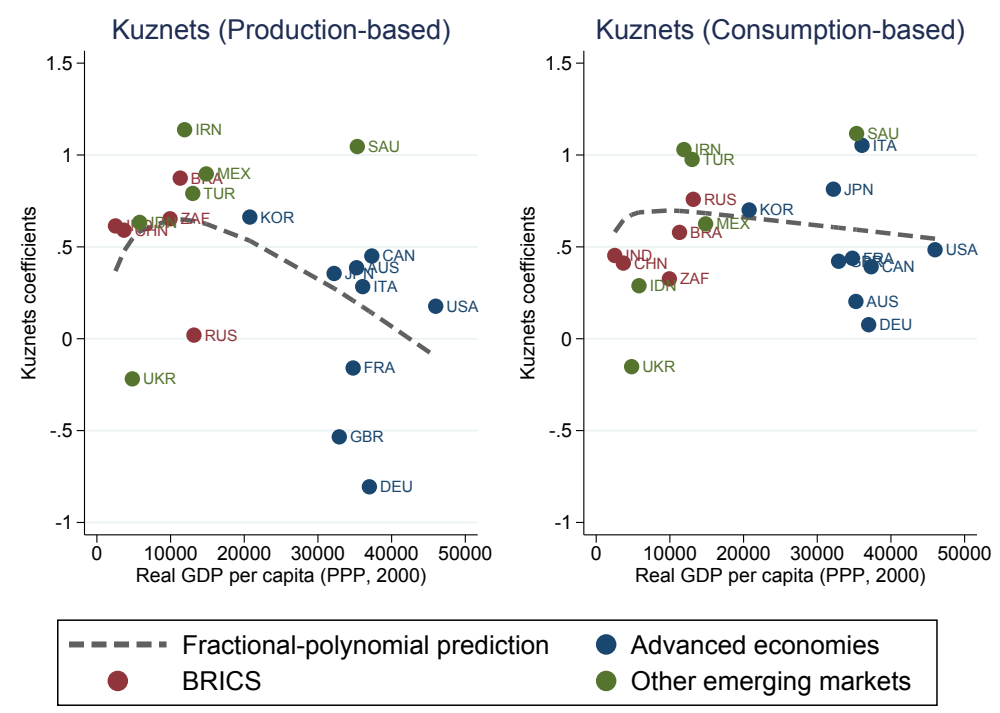

We also consider the economic structure of these countries as a determinant for differences in Kuznets elasticities. We first assess the linear relationship between production- and consumptionbased Kuznets elasticities and the 1990-2012 average sectoral shares in value added to assess the structural relationship between sectoral compositions and emissions, and then pool the time-varying

\footnotetext{
${ }^{12}$ Figure A.18 relates y-intercepts for both types of emissions.
} 
Okun coefficients for the 20 largest GHG emitters to analyze how the economic structure influences carbon intensities over the business cycle by estimating the panel regression

$$
\beta_{i, t}^{\text {okun }}=\kappa+\vartheta_{i}+\delta_{t}+\sum_{j=\{\mathrm{ag}, \text { ind, ser }\}} \theta^{j} V A_{i, t}^{j}+\epsilon_{i, t}
$$

where $\theta^{j}$ is the weighted least squares estimate with the weight defined as the reciprocal of $\beta_{i, t}^{\text {okun 's vari- }}$ ance, i.e. $w_{i}=1 /\left(\sigma_{i, t}^{\text {okun }}\right)^{2}$. Peralta-Alva et al. (2017), for instance, argue that sectoral composition, and sectoral energy intensity in particular, are key to explain the hump shape relationship between energy intensity and income per capita. Jakob et al. (2012) find that economic growth has decoupled from energy consumption in advanced economies, but the catching-up of developing countries has also resulted in energy use not significantly less carbon-intensive than those of advanced economies.

Among the top 20 GHG emitters, the link with industry value added leaves no room for doubts: countries with larger shares of industry have higher production- and consumption-based Kuznets coefficients, though this relationship is stronger with production-based elasticities (Figure 13). As one would expect, countries with higher shares of value added in services tend to have lower Kuznets elasticities. While smaller shares of value added in agriculture are associated with smaller productionbased Kuznets, this link is attenuated if consumption-based Kuznets are considered instead. These results are confirmed looking at the elasticities across the business cycle, in particular for industry and manufacturing value added (with slightly stronger coefficients with manufacturing). We find that economies with higher shares of manufacturing tend to have greater short-term (production-based) emissions elasticities - an increase of 1 percent in the share of manufacturing value added is associated with an increase in carbon intensity of about 0.09 and 0.14 over the business cycle (Table B.9 for both production-based emissions). More surprisingly, there is a statistically significant relationship between an increase in the share of services in value added and an increase in Okun elasticities over time (except when Okun elasticities are regressed solely on the services' share of value added alone). The relationship between the economic structure and the time-varying consumption-based Okun elasticities is more mixed (Table B.10 for consumption-based emissions). Although agriculture, manufacturing, and services shares in total value added are associated with a greater Okun coefficient, when the latter is regressed on each value added component the results suggest that greater shares of manufacturing are correlated with lower consumption-based Okun elasticities (the opposite of the relationship using production-based elasticities). This may indicate that over the business cycle countries that have large manufacturing sectors produce more emissions than the ones embodied in its net imports.

We measure the environmental policy setting using alternative indices capturing the relative attractiveness and quality of climate change policies. We contrast these measures with Kuznets estimates to gauge whether countries with stronger environmental protection frameworks have indeed been able to delink their emissions from real GDP. As above, we also pool all the time-varying Okun elasticities and assess whether good policies are correlated with weaker emissions elasticities with respect to output over the business cycle by estimating equation 18 replacing value added shares with measures of policy. We find that the policy environment seems to matter for long-term elasticities for both production and consumption-based emissions (Figure 14), but very little for elasticities over the business cycle. Across the different indices, well-ranked countries tend to have lower Kuznets; however, the relation- 
Figure 13: Kuznets elasticities and Sectoral value added
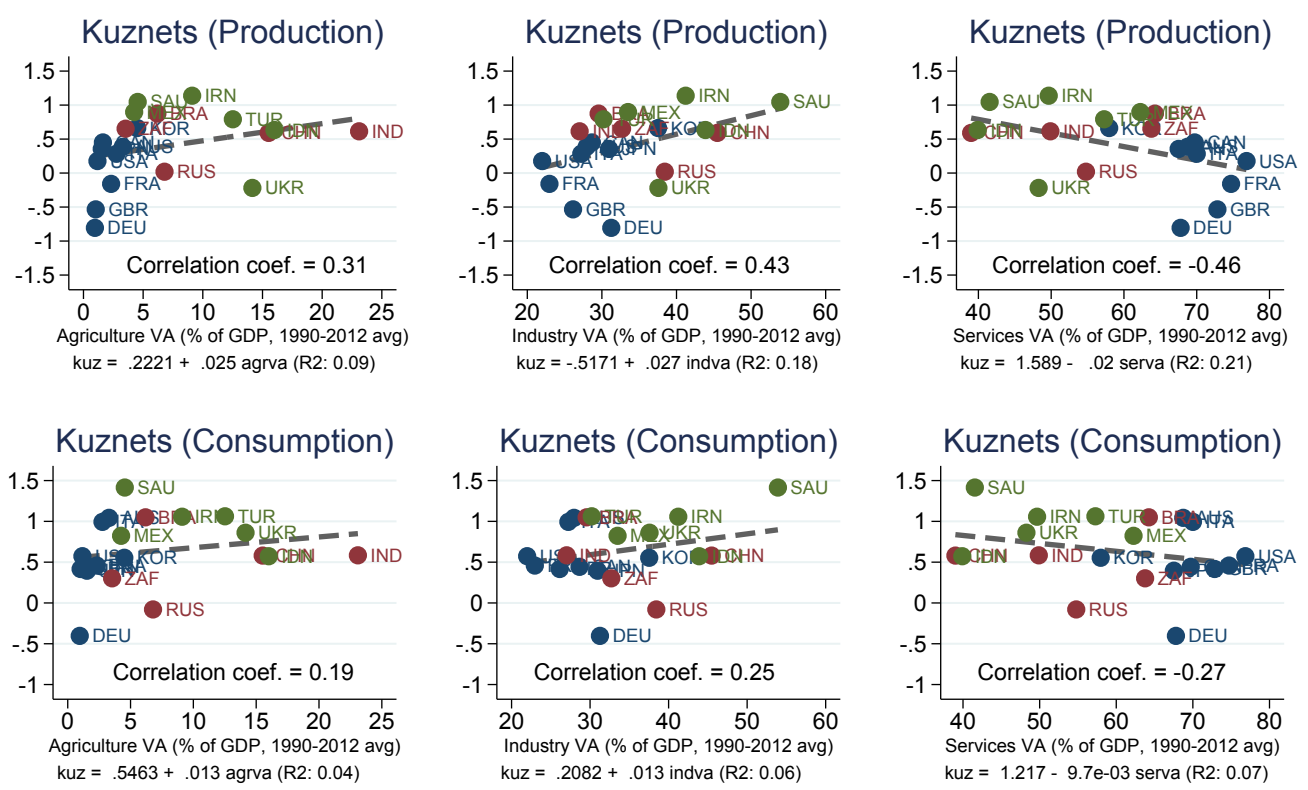

$$
\begin{array}{|cl}
\hline-=- \text { Fitted values } & \text { Advanced economies } \\
\text { BRICS } & \text { Other emerging markets }
\end{array}
$$

ship becomes weaker with consumption-based elasticities. This may reflect the fact that these rankings place countries according to their policies curbing production-based emissions rather than including measures embedding the carbon-intensity of consumption. Contrasting the time-varying estimates in a panel regression indicates that the policy environment does not seem to matter much for short-term elasticities. 
Figure 14: Kuznets elasticities and Policy framework

\section{Kuznets and G's CCPI}
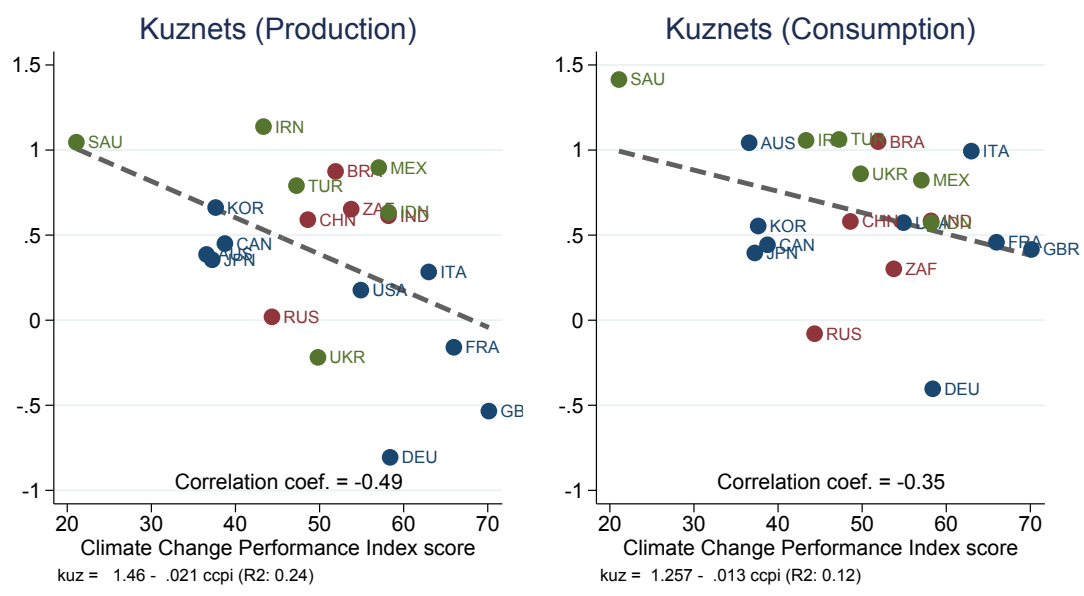

Kuznets and Energy Trilemma
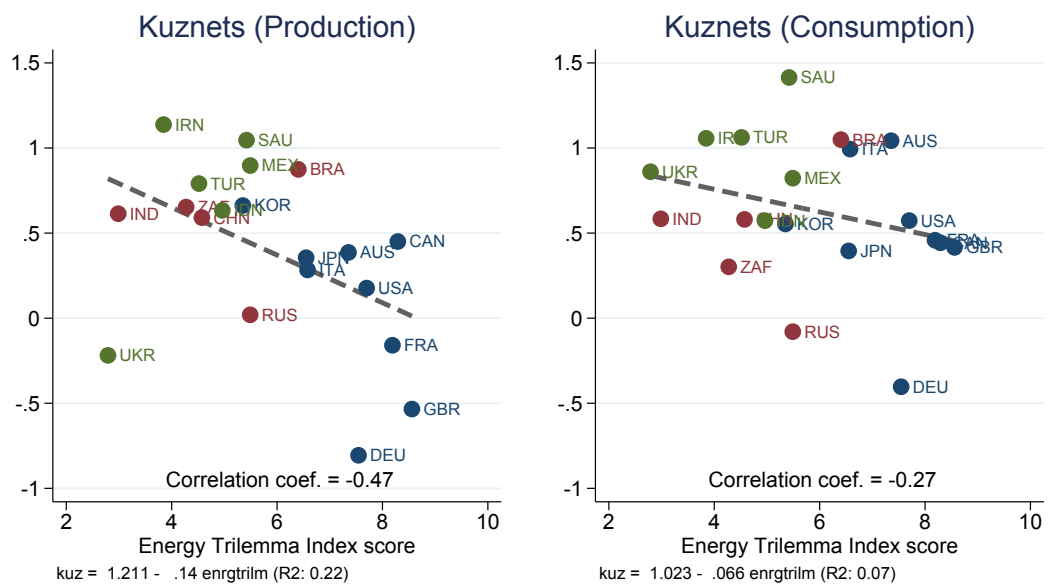

Kuznets and EY's RECAI
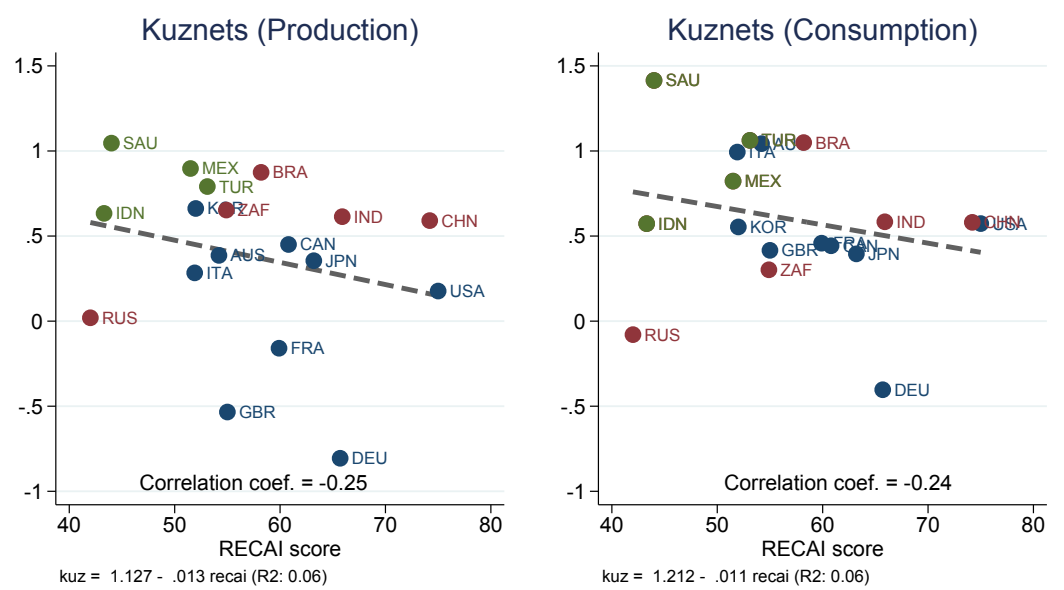

\begin{tabular}{|cll|}
\hline$-+-\boldsymbol{-}$ & Fitted values & Advanced economies \\
& BRICS & Other emerging markets \\
\hline
\end{tabular}

\section{C)International Monetary Fund. Not for Redistribution}




\section{Conclusion}

In this paper, we reexamined the relationship between emissions and GDP and argued that the recent decoupling between emissions growth and real GDP growth may point to misleading assertions. First, we need to distinguish cycles from trends. There is an Environmental Okun's Law - the cyclical relationship between emissions and GDP - that obscures the Environmental Kuznets Curve - the trend relationship between emissions and GDP. Emissions could temporarily be low simply because the economy is in a downswing or temporarily high during a boom. By contrast, the trend relationship should reflect structural changes in the economy, with inflexion points depicting major changes in policy, productivity, or activity composition. Second, accounting for cross-border trade complicates the story. Looking at consumption-based emissions allows us to understand whether changes in production structures are followed by shifts in the carbon intensity of trade and consumption patterns.

The main results of our paper can be summarized as follows. First, our production-based Kuznets elasticities do show a decoupling of emissions and GDP for many countries. Indeed, several advanced economies have managed to transition to a low-carbon path; however, globalization has played an important role. Accounting for net emission transfers from international trade, i.e. using consumptionbased emissions, shows that the evidence for decoupling among the richer countries gets weaker- the exception being Germany, where both production- and consumption-based emissions show a strong decoupling from GDP. Second, there is still some hope. When decomposing the time series into different periods, we see that the period of the Great Moderation (1983-2007) was characterized by much lower Kuznets elasticities for both the top 20 largest emitters as well as the extended sample (with more than 120 countries) relative to the post-WWII period. Third, emissions, like GDP, move in cycles. There is a strong cyclical relationship between emissions and output-what we call the Environmental Okun's Law - that policymakers across the world may fail to see: they tend to be complacent with emissions when the economy is in a recession and overly worried during booms.

Finally, policy may play a role. Countries with underlying policy frameworks more supportive of renewable energy and climate change tend to experience a greater decoupling between trend emissions and trend GDP - for both production- and consumption-based emissions. We also see that countries with larger shares of industry (in terms of their gross value added) are associated with larger production- and consumption-based Kuznets elasticities (countries with a larger agriculture sector tend to have larger elasticities as well, but the link is slightly weaker). The Environmental Kuznets Curve hypothesis holds mostly for production-based emissions - richer and poorer countries alike (in income per capita terms) have low emissions elasticities with respect to GDP, whereas countries inbetween (mostly emerging economies) have larger Kuznets coefficients. A few caveats nonetheless. Although our results are fairly robust across alternative estimation and filtering methods, the trend and cyclical components are by construction sensitive to the amount of historical data available and the type of emissions used. Another consideration when using consumption-based emissions is that several (mostly low-income) countries tend to have negative emissions, which we discarded and therefore gave us less granularity than with advanced and emerging economies.

In conclusion, these results have implications for both policy and research. For policy, policymakers 
should pay closer attention to consumption-based emissions since these depict a complementary picture of the carbon intensity of domestic consumption. Also relevant for policy dialogue is the discussion on the appropriate tax instruments policymakers should use to ultimately curb GHG emissions and the latter could include analyzing through the lens of a structural model the pros and cons of taxes on emissions consumed or emissions produced. On the other hand, it should also be clear that there is a (trade) specialization argument that policymakers should not overlook. Countries that have high Kuznets elasticities may just reflect the fact these economies have comparative advantages in producing goods and services that are carbon-intensive, while others could focus on using these as inputs to produce other emission-friendly goods and services. Analyzing this balance warrants further research for the next few years. 


\section{References}

Aichele, R. and G. Felbermayr, 2012, "Kyoto and the carbon footprint of nations," Journal of Environmental Economics and Management, 63(3), 336-354.

Akbostanci E., Turut-Asik S., and G. Dpek-Tunc, 2009, "The relationship between income and environment in Turkey: Is there an environmental Kuznets curve?," Energy Policy, 37, 861-867.

Ang, J.B., 2007, "CO2 emissions, energy consumption, and output in France," Energy Policy, 35, 47-72

Ang, J.B., 2008, "Economic development, pollutant emissions and energy consumption in Malaysia," Journal of Policy Modeling, 30, 271-278.

Anjum, Z., Burke, P.J., Gerlagh, R., and D. Stern, 2014, "Modeling the emissions-income relationship using long-run growth rates," CCEP Working Paper No. 1403.

Burke, P., Shahiduzzaman, M., and D. Stern, 2015, "Carbon dioxide emissions in the short run: The rate and sources of economic growth matter," Global Environmental Change, 33, 109-121.

Chang, C., Chen, K., Waggoner, D., and T. Zha, 2015, "Trends and Cycles in China's Macroeconomy," NBER Working Paper No. 21244.

Cogley, T. and J. Nason, 1995, "Effects of the Hodrick-Prescott filter on trend and difference stationary time series Implications for business cycle research," Journal of Economic Dynamics and Control, 19(1-2), 253278.

Dasgupta, S., Laplante, B., Wang, H., and D. Wheeler, 2002, "Confronting the environmental Kuznets curve," Journal of Economic Perspectives, 16, 147-168.

Davis, S. and K. Caldeira (2010), "Consumption-based accounting of CO2 emissions," Proceedings of the National Academy of Sciences of the United States of America, 107(12), 5687-5692.

Dinda, S. and D. Coondo, 2006, "Income and emission: a panel data-based cointegration analysis," Ecological Economics, 57, 167-181.

Doda, B., 2014, "Evidence on business cycles and CO2 emissions," Journal of Macroeconomics, 40, 214-227.

Grossman, G.M. and A.B. Krueger, 1991, "Environmental impacts of a North American Free Trade Agreement," NBER Working Paper No. 3914.

Grossman, G.M. and A.B. Krueger, 1995, "Economic growth and the environment," Quarterly Journal of Economics, 110, 353-377.

Hamilton, J., 2017, "Why You Should Never Use the Hodrick-Prescott Filter," working paper.

Harvey, A. and A. Jaeger, 1993, "Detrending, Stylized Facts and the Business Cycle," Journal of Applied Econometrics, 8(3), 231-47.

Heutel, G., 2012, "How should environmental policy respond to business cycles? Optimal policy under persistent productivity shocks," Review of Economic Dynamics, 15(2), 244-264.

Hodrick, R.J. and E.C. Prescott, 1981, "Postwar U.S. Business Cycles: An Empirical Investigation," working paper, Northwestern University.

Hodrick, R.J., and E.C. Prescott, 1997, "Postwar U.S. Business Cycles: An Empirical Investigation," Journal of Money, Credit and Banking, 29(1), 1-16.

Huang W.M, G.W.M. Lee, and C.C. Wu, 2008, "GHG emissions, GDP growth and the Kyoto protocol: a revisit of Environmental Kuznets curve hypothesis," Energy Policy, 36, 239-47. 
Jakob, M., Haller, M., and R. Marschinski, 2012, "Will history repeat itself? Economic convergence and convergence in energy use patterns," Energy Economics, 34, 95-104.

Jakob, M. and R. Marschinski, 2013, "Interpreting trade-related CO2 emission transfers," Nature Climate Change, 3, 19-23.

Jakob, M., Steckel, J.C., and O Edenhofer, 2014, "Consumption- Versus Production-Based Emission Policies," Annual Review of Resource Economics, 6(14), 1-22.

Kander, A., Jiborn, M., Moran, D., and T. Wiedmann, 2015, "National greenhouse-gas accounting for effective climate policy on international trade," Nature Climate Change, 5, 431-435

Lenzen, M., Kanemoto, K., Moran, D., and A. Geschke, 2012, "Mapping the Structure of the World Economy," Environmental Science Technology, 46(15), 8374-8381.

Lenzen, M., Moran, D., Kanemoto, K., and A. Geschke, 2013, "Building Eora: A Global Multi-regional InputOutput Database at High Country and Sector Resolution," Economic Systems Research, 25(1), 20-49.

Moomaw W. and G. Unruh, 1997, "Are environmental Kuznets curves misleading us? The case of CO2 emissions," Environment and Development Economics, 2, 451-463.

Okun, A., 1962, "Potential GNP: Its Measurement and Significance," Proceedings of the Business and Economics Statistics Section, American Statistical Association, 89-104.

Pan, J., Phillips, J., and Y. Chen, 2008, "China's balance of emissions embodied in trade: approaches to measurement and allocating international responsibility," Oxford Review of Economic Policy, 24(2), 354376

Pao, H. and C. Tsai, 2010, "CO2 emissions, energy consumption and economic growth in BRIC countries," Energy Policy, 38(12), 7850-7860.

Peralta-Alva, A., Tavares, M.M., and X. Xi, 2017, "Accounting for Energy Intensity Across Countries: Composition, Prices and Technology," IMF Working Paper (forthcoming).

Perman, R. and D. I. Stern, 2003, "Evidence from panel unit root and cointegration tests that the environmental Kuznets curve does not exist," Australian Journal of Agricultural and Resource Economics, 47, 325-347.

Peters, G., 2008, "From production-based to consumption-based national emission inventories," Ecological Economics, 65(1), 13-23.

Peters, G. and E. Hertwich, 2008, "CO2 Embodied in International Trade with Implications for Global Climate Policy," Environmental Science \& Technology, 42(5), 1401-1407.

Peters, G., Minx, J., Weber, C., and O. Edenhofer, 2011, "Growth in Emission Transfers via International Trade from 1990 to 2008," PNAS, 108(21), 8903-8908.

Ravn, M. and H. Uhlig, 2002, "On Adjusting the Hodrick-Prescott Filter for the Frequency of Observations," Review of Economics and Statistics, 84 (2), 371-380.

Schlicht, E., 1985, Isolation and Aggregation in Economics, Berlin-Heidelberg-New York-Tokyo: SpringerVerlag.

Schlicht, E., 1988, "Variance Estimation in a Random Coefficients Model," paper presented at the Econometric Society European Meeting Munich 1989.

Sheldon, T., 2017, "Asymmetric effects of the business cycle on carbon dioxide emissions," Energy Economics, 61, 289-297.

Stern, D., 2010, "Between estimates of the emissions-income elasticity," Ecological Economics, 69(11), 21732182 . 
York, R., 2012, "Asymmetric effects of economic growth and decline on CO2 emissions," Nature Climate Change, 2(11), 762-764. 


\section{Appendix}

\section{Additional figures}

Figure A.1: Top 20 emitters by gas

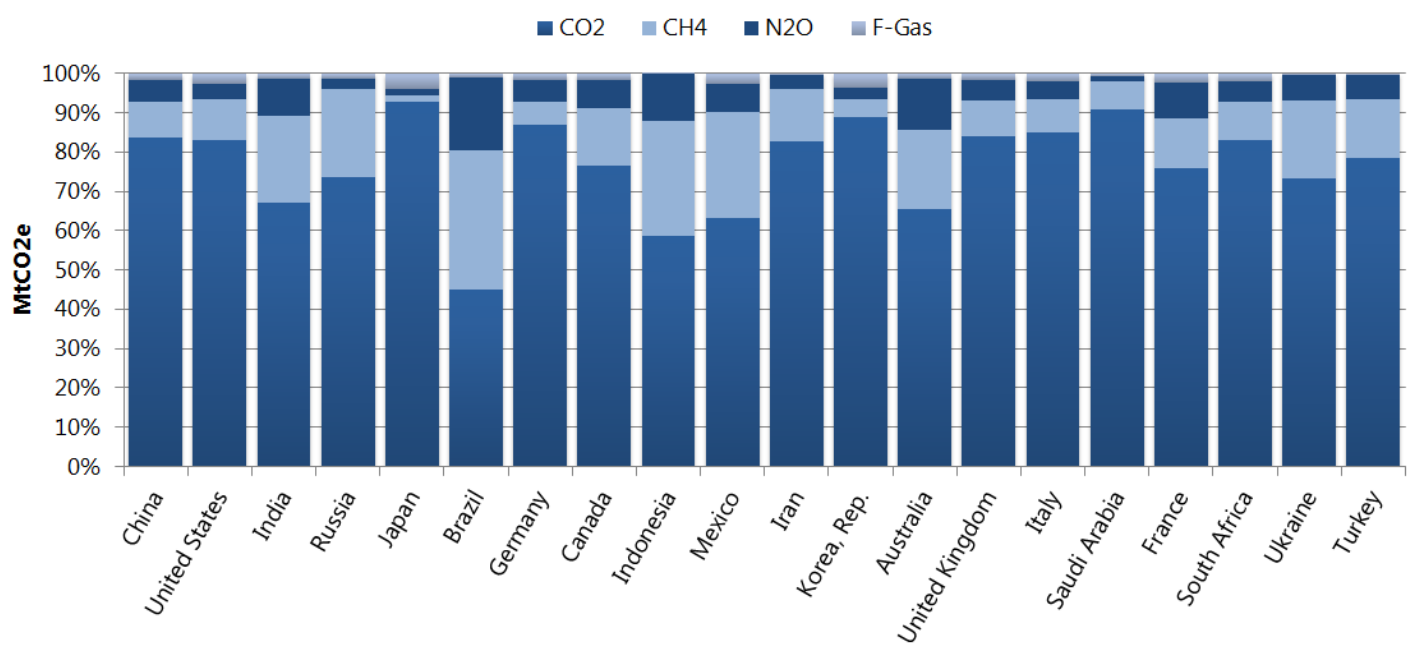

Source: World Resources Institute.

Note: 2008-2012 average of total GHG emissions (excluding land-use and land-use change and forestry.)

Figure A.2: Top 20 emitters by gas

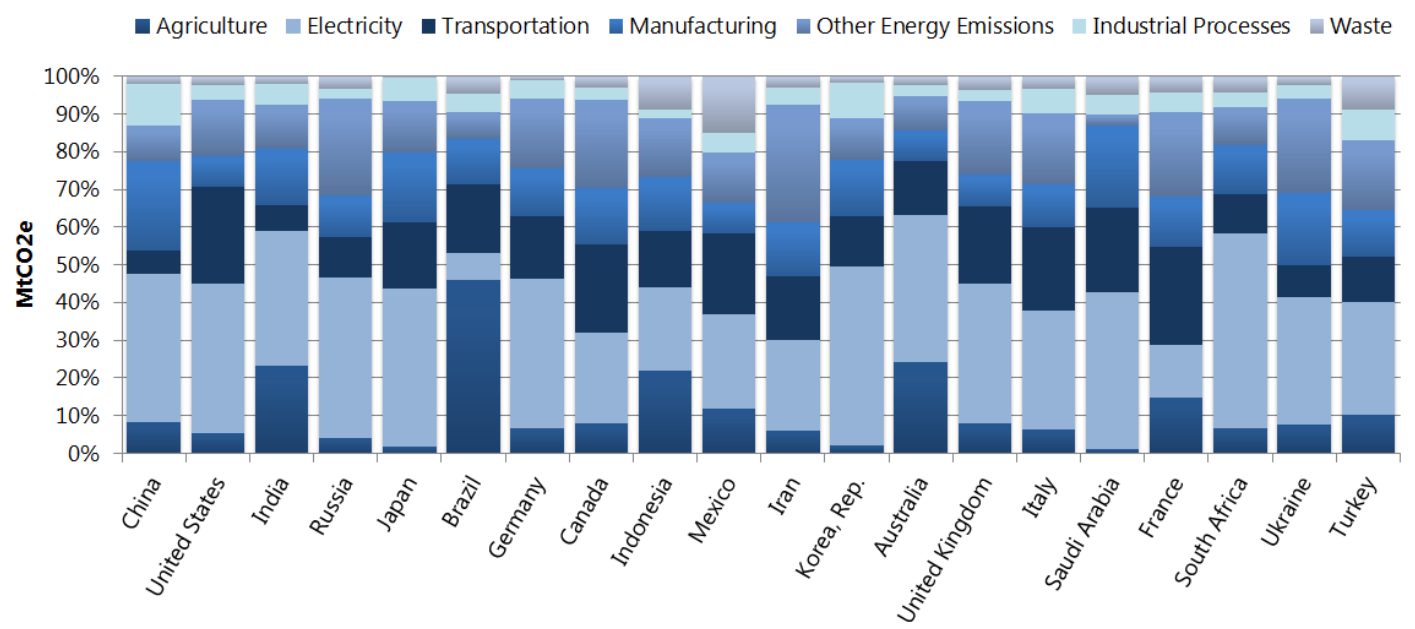

Source: World Resources Institute.

Note: 2008-2012 average of total GHG emissions (excluding land-use and land-use change and forestry.) 
Figure A.3: Elasticity of emissions growth with respect to GDP growth

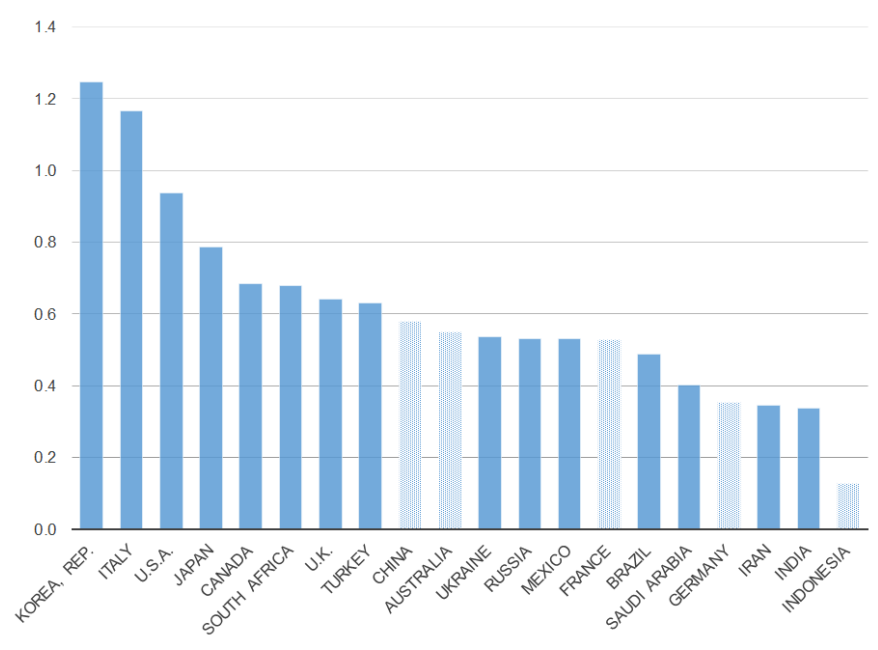

Note: Shaded bars for non-statistically significant coefficients

Figure A.4: Variance decomposition of emissions
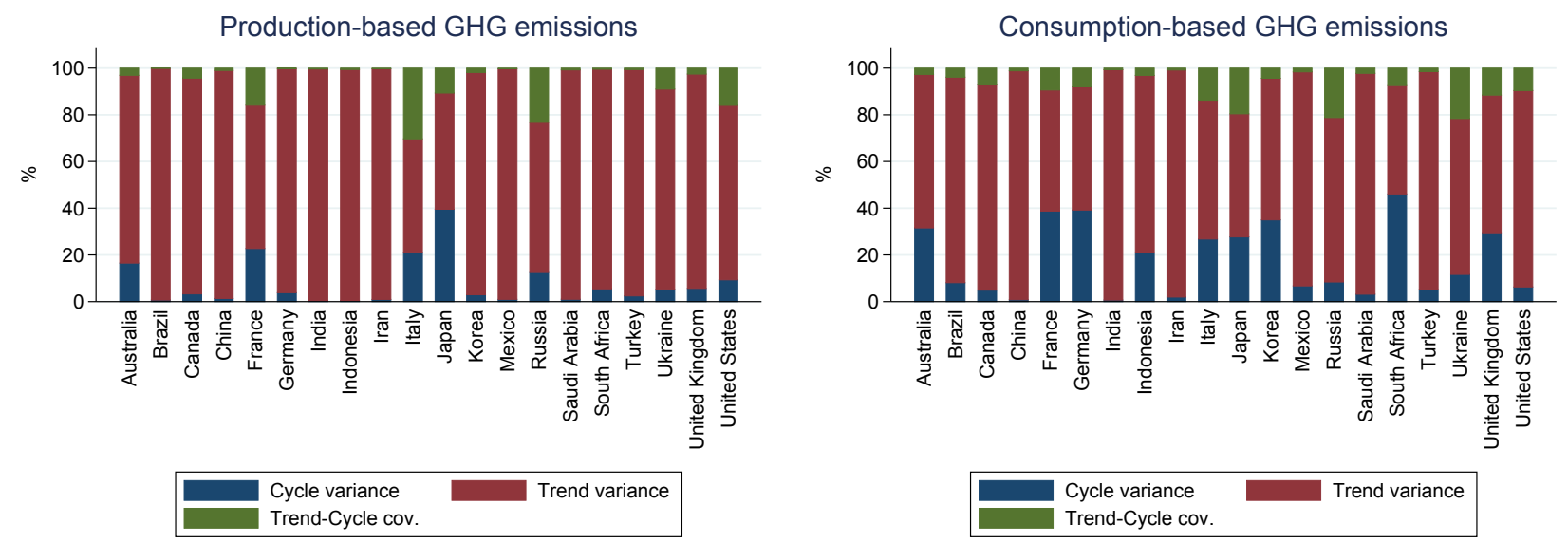
Figure A.5: Production-based Okun elasticities around the world
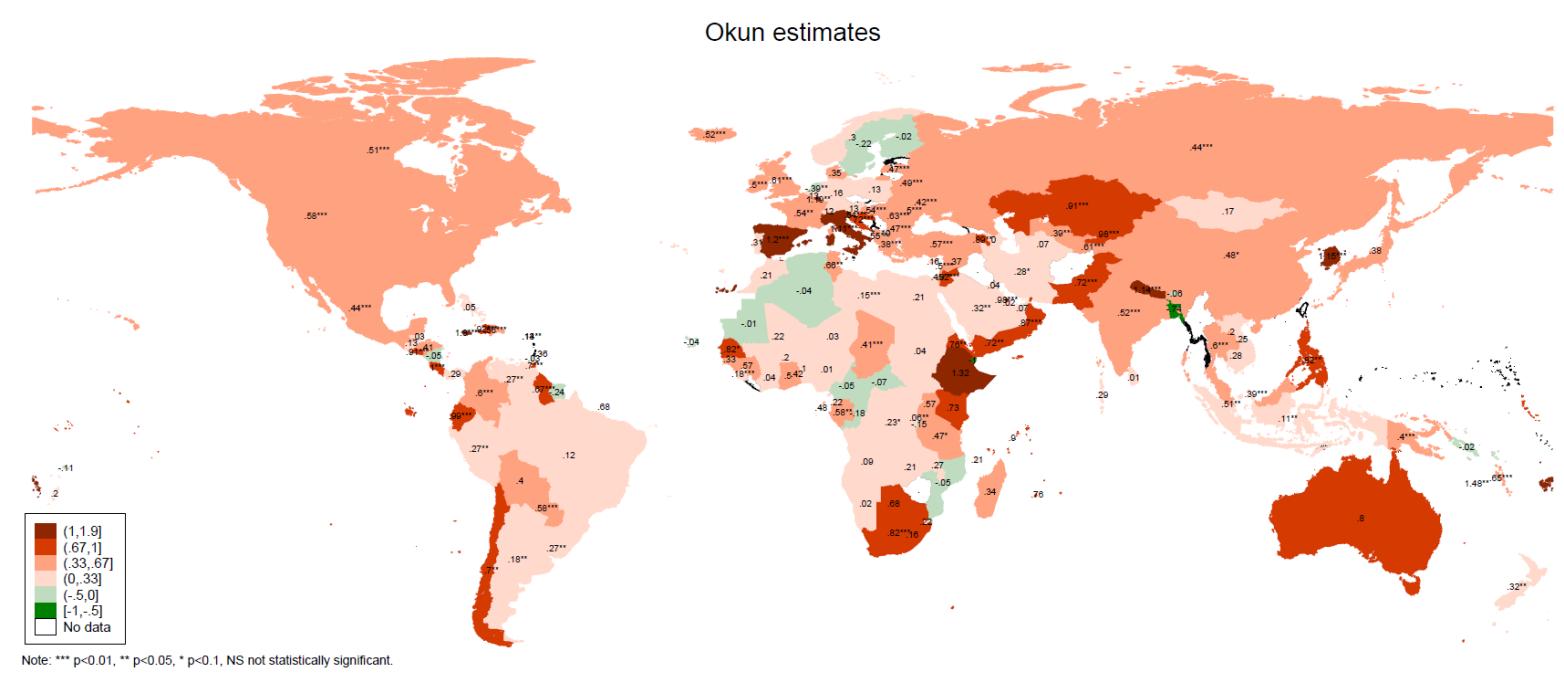

Figure A.6: Production-based Kuznets elasticities around the world
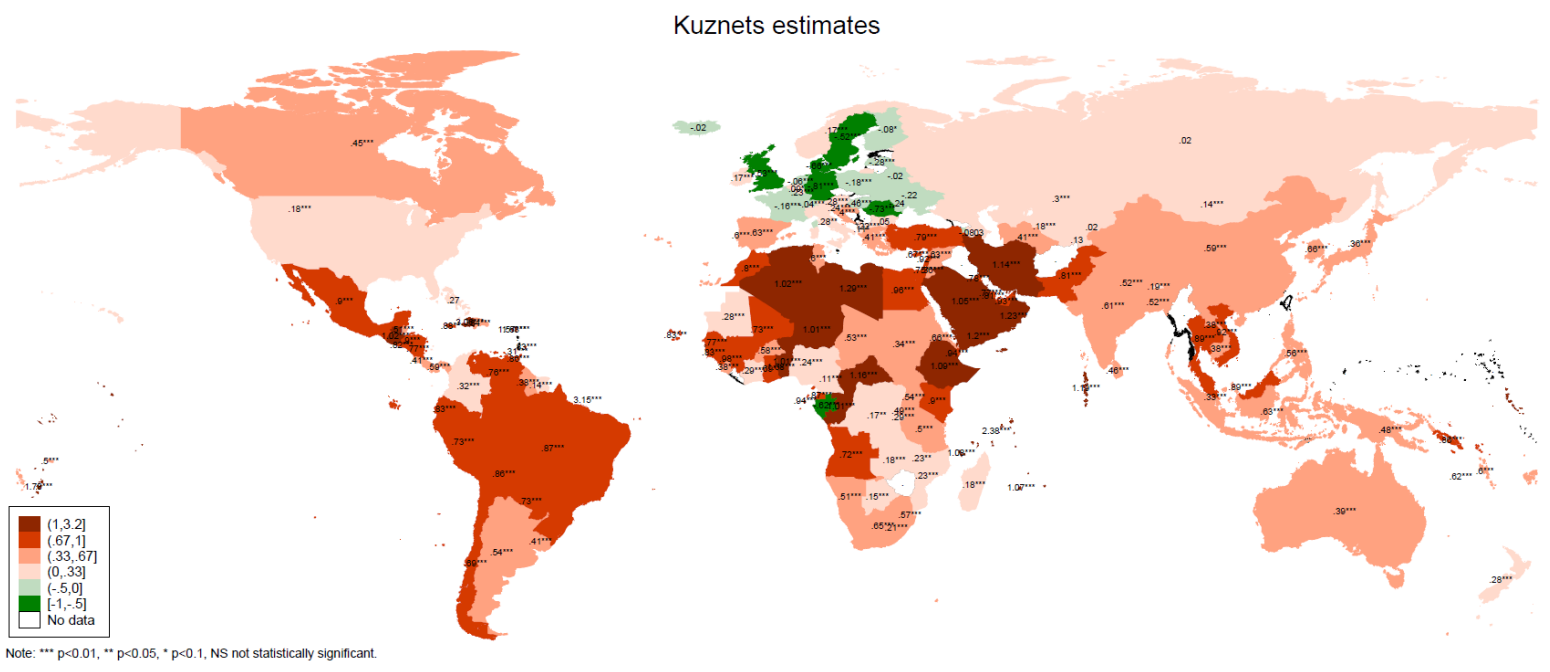
Figure A.7: Production-based Kuznets residuals

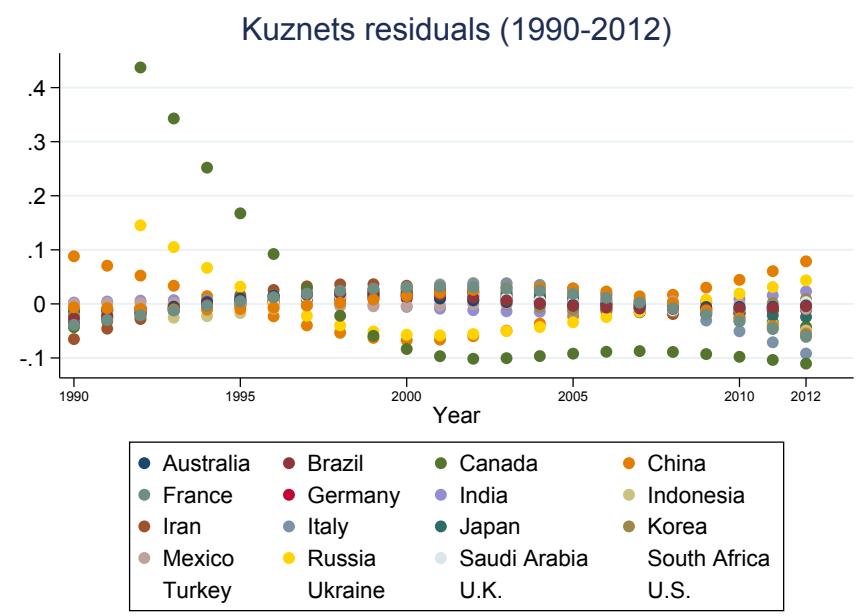

Figure A.8: Production-based Kuznets residuals for longer time series

Kuznets residuals (1870-1913)

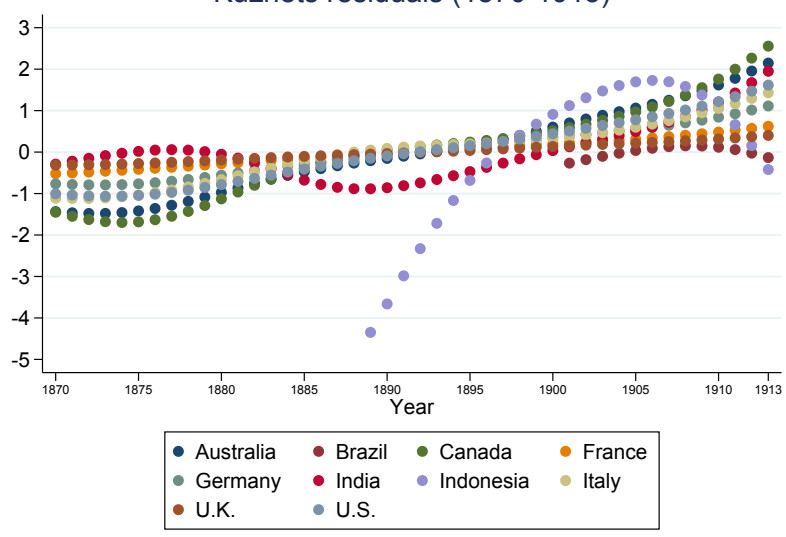

Kuznets residuals (1946-1982)

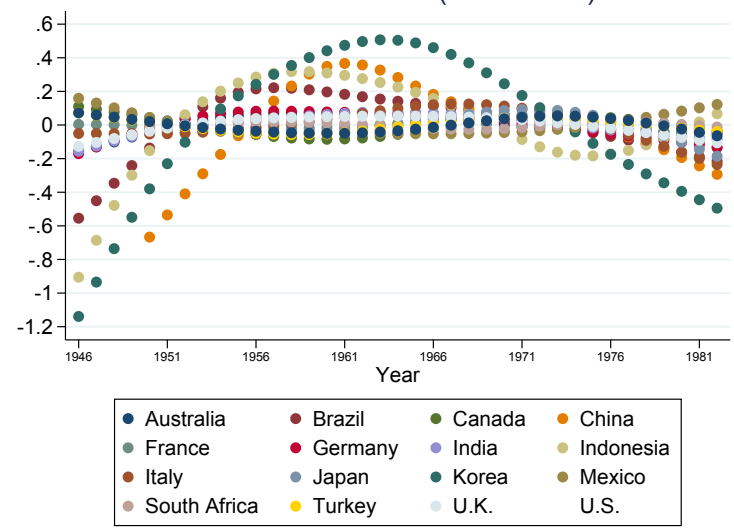

Kuznets residuals (1914-1945)

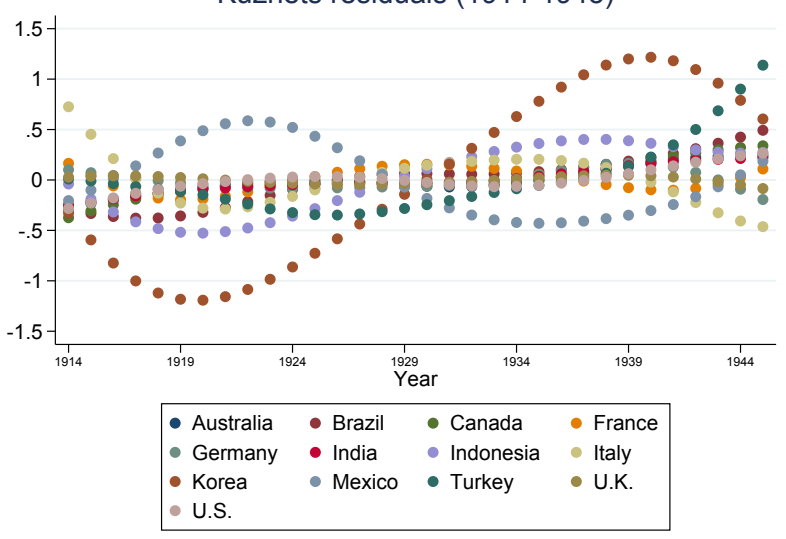

Kuznets residuals (1983-2007)

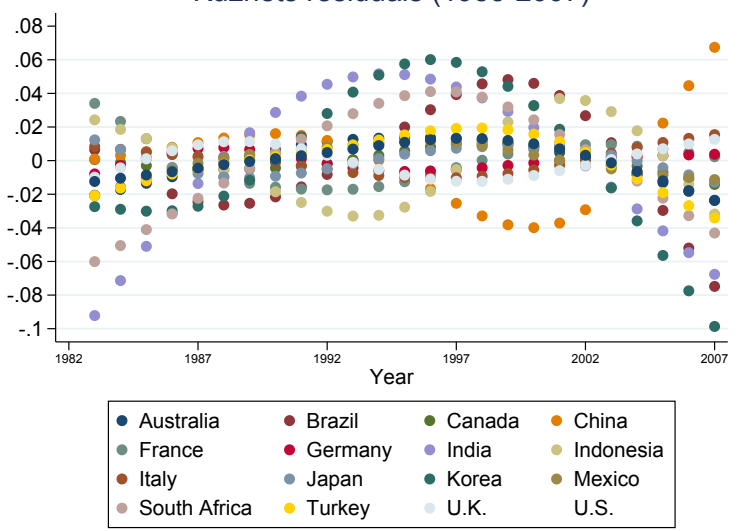


Figure A.9: Comparing OLS estimates with Bayesian estimates for production-based emissions OLS vs. Bayesian estimations
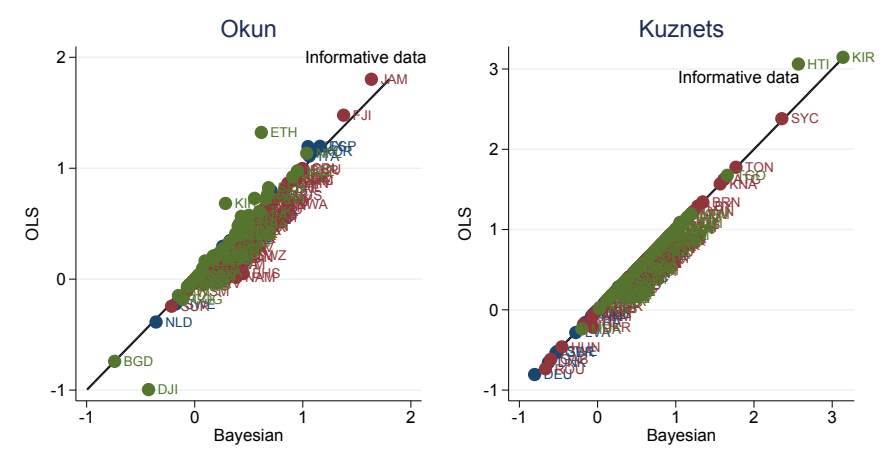

Note: All coefficients.

OLS = Bayesian

Advanced economies

- Emerging markets

- Low income countries

Figure A.10: Comparing HP estimates with Hamilton, Baxter-King, and Christiano-Fitzgerald estimates for production-based emissions

HP vs. Hamilton filters
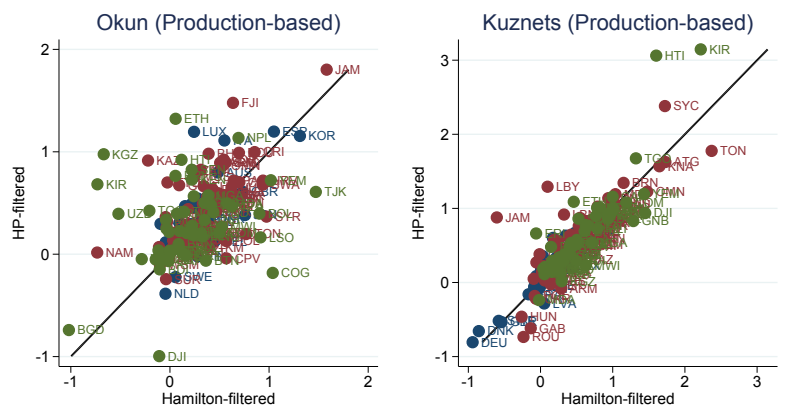

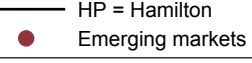

\section{- Advanced economies Low income countries}

Note: All coefficients.
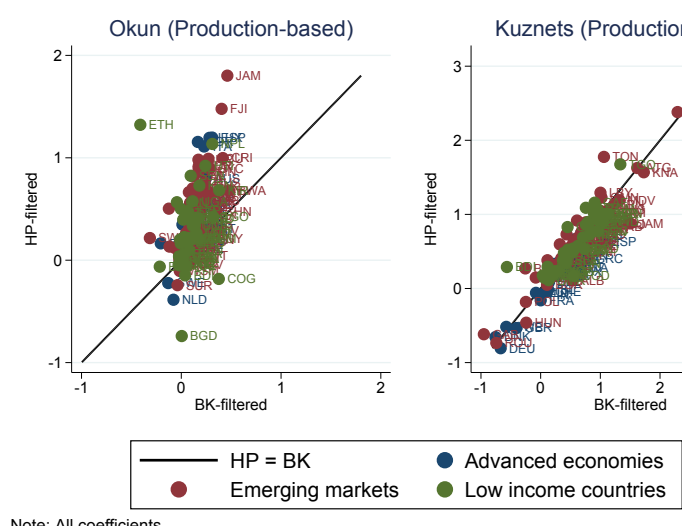

Note: All coefficients.

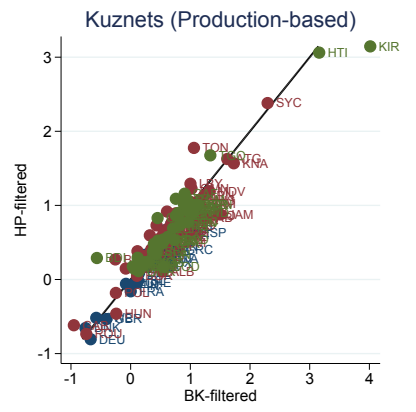

HP vs. BK filters

Low income countries

HP vs. CF filters
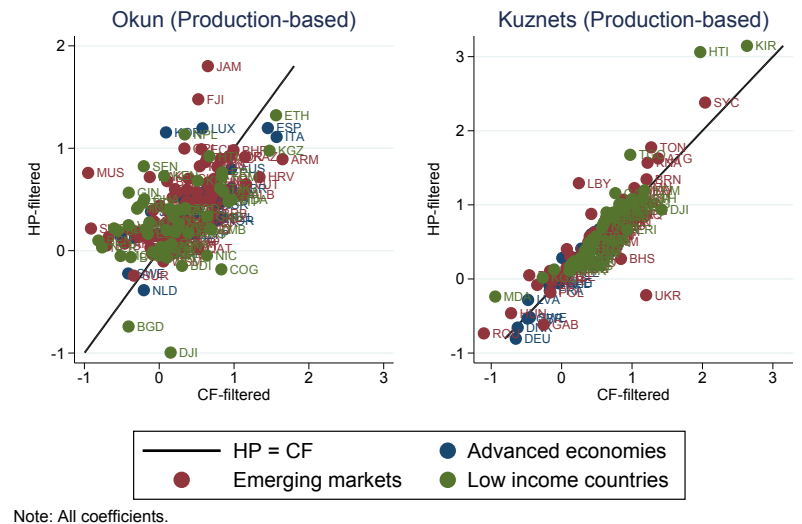
Figure A.11: Trends and cycles in some advanced economies (production-based vs. consumption-based emissions)
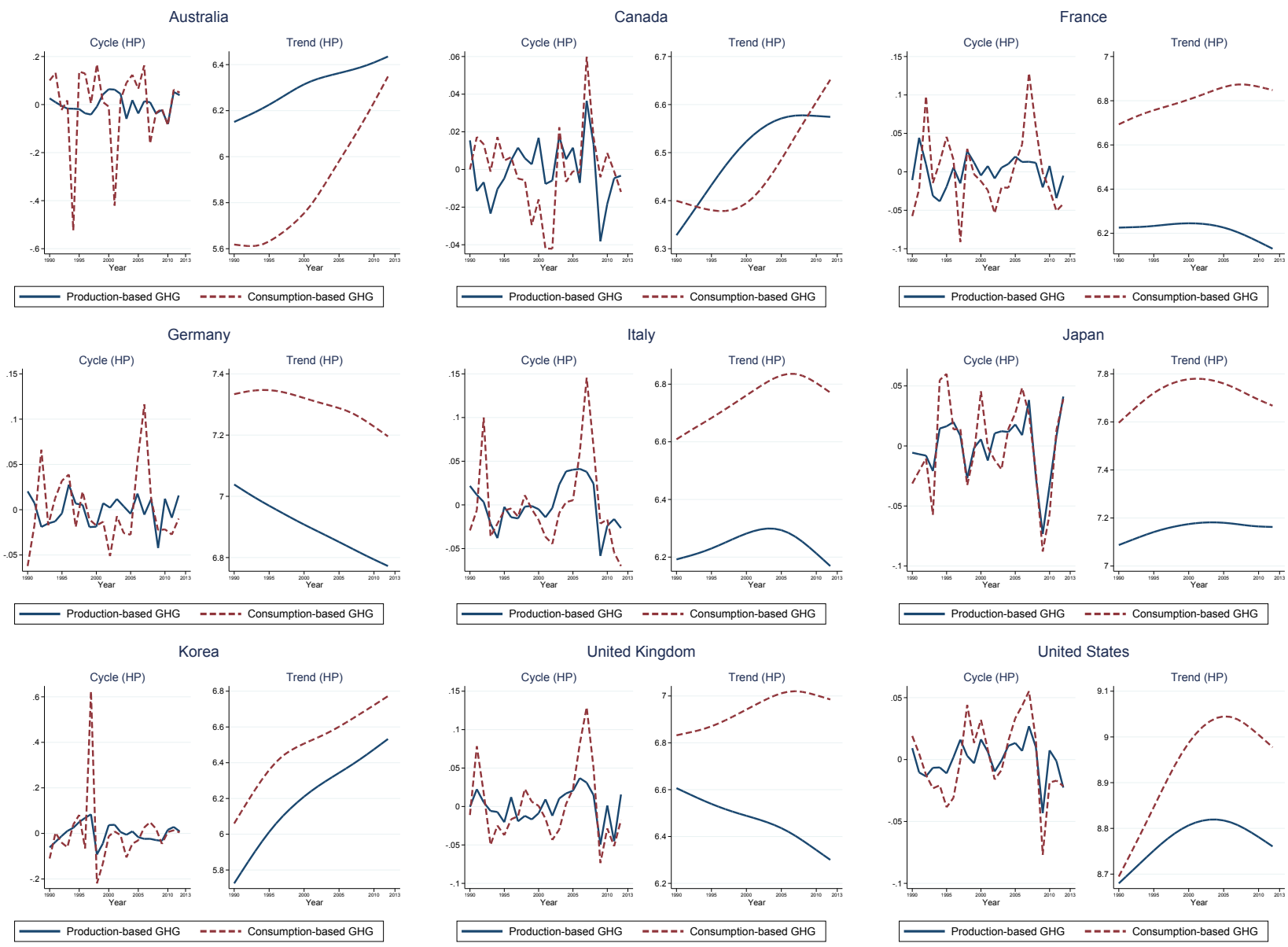
Figure A.12: Trends and cycles in some emerging economies (production-based vs. consumption-based emissions)
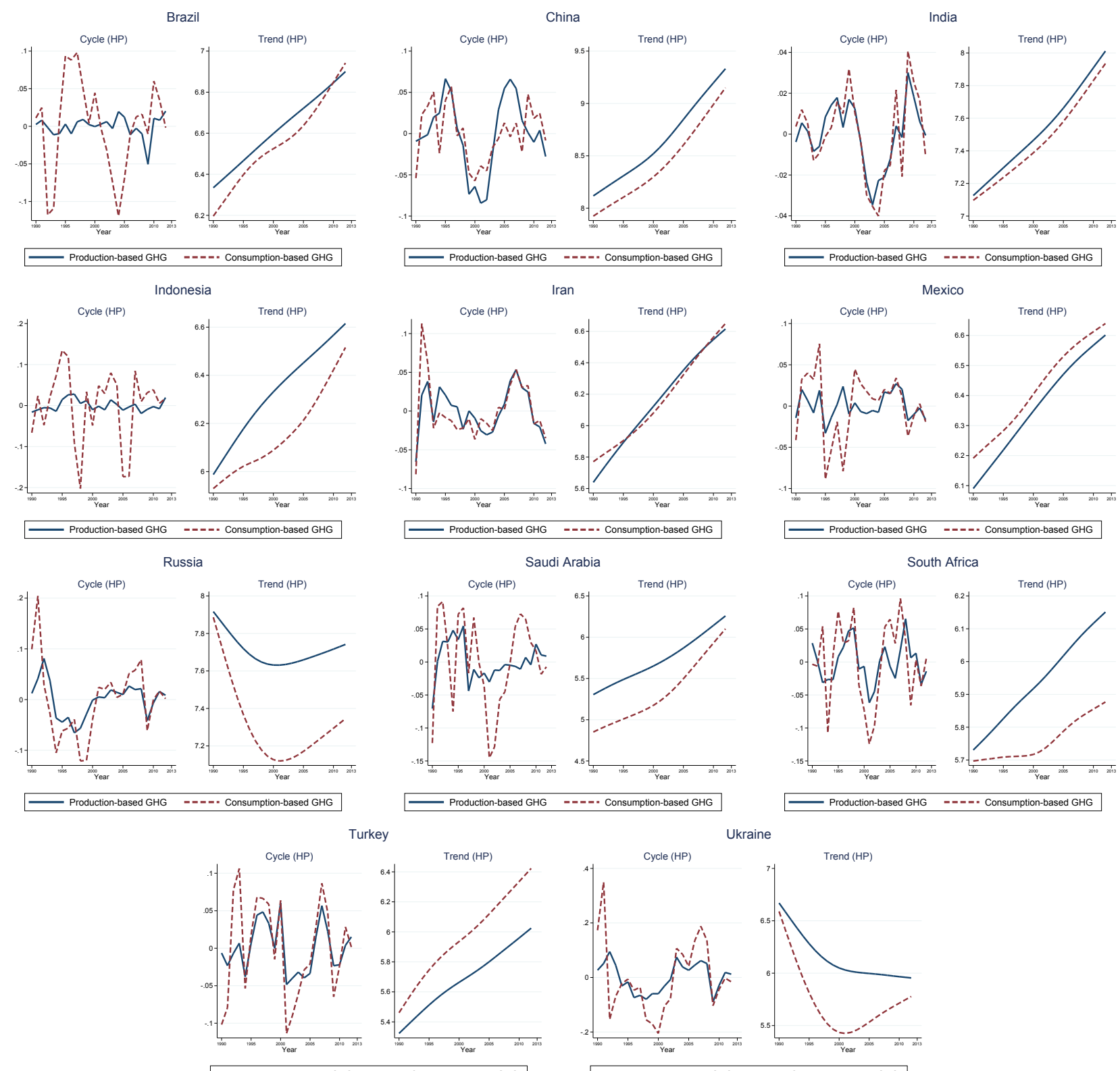

_- Production-based GHG $\quad$----.. Consumption-based GHG

—— Production-based GHG -----. Consumption-based GHG 
Figure A.13: Consumption-based Okun elasticities around the world
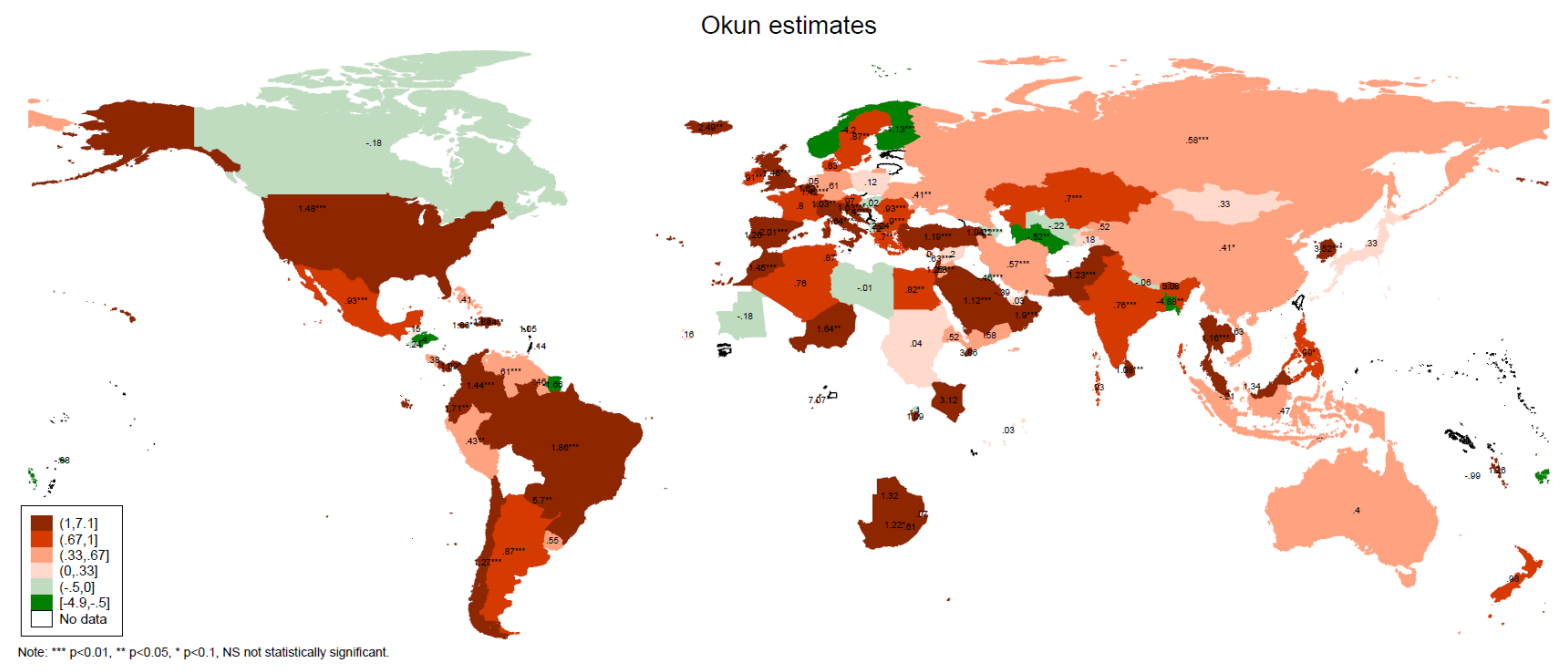

Figure A.14: Consumption-based Kuznets residuals

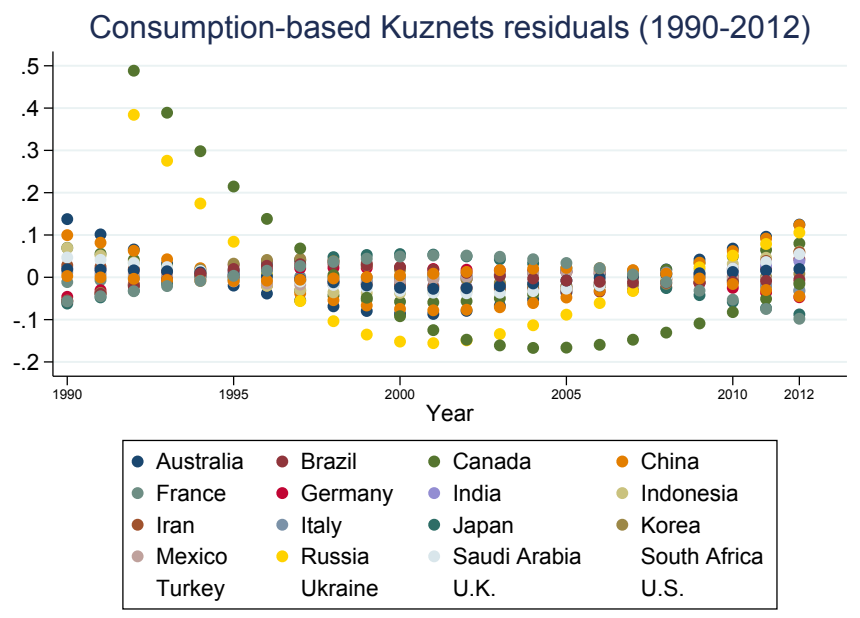


Figure A.15: Consumption-based Kuznets elasticities around the world
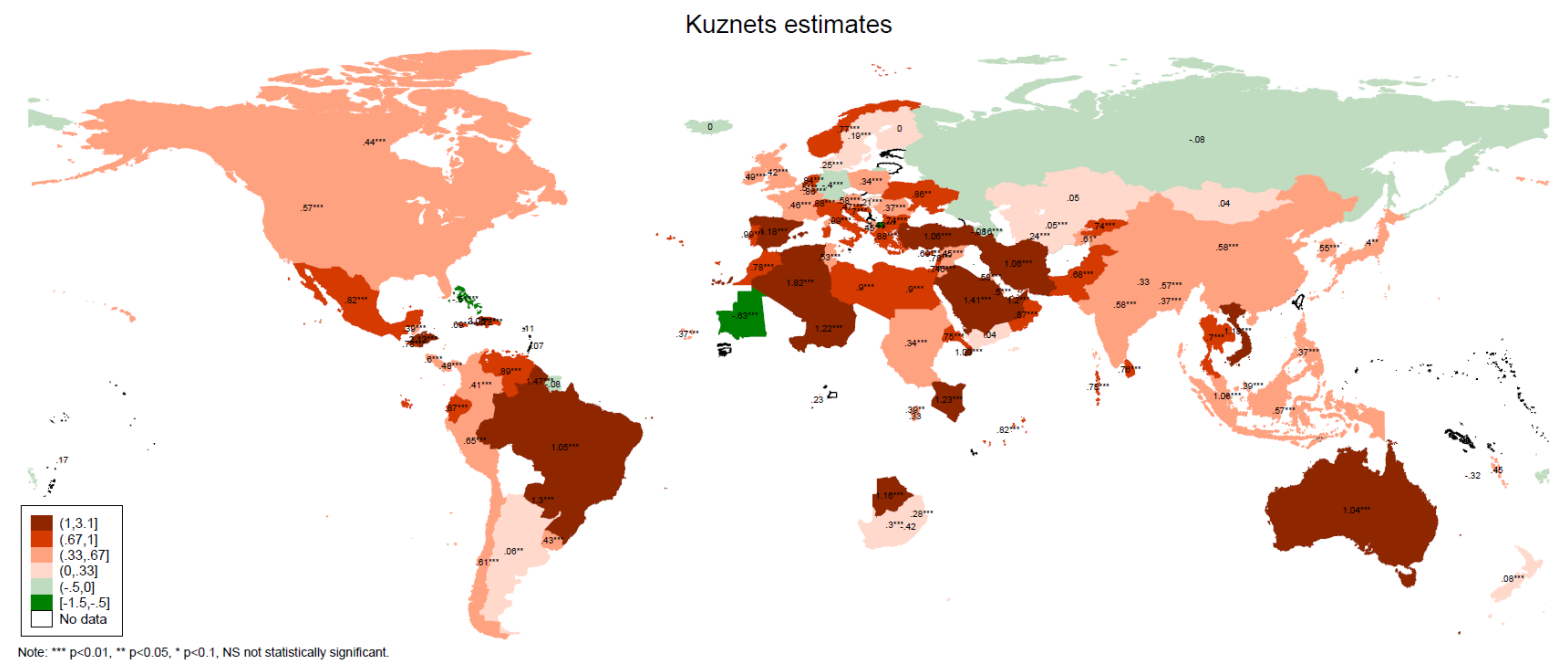

Figure A.16: Kuznets elasticities and real GDP per capita
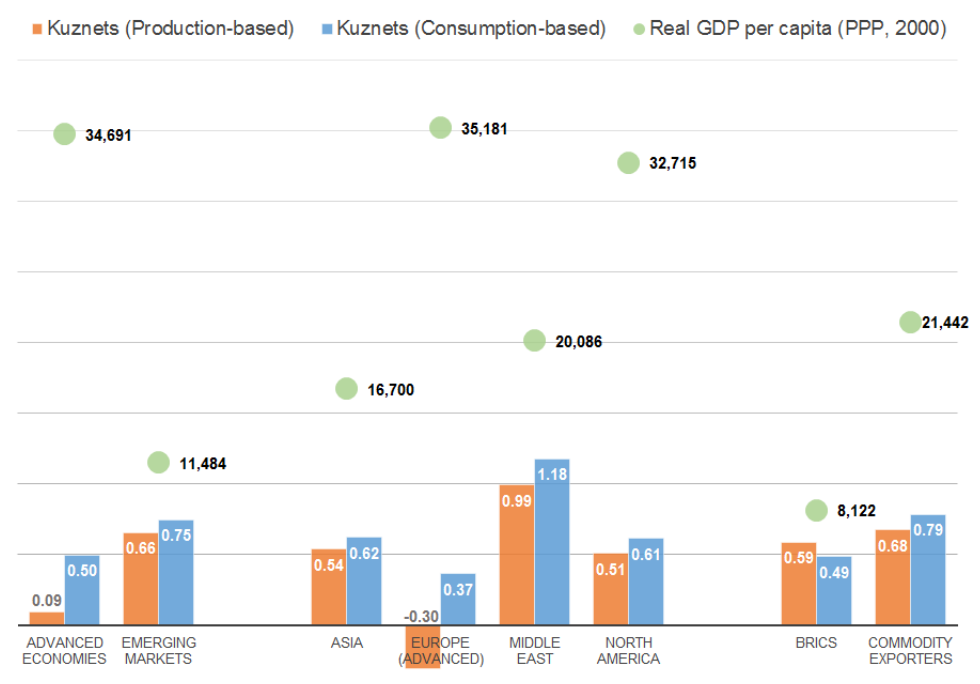

CInternational Monetary Fund. Not for Redistribution 
Figure A.17: Kuznets' y-intercepts and real GDP per capita
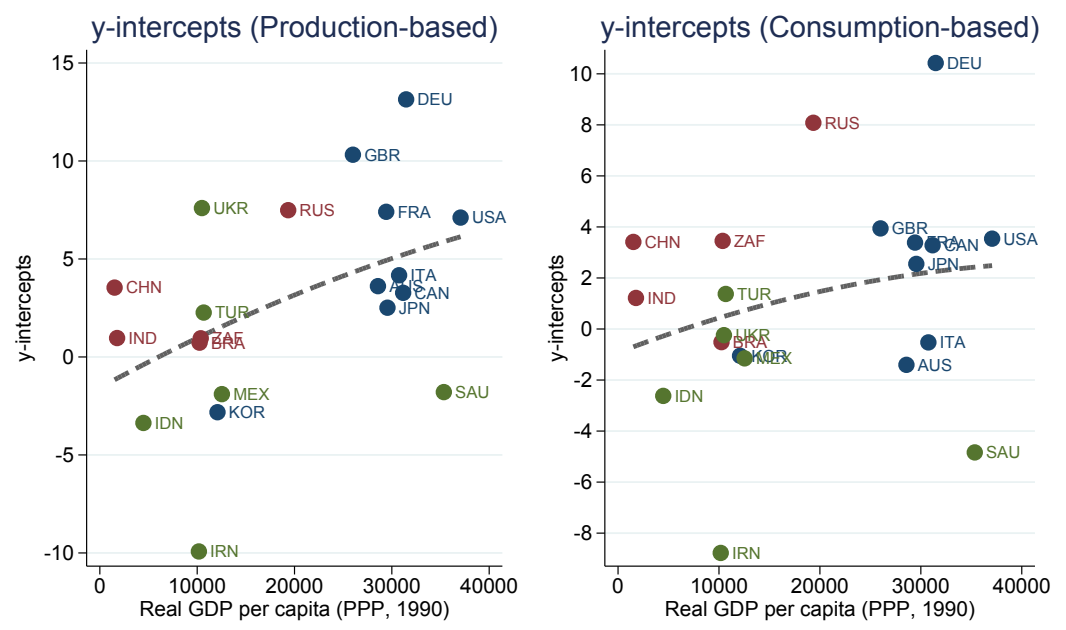

\begin{tabular}{|c|c|}
\hline $\begin{array}{l}-=- \text { Quadratic } p \\
\text { BRICS }\end{array}$ & $\begin{array}{l}\text { Advanced economies } \\
\text { Other emerging markets }\end{array}$ \\
\hline
\end{tabular}

Figure A.18: Kuznets y-intercepts: Production- vs. consumption-based

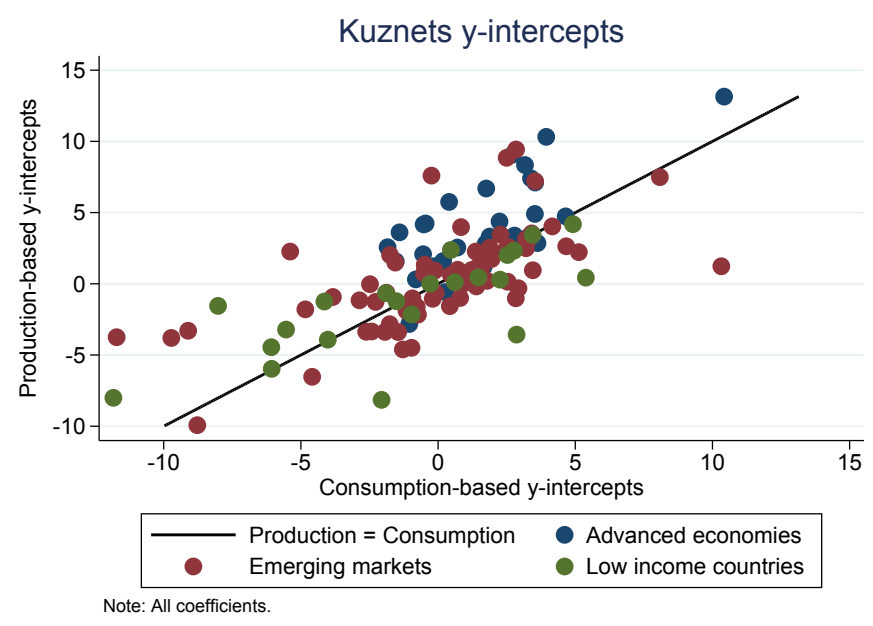




\section{Additional tables}

Table B.1: Augmented Dickey-Fuller test for unit root

\begin{tabular}{|c|c|c|c|c|c|}
\hline & \multicolumn{5}{|c|}{ Production-based Kuznets residuals (1990-2012) } \\
\hline & $(1)$ & $(2)$ & $(3)$ & $(4)$ & $(5)$ \\
\hline COUNTRY & $\mathrm{Z}(\mathrm{t})$ & $\hat{\varepsilon}_{t-1}^{\tau}$ & $\Delta \hat{\varepsilon}_{t-1}^{\tau}$ & $\Delta \hat{\varepsilon}_{t-2}^{\tau}$ & $\Delta \hat{\varepsilon}_{t-3}^{\tau}$ \\
\hline \multicolumn{6}{|c|}{ Advanced economies } \\
\hline Australia & $-2.732^{* * *}$ & $-0.043^{* *}$ & $2.198^{* * *}$ & $-1.889 * * *$ & $0.679^{* * *}$ \\
\hline Canada & $-2.022^{* *}$ & $-0.008^{*}$ & $2.110^{* * *}$ & $-1.679 * * *$ & $0.559^{* *}$ \\
\hline France & $-5.702^{* * *}$ & $-0.028^{* * *}$ & $2.067 * * *$ & $-1.611^{* * *}$ & $0.615^{* * *}$ \\
\hline Germany & $-3.076 * * *$ & $-0.025^{* * *}$ & $1.676^{* * *}$ & $-1.150^{* *}$ & $0.401^{*}$ \\
\hline Italy & $-2.865^{* * *}$ & $-0.047^{* *}$ & $2.879^{* * *}$ & $-3.294^{* * *}$ & $1.628^{* * *}$ \\
\hline Japan & $-1.727^{*}$ & -0.033 & $2.520^{* * *}$ & $-2.513^{* * *}$ & $1.065^{* * *}$ \\
\hline Korea, Republic & -1.227 & -0.023 & $2.269 * * *$ & $-1.847^{* * *}$ & $0.546^{* *}$ \\
\hline U.K. & $-2.024^{* * *}$ & $-0.056^{*}$ & $2.490^{* * *}$ & $-2.418^{* * *}$ & $1.086^{* * *}$ \\
\hline U.S.A. & $-3.862^{* * *}$ & $-0.025^{* * *}$ & $1.705^{* * *}$ & $-1.323^{* * *}$ & $0.672^{* * *}$ \\
\hline \multicolumn{6}{|c|}{ Emerging markets } \\
\hline Brazil & $-7.777 * * *$ & $-0.022^{* * *}$ & $2.265^{* * *}$ & $-1.763^{* * *}$ & $0.462^{* * *}$ \\
\hline China & $-4.926 * * *$ & $-0.009^{* * *}$ & $2.761^{* * *}$ & $-2.816^{* * *}$ & $1.065^{* * *}$ \\
\hline India & -0.510 & -0.018 & $2.875^{* * *}$ & $-2.951^{* * *}$ & $1.140^{* *}$ \\
\hline Indonesia & $-1.582^{*}$ & -0.015 & $2.839^{* * *}$ & $-2.902^{* * *}$ & $1.104^{* * *}$ \\
\hline Iran & -1.012 & -0.008 & $2.113^{* * *}$ & $-1.427^{* * *}$ & 0.264 \\
\hline Mexico & $-1.500 * * *$ & -0.045 & $2.389^{* * *}$ & $-2.002^{* * *}$ & $0.656^{* * *}$ \\
\hline Russia & $-1.374^{*}$ & -0.004 & $2.437 * * *$ & $-2.140 * * *$ & $0.679 * * *$ \\
\hline Saudi Arabia & -0.895 & -0.011 & $2.324^{* * *}$ & $-1.770^{* * *}$ & 0.404 \\
\hline South Africa & $-3.797 * * *$ & $-0.058 * * *$ & $1.918^{* * *}$ & $-1.631^{* * *}$ & $0.626^{* * *}$ \\
\hline Turkey & $-4.810^{* * *}$ & $-0.057^{* * *}$ & $2.035^{* * *}$ & $-1.744^{* * *}$ & $0.684^{* * *}$ \\
\hline Ukraine & $-2.343^{* *}$ & $-0.022^{* *}$ & $1.655^{* * *}$ & -0.877 & 0.093 \\
\hline
\end{tabular}

CInternational Monetary Fund. Not for Redistribution 
Table B.2: Augmented Dickey-Fuller test for unit root

\begin{tabular}{|c|c|c|c|c|c|}
\hline \multicolumn{6}{|c|}{ Production-based Kuznets residuals (1850-2009) } \\
\hline & $(1)$ & $(2)$ & $(3)$ & $(4)$ & $(5)$ \\
\hline COUNTRY & $\mathrm{Z}(\mathrm{t})$ & $\hat{\varepsilon}_{t-1}^{\tau}$ & $\Delta \hat{\varepsilon}_{t-1}^{\tau}$ & $\Delta \hat{\varepsilon}_{t-2}^{\tau}$ & $\Delta \hat{\varepsilon}_{t-3}^{\tau}$ \\
\hline \multicolumn{6}{|c|}{ Advanced economies } \\
\hline Australia & $-1.915^{* *}$ & $-0.000^{*}$ & $2.672^{* * *}$ & $-2.490^{* * *}$ & $0.815^{* * *}$ \\
\hline $1870-1913$ & 1.445 & 0.001 & $2.683^{* * *}$ & $-2.492^{* * *}$ & $0.793^{* * *}$ \\
\hline $1914-1945$ & 1.534 & 0.002 & $2.667 * * *$ & $-2.479 * * *$ & $0.784^{* * *}$ \\
\hline 1946-1982 & $-2.762^{* * *}$ & $-0.005^{* * *}$ & $2.271^{* * *}$ & $-1.925^{* * *}$ & $0.618^{* * *}$ \\
\hline 1983-2007 & $-4.460 * * *$ & $-0.010^{* * *}$ & $2.468^{* * *}$ & $-2.368 * * *$ & $0.919 * * *$ \\
\hline Canada & $-2.072^{* *}$ & $-0.000 * *$ & $2.725^{* * *}$ & $-2.557^{* * *}$ & $0.827^{* * *}$ \\
\hline $1870-1913$ & 0.870 & 0.000 & $2.785^{* * *}$ & $-2.649^{* * *}$ & $0.858^{* * *}$ \\
\hline $1914-1945$ & 0.257 & 0.000 & $2.604^{* * *}$ & $-2.366^{* * *}$ & $0.743^{* * *}$ \\
\hline $1946-1982$ & $-1.831^{* *}$ & $-0.005^{*}$ & $2.257^{* * *}$ & $-1.679^{* * *}$ & $0.397^{* * *}$ \\
\hline 1983-2007 & $-2.940 * * *$ & $-0.050^{* *}$ & $2.298^{* * *}$ & $-2.054^{* *}$ & $0.850^{* * *}$ \\
\hline France & -0.346 & -0.000 & $2.720^{* * *}$ & $-2.556^{* * *}$ & $0.831^{* * *}$ \\
\hline $1870-1913$ & 1.125 & 0.000 & $2.654^{* * *}$ & $-2.464^{* * *}$ & $0.805^{* * *}$ \\
\hline $1914-1945$ & $-6.029 * * *$ & $-0.017^{* * *}$ & $2.847 * * *$ & $-2.884^{* * *}$ & $1.052^{* * *}$ \\
\hline $1946-1982$ & $-5.440 * * *$ & $-0.030^{* * *}$ & $2.361^{* * *}$ & $-2.144 * * *$ & $0.905^{* * *}$ \\
\hline 1983-2007 & $-3.471^{* * *}$ & $-0.028^{* * *}$ & $2.184^{* * *}$ & $-1.894^{* * *}$ & $0.656^{* * *}$ \\
\hline Germany & -0.653 & -0.000 & $2.514^{* * *}$ & $-2.225^{* * *}$ & $0.702^{* * *}$ \\
\hline $1870-1913$ & 1.721 & $0.001^{*}$ & $2.556^{* * *}$ & $-2.213^{* * *}$ & $0.639 * * *$ \\
\hline $1914-1945$ & $-2.498^{* *}$ & $-0.011^{* *}$ & $2.702^{* * *}$ & $-2.558 * * *$ & $0.850^{* * *}$ \\
\hline 1946-1982 & -0.408 & -0.000 & $2.462^{* * *}$ & $-2.172^{* * *}$ & $0.690^{* * *}$ \\
\hline 1983-2007 & -1.134 & -0.024 & $2.261^{* * *}$ & $-1.911^{* * *}$ & $0.599^{* *}$ \\
\hline Italy & $-1.478^{*}$ & -0.000 & $2.560^{* * *}$ & $-2.297^{* * *}$ & $0.724^{* * *}$ \\
\hline $1870-1913$ & 2.343 & $0.001^{* *}$ & $2.583^{* * *}$ & $-2.226^{* * *}$ & $0.630^{* * *}$ \\
\hline $1914-1945$ & $-2.181^{* * *}$ & $-0.007^{* *}$ & $2.496^{* * *}$ & $-2.173^{* * *}$ & $0.659 * * *$ \\
\hline $1946-1982$ & $-4.944^{* * *}$ & $-0.009 * * *$ & $2.647^{* * *}$ & $-2.582^{* * *}$ & $0.974^{* * *}$ \\
\hline 1983-2007 & $-3.061^{* * *}$ & $-0.020^{* * *}$ & $2.449^{* * *}$ & $-2.314^{* * *}$ & $0.906^{* * *}$ \\
\hline Japan & $-1.972^{* *}$ & $-0.001 *$ & $2.717^{* * *}$ & $-2.522^{* * *}$ & $0.799 * * *$ \\
\hline 1946-1982 & 0.020 & 0.000 & $2.446^{* * *}$ & $-1.923 * * *$ & $0.454^{* *}$ \\
\hline 1983-2007 & -0.573 & -0.006 & $2.471^{* * *}$ & $-2.115^{* * *}$ & $0.624^{* *}$ \\
\hline Korea, Republic & $-2.696^{* * *}$ & $-0.003^{* * *}$ & $2.448^{* * *}$ & $-2.116^{* * *}$ & $0.648^{* *}$ \\
\hline $1914-1945$ & $-6.583^{* * *}$ & $-0.006^{* * *}$ & $2.807^{* * *}$ & $-2.844^{* * *}$ & $1.036^{* * *}$ \\
\hline $1946-1982$ & $-4.360 * * *$ & $-0.002^{* * *}$ & $2.597^{* * *}$ & $-2.397^{* * *}$ & $0.790 * * *$ \\
\hline 1983-2007 & $-2.519^{* *}$ & $-0.011^{* *}$ & $2.774^{* * *}$ & $-2.770^{* * *}$ & $1.033^{* * *}$ \\
\hline U.K. & -0.476 & -0.000 & $2.447 * * *$ & $-2.026^{* * *}$ & $0.575^{* * *}$ \\
\hline $1870-1913$ & 1.893 & $0.001^{*}$ & $2.541^{* * *}$ & $-2.243^{* * *}$ & $0.669^{* * *}$ \\
\hline $1914-1945$ & $-1.380^{*}$ & -0.020 & $2.265^{* * *}$ & $-1.753^{* * *}$ & $0.495^{* *}$ \\
\hline $1946-1982$ & 0.338 & 0.000 & $2.478^{* * *}$ & $-2.200 * * *$ & $0.712^{* * *}$ \\
\hline 1983-2007 & 2.493 & $0.047^{* *}$ & $2.090 * * *$ & $-1.161^{*}$ & -0.076 \\
\hline U.S.A. & $-1.304^{*}$ & -0.000 & $2.758^{* * *}$ & $-2.649 * * *$ & $0.889 * * *$ \\
\hline $1870-1913$ & 0.936 & 0.000 & $2.770^{* * *}$ & $-2.637^{* * *}$ & $0.857^{* * *}$ \\
\hline $1914-1945$ & -0.057 & -0.000 & $2.600^{* * *}$ & $-2.331^{* * *}$ & $0.716^{* * *}$ \\
\hline $1946-1982$ & -1.103 & -0.003 & $2.436^{* * *}$ & $-1.973^{* * *}$ & $0.518^{* * *}$ \\
\hline 1983-2007 & $-2.402^{* *}$ & $-0.011^{* *}$ & $2.435^{* * *}$ & $-2.138^{* * *}$ & $0.729^{* * *}$ \\
\hline
\end{tabular}

Note: ${ }^{* * *} \mathrm{p}<0.01,{ }^{* *} \mathrm{p}<0.05,{ }^{*} \mathrm{p}<0.1$.

\section{CInternational Monetary Fund. Not for Redistribution}


Production-based Kuznets residuals (1850-2009)

\begin{tabular}{|c|c|c|c|c|c|}
\hline & (1) & $(2)$ & (3) & $(4)$ & (5) \\
\hline COUNTRY & $\mathrm{Z}(\mathrm{t})$ & $\hat{\varepsilon}_{t-1}^{\tau}$ & $\Delta \hat{\varepsilon}_{t-1}^{\tau}$ & $\Delta \hat{\varepsilon}_{t-2}^{\tau}$ & $\Delta \hat{\varepsilon}_{t-3}^{\tau}$ \\
\hline \multicolumn{6}{|c|}{ Emerging markets } \\
\hline Brazil & $-4.557 * * *$ & $-0.002^{* * *}$ & $2.720^{* * *}$ & $-2.595^{* * *}$ & $0.868^{* * *}$ \\
\hline $1870-1913$ & 0.248 & 0.003 & $2.786^{* *}$ & -2.307 & 0.415 \\
\hline $1914-1945$ & 1.492 & 0.002 & $2.594^{* * *}$ & $-2.336 * * *$ & $0.719 * * *$ \\
\hline 1946-1982 & 0.237 & 0.000 & $2.293^{* * *}$ & $-1.845^{* * *}$ & $0.523^{* * *}$ \\
\hline 1983-2007 & $-1.514^{*}$ & -0.013 & $2.732^{* * *}$ & $-2.628^{* * *}$ & $0.926^{* * *}$ \\
\hline China & $-2.471 * * *$ & $-0.001^{* *}$ & $2.695^{* * *}$ & $-2.538^{* * *}$ & $0.834^{* * *}$ \\
\hline 1946-1982 & $-2.516^{* * *}$ & $-0.003^{* *}$ & $2.672^{* * *}$ & $-2.556^{* * *}$ & $0.869 * * *$ \\
\hline 1983-2007 & $-4.420 * * *$ & $-0.100 * * *$ & $2.510^{* * *}$ & $-2.644^{* * *}$ & $1.451^{* * *}$ \\
\hline India & -0.928 & -0.000 & $2.685^{* * *}$ & $-2.481^{* * *}$ & $0.794^{* * *}$ \\
\hline $1870-1913$ & -0.524 & -0.001 & $2.878^{* * *}$ & $-2.855^{* * *}$ & $0.981^{* * *}$ \\
\hline $1914-1945$ & 0.613 & 0.001 & $2.514^{* * *}$ & $-2.227^{* * *}$ & $0.675^{* * *}$ \\
\hline 1946-1982 & $-1.327^{*}$ & -0.002 & $2.387^{* * *}$ & $-2.066^{* * *}$ & $0.660^{* * *}$ \\
\hline 1983-2007 & $-3.087 * * *$ & $-0.014 * * *$ & $1.691^{* * *}$ & $-1.196^{* * *}$ & $0.477^{* *}$ \\
\hline Indonesia & $-1.530^{*}$ & -0.001 & $2.565^{* * *}$ & $-2.305^{* * *}$ & $0.723^{* * *}$ \\
\hline $1870-1913$ & $-1.925^{* *}$ & $-0.002^{*}$ & $2.891^{* * *}$ & $-2.966^{* * *}$ & $1.075^{* * *}$ \\
\hline $1914-1945$ & $-1.600 *$ & -0.005 & $2.581^{* * *}$ & $-2.411^{* * *}$ & $0.811^{* * *}$ \\
\hline 1946-1982 & $-4.985^{* * *}$ & $-0.007 * * *$ & $2.327^{* * *}$ & $-1.893^{* * *}$ & $0.544^{* * *}$ \\
\hline 1983-2007 & $-3.058^{* * *}$ & $-0.038^{* * *}$ & $2.315^{* * *}$ & $-1.966^{* * *}$ & $0.661^{* * *}$ \\
\hline Mexico & $-7.931 * * *$ & $-0.002^{* * *}$ & $2.740^{* * *}$ & $-2.615^{* * *}$ & $0.869 * * *$ \\
\hline $1914-1945$ & $-8.353^{* * *}$ & $-0.012^{* * *}$ & $2.754^{* * *}$ & $-2.758^{* * *}$ & $1.014^{* * *}$ \\
\hline 1946-1982 & 1.410 & 0.002 & $2.550^{* * *}$ & $-2.306^{* * *}$ & $0.743^{* * *}$ \\
\hline 1983-2007 & $-1.951^{* *}$ & $-0.010^{*}$ & $2.336^{* * *}$ & $-2.106^{* * *}$ & $0.741^{* * *}$ \\
\hline South Africa & $-1.710^{* *}$ & $-0.004 *$ & $2.819^{* * *}$ & $-2.797 * * *$ & $0.997^{* * *}$ \\
\hline 1946-1982 & $-3.876^{* * *}$ & $-0.044^{* * *}$ & $2.351^{* * *}$ & $-2.121^{* * *}$ & $0.801^{* * *}$ \\
\hline 1983-2007 & $-3.734^{* * *}$ & $-0.011 * * *$ & $2.416^{* * *}$ & $-2.214^{* * *}$ & $0.802^{* * *}$ \\
\hline Turkey & -0.574 & -0.001 & $2.587^{* * *}$ & $-2.360 * * *$ & $0.755^{* * *}$ \\
\hline $1914-1945$ & -0.667 & -0.003 & $2.754^{* * *}$ & $-2.684^{* * *}$ & $0.962^{* * *}$ \\
\hline 1946-1982 & $-3.473 * * *$ & $-0.014^{* * *}$ & $2.179^{* * *}$ & $-1.682^{* * *}$ & $0.487^{* * *}$ \\
\hline 1983-2007 & $-1.451^{*}$ & -0.009 & $2.524^{* * *}$ & $-2.343^{* * *}$ & $0.845^{* * *}$ \\
\hline
\end{tabular}

Note: ${ }^{* * *} \mathrm{p}<0.01,{ }^{* *} \mathrm{p}<0.05,{ }^{*} \mathrm{p}<0.1$. 
Table B.3: Contrasting elasticities with LULUCF and $\mathrm{CO}_{2}$

\begin{tabular}{|c|c|c|c|c|c|c|c|}
\hline & \multicolumn{3}{|c|}{$(H P, O L S)$} & \multicolumn{2}{|c|}{ (GHG with $L U L U C F, H P, O L S)$} & \multicolumn{2}{|c|}{$\left(\mathrm{CO}_{2}, \mathrm{HP}, \mathrm{OLS}\right)$} \\
\hline & (1) & $(2)$ & (3) & (4) & $(5)$ & (6) & (7) \\
\hline COUNTRY & $\hat{\omega}$ & $\hat{\beta}^{\text {Okun }}$ & $\hat{\beta}^{\text {Kuznets }}$ & $\hat{\beta}^{\text {Okun }}$ & $\hat{\beta}^{\text {Kuznets }}$ & $\hat{\beta}^{\text {Okun }}$ & $\hat{\beta}^{\text {Kuznets }}$ \\
\hline \multicolumn{8}{|c|}{ Advanced economies } \\
\hline Australia & 0.551 & 0.798 & $0.386^{* * *}$ & 0.691 & $0.437^{* * *}$ & $0.786^{* * *}$ & $0.646^{* * *}$ \\
\hline Canada & $0.683^{* * *}$ & $0.514^{* * *}$ & $0.450 * * *$ & 1.285 & $0.749^{* * *}$ & $0.763^{* * *}$ & $0.444^{* * *}$ \\
\hline France & 0.529 & $0.543^{* *}$ & $-0.159^{* * *}$ & 0.581 & $-0.290^{* * *}$ & $0.868^{* *}$ & 0.003 \\
\hline Germany & 0.353 & 0.164 & $-0.806^{* * *}$ & 0.106 & $-0.913^{* * *}$ & 0.078 & $-0.678^{* * *}$ \\
\hline Italy & $1.165^{* * *}$ & $1.110^{* * *}$ & $0.284^{* *}$ & $1.279^{* * *}$ & $0.249^{* *}$ & $1.341^{* * *}$ & $0.431^{* * *}$ \\
\hline Japan & $0.786^{* * *}$ & 0.382 & $0.355^{* * *}$ & 0.332 & 0.099 & $0.905^{* * *}$ & $0.579^{* * *}$ \\
\hline Korea, Republic & $1.247^{* * *}$ & $1.155^{* * *}$ & $0.662^{* * *}$ & $1.205^{* * *}$ & $0.692^{* * *}$ & $1.516^{* * *}$ & $0.723^{* * *}$ \\
\hline U.K. & $0.642^{* *}$ & $0.610 * * *$ & $-0.534^{* * *}$ & $0.606^{* * *}$ & $-0.563^{* * *}$ & $0.840^{* * *}$ & $-0.286^{* * *}$ \\
\hline U.S.A. & $0.936^{* * *}$ & $0.581^{* * *}$ & $0.177^{* * *}$ & $0.673^{* * *}$ & $0.136^{* * *}$ & $0.752^{* * *}$ & $0.195^{* * *}$ \\
\hline \multicolumn{8}{|c|}{ Emerging markets } \\
\hline Brazil & $0.487^{* * *}$ & 0.118 & $0.874^{* * *}$ & -0.390 & $0.136^{* * *}$ & $0.815^{* *}$ & $1.148^{* * *}$ \\
\hline China & 0.580 & $0.478^{*}$ & $0.591 * * *$ & 0.489 & $0.618^{* * *}$ & 0.555 & $0.677^{* * *}$ \\
\hline India & $0.336^{* *}$ & $0.518^{* * *}$ & $0.614^{* * *}$ & $1.074^{* * *}$ & $0.592^{* * *}$ & $0.682^{* * *}$ & $0.837^{* * *}$ \\
\hline Indonesia & 0.128 & $0.109^{* *}$ & $0.633^{* * *}$ & 0.229 & $0.729 * * *$ & $0.223^{* *}$ & $1.040^{* * *}$ \\
\hline Iran & $0.344^{* *}$ & $0.283^{*}$ & $1.138^{* * *}$ & $0.283^{*}$ & $1.131^{* * *}$ & $0.478^{* *}$ & $1.315^{* * *}$ \\
\hline Mexico & $0.530^{* * *}$ & $0.440^{* * *}$ & $0.897^{* * *}$ & $0.440^{* * *}$ & $0.828^{* * *}$ & $0.647^{* * *}$ & $0.803^{* * *}$ \\
\hline Russia & $0.531^{* * *}$ & $0.440^{* * *}$ & 0.020 & $0.308^{* * *}$ & $-0.235^{* * *}$ & $0.442^{* * *}$ & -0.024 \\
\hline Saudi Arabia & $0.403^{*}$ & $0.319 * *$ & $1.046^{* * *}$ & $0.319^{* *}$ & $1.046^{* * *}$ & $0.335^{*}$ & $1.069^{* * *}$ \\
\hline South Africa & $0.678^{*}$ & $0.818^{* * *}$ & $0.653^{* * *}$ & $0.859^{* * *}$ & $0.645^{* * *}$ & $1.001^{* * *}$ & $0.688^{* * *}$ \\
\hline Turkey & $0.630^{* * *}$ & $0.571^{* * *}$ & $0.791^{* * *}$ & $0.714^{* * *}$ & $0.790^{* * *}$ & $0.758^{* * *}$ & $1.010^{* * *}$ \\
\hline Ukraine & $0.537^{* * *}$ & $0.417^{* * *}$ & -0.219 & $0.541 * * *$ & -0.105 & $0.517^{* * *}$ & -0.294 \\
\hline
\end{tabular}

Note: ${ }^{* * *} \mathrm{p}<0.01,{ }^{* *} \mathrm{p}<0.05,{ }^{*} \mathrm{p}<0.1$. 
Table B.4: Contrasting elasticities with longer time series

\begin{tabular}{|c|c|c|c|c|}
\hline & \multicolumn{2}{|c|}{$\left(C_{2}, H P, O L S\right)$} & \multicolumn{2}{|c|}{ (Long $\mathrm{CO}_{2}, \mathrm{HP}, \mathrm{OLS}$} \\
\hline & (1) & $(2)$ & (3) & (4) \\
\hline COUNTRY & $\hat{\beta}^{\text {Okun }}$ & $\hat{\beta}^{\text {Kuznets }}$ & $\hat{\beta}^{\text {Okun }}$ & $\hat{\beta}^{\text {Kuznets }}$ \\
\hline \multicolumn{5}{|c|}{ Advanced economies } \\
\hline Australia & $0.779^{* * *}$ & $0.688^{* * *}$ & $0.753^{* * *}$ & $1.406^{* * *}$ \\
\hline Canada & $0.745^{* * *}$ & $0.506^{* * *}$ & $0.906^{* * *}$ & $1.023^{* * *}$ \\
\hline France & $0.917^{* * *}$ & $0.125^{* * *}$ & $0.926^{* * *}$ & $0.732^{* * *}$ \\
\hline Germany & 0.110 & $-0.645^{* * *}$ & $0.740 * * *$ & $0.895^{* * *}$ \\
\hline Italy & $1.331^{* * *}$ & $0.555^{* * *}$ & $3.747^{* * *}$ & $1.517^{* * *}$ \\
\hline Japan & $0.934^{* * *}$ & $0.680^{* * *}$ & $1.205^{* * *}$ & $0.850^{* * *}$ \\
\hline Korea, Republic & $1.497^{* * *}$ & $0.735^{* * *}$ & 0.384 & $1.428^{* * *}$ \\
\hline U.K. & $0.893^{* * *}$ & $-0.192^{* * *}$ & $0.797^{* * *}$ & $0.409^{* * *}$ \\
\hline U.S.A. & $0.814^{* * *}$ & $0.278^{* * *}$ & $0.682^{* * *}$ & $0.979^{* * *}$ \\
\hline \multicolumn{5}{|c|}{ Emerging markets } \\
\hline Brazil & $0.826^{* *}$ & $1.182^{* * *}$ & $1.366^{* * *}$ & $1.187^{* * *}$ \\
\hline China & $0.647^{*}$ & $0.642^{* * *}$ & $1.200^{* * *}$ & $1.040^{* * *}$ \\
\hline India & $0.686^{* * *}$ & $0.826^{* * *}$ & -0.094 & $1.780^{* * *}$ \\
\hline Indonesia & $0.226^{* *}$ & $1.180^{* * *}$ & 0.721 & $1.679^{* * *}$ \\
\hline Mexico & $0.662^{* * *}$ & $0.802^{* * *}$ & 0.428 & $1.059^{* * *}$ \\
\hline South Africa & $1.047^{* * *}$ & $0.695^{* * *}$ & $0.590^{* *}$ & $0.923^{* * *}$ \\
\hline Turkey & $0.766^{* * *}$ & $1.013^{* * *}$ & 0.083 & $1.287^{* * *}$ \\
\hline
\end{tabular}

Note: $* * * \mathrm{p}<0.01, * * \mathrm{p}<0.05, * \mathrm{p}<0.1$. Columns (1) and (2) are for the period 1990-2009. For columns (3) and (4), the starting date is: 1850 for France, Germany, U.K., and U.S.; 1860 for Australia and Italy; 1870 for Canada; 1884 for India; 1889 for Indonesia; 1900 for Mexico; 1901 for Brazil; 1911 for Korea; 1923 for Turkey; 1950 for China, Japan, and

South Africa. Iran, Russia, Saudi Arabia, and Ukraine have more limited data. 
Table B.5: GDP decomposition and emissions

\begin{tabular}{|c|c|c|c|}
\hline VARIABLE & $\begin{array}{c}(1) \\
\Delta \mathrm{GHG}\end{array}$ & $\begin{array}{c}(2) \\
\text { GHG }^{\text {cycle }}\end{array}$ & $\begin{array}{c}(3) \\
\mathrm{GHG}^{\text {trend }}\end{array}$ \\
\hline$\Delta$ Real Hh. Cons. & $\begin{array}{c}0.088^{* * *} \\
(0.019)\end{array}$ & & \\
\hline$\Delta$ Real Cap. Spend. (GCF) & $\begin{array}{l}0.00 *^{*} \\
(0.000)\end{array}$ & & \\
\hline$\Delta$ Real Gov. Cons. & $\begin{array}{c}0.047 * * * \\
(0.010)\end{array}$ & & \\
\hline$\Delta$ Real Exports (G. \& S.) & $\begin{array}{c}0.088^{* * *} \\
(0.012)\end{array}$ & & \\
\hline$\Delta$ Real Imports (G. \& S.) & $\begin{array}{c}0.038^{* * *} \\
(0.013)\end{array}$ & & \\
\hline Real Hh. Cons. ${ }^{\text {cycle }}$ & & $\begin{array}{c}0.108^{* * *} \\
(0.016)\end{array}$ & \\
\hline Real Cap. Spend. $(\mathrm{GCF})^{\text {cycle }}$ & & $\begin{array}{c}0.044^{* * *} \\
(0.007)\end{array}$ & \\
\hline Real Gov. Cons. ${ }^{\text {cycle }}$ & & $\begin{array}{c}0.040^{* * *} \\
(0.009)\end{array}$ & \\
\hline Real Exports (G. \& S.) $)^{\text {cycle }}$ & & $\begin{array}{c}0.086^{* * *} \\
(0.011)\end{array}$ & \\
\hline Real Imports (G. \& S.) $)^{\text {cycle }}$ & & $\begin{array}{l}-0.009 \\
(0.012)\end{array}$ & \\
\hline Real Hh. Cons. ${ }^{\text {trend }}$ & & & $\begin{array}{c}0.535^{* * *} \\
(0.023)\end{array}$ \\
\hline Real Cap. Spend. $(\mathrm{GCF})^{\text {trend }}$ & & & $\begin{array}{c}0.076^{* * *} \\
(0.012)\end{array}$ \\
\hline Real Gov. Cons. ${ }^{\text {trend }}$ & & & $\begin{array}{c}0.239^{* * *} \\
(0.016)\end{array}$ \\
\hline Real Exports (G. \& S.) $)^{\text {trend }}$ & & & $\begin{array}{c}0.193^{* * *} \\
(0.015)\end{array}$ \\
\hline Real Imports (G. \& S.) $)^{\text {trend }}$ & & & $\begin{array}{c}-0.201^{* * *} \\
(0.020)\end{array}$ \\
\hline Constant & $\begin{array}{l}-0.002 \\
(0.016)\end{array}$ & & $\begin{array}{c}-15.708^{* * *} \\
(0.528)\end{array}$ \\
\hline Country effects & Yes & Yes & Yes \\
\hline Time effects & Yes & Yes & Yes \\
\hline Observations & 2,717 & 2,804 & 2,804 \\
\hline R-squared & 0.226 & 0.145 & 0.995 \\
\hline
\end{tabular}

Note: ${ }^{* * *} \mathrm{p}<0.01,{ }^{* *} \mathrm{p}<0.05,{ }^{*} \mathrm{p}<0.1$. Standard errors in parentheses. 
Table B.6: GDP decomposition, regional trade, and emissions

\begin{tabular}{|c|c|c|c|}
\hline & $(1)$ & $(2)$ & $(3)$ \\
\hline VARIABLE & $\Delta \mathrm{GHG}$ & GHG ${ }^{\text {cycle }}$ & $\mathrm{GHG}^{\text {trend }}$ \\
\hline Real Hh. Cons. $\Delta /$ cycle / trend & $0.129^{* * *}(0.033)$ & $0.144^{* * *}(0.028)$ & $0.482^{* * *}(0.031)$ \\
\hline Real Cap. Spend. $(\mathrm{GCF}) \Delta /{ }^{\text {cycle} / \text { trend }}$ & $0.000 *(0.000)$ & $0.052^{* * *}(0.010)$ & $0.170^{* * *}(0.019)$ \\
\hline Real Gov. Cons. $\Delta /$ cycle / trend & $0.073^{* * *}(0.022)$ & $0.048^{* * *}(0.016)$ & $0.241^{* * *}(0.021)$ \\
\hline Real Exports (Services) $\Delta /$ cycle / trend & $0.010(0.009)$ & $0.102^{* * *}(0.018)$ & $0.150^{* * *}(0.022)$ \\
\hline Real Imports (Services) $\Delta /$ cycle / trend & $0.096^{* * *}(0.023)$ & $0.010(0.021)$ & $-0.307 * * *(0.028)$ \\
\hline Real Exports (Goods) to Eastern Europe $\Delta /{ }^{\text {cycle } / \text { trend }}$ & $-0.013(0.094)$ & $0.375^{* * *}(0.082)$ & $0.156^{* * *}(0.022)$ \\
\hline Real Exports (Goods) to Latin America $\Delta /{ }^{\text {cycle } / \text { trend }}$ & $-2.557 * * *(0.758)$ & $4.157^{* * *}(1.332)$ & $0.052(0.033)$ \\
\hline Real Exports (Goods) to North Africa and M.E. $\Delta /$ cycle / trend & $0.195(0.319)$ & $-0.181(0.245)$ & $0.174^{* * *}(0.023)$ \\
\hline Real Exports (Goods) to Sub-Saharan Africa $\Delta /$ cycle / trend & $0.164(0.125)$ & $0.130(0.086)$ & $0.151^{* * *}(0.022)$ \\
\hline Real Exports (Goods) to W. Europe and N. America $\Delta /$ cycle / trend & $0.024(0.047)$ & $0.105^{* *}(0.052)$ & $0.152^{* * *}(0.022)$ \\
\hline Real Exports (Goods) to East Asia $\Delta /{ }^{\text {cycle } / \text { trend }}$ & $-0.072 *(0.039)$ & $0.067^{* * *}(0.023)$ & $0.150^{* * *}(0.022)$ \\
\hline Real Exports (Goods) to Southeast Asia $\Delta /$ cycle / trend & $-0.050(0.064)$ & $0.039(0.069)$ & $0.147^{* * *}(0.022)$ \\
\hline Real Exports (Goods) to South Asia $\Delta /{ }^{\text {cycle } / \text { trend }}$ & $-0.325(0.212)$ & $-0.222(0.297)$ & $0.139^{* * *}(0.022)$ \\
\hline Real Exports (Goods) to Pacific $\Delta /$ cycle / trend & $-0.784^{* *}(0.307)$ & $0.045(0.302)$ & $0.161^{* * *}(0.023)$ \\
\hline Real Exports (Goods) to Caribbean $\Delta /$ cycle / trend & $2.105(8.843)$ & $3.833(12.912)$ & $0.258^{* *}(0.101)$ \\
\hline Real Imports (Goods) from Eastern Europe $\Delta /$ cycle / trend & $0.060(0.053)$ & $-0.068(0.048)$ & $-0.306^{* * *}(0.028)$ \\
\hline Real Imports (Goods) from Latin America $\Delta /$ cycle/ trend & $-2.225(2.098)$ & $-1.849 *(0.981)$ & $-0.382^{* * *}(0.035)$ \\
\hline Real Imports (Goods) from North Africa and M.E. $\Delta /$ cycle $/$ trend & $0.061(0.212)$ & $0.001(0.062)$ & $-0.315^{* * *}(0.029)$ \\
\hline Real Imports (Goods) from Sub-Saharan Africa $\Delta /$ cycle / trend & $0.107(0.138)$ & $0.228^{* *}(0.101)$ & $-0.307^{* * *}(0.028)$ \\
\hline Real Imports (Goods) from W. Europe and N. America $\Delta /$ cycle/trend & $-0.515 * * *(0.146)$ & $-0.340^{* * *}(0.115)$ & $-0.304^{* * *}(0.028)$ \\
\hline Real Imports (Goods) from East Asia $\Delta /{ }^{\text {cycle } / \text { trend }}$ & $0.154^{* * *}(0.044)$ & $0.012(0.028)$ & $-0.306^{* * *}(0.028)$ \\
\hline Real Imports (Goods) from Southeast Asia $\Delta /$ cycle / trend & $0.197(0.166)$ & $0.095(0.096)$ & $-0.311^{* * *}(0.028)$ \\
\hline Real Imports (Goods) from South Asia $\Delta /$ cycle / trend & $0.181(0.318)$ & $-0.335(0.236)$ & $-0.282^{* * *}(0.029)$ \\
\hline Real Imports (Goods) from Pacific $\Delta /$ cycle / trend & $0.113(0.337)$ & $-0.170(0.202)$ & $-0.320^{* * *}(0.029)$ \\
\hline Real Imports (Goods) from Caribbean $\Delta /$ cycle / trend & $9.614(7.831)$ & $3.310(3.360)$ & $-0.410^{* * *}(0.096)$ \\
\hline \multirow[t]{2}{*}{ Constant } & 0.001 & & $-12.753^{* * *}$ \\
\hline & $(0.012)$ & & $(0.717)$ \\
\hline Country effects & Yes & Yes & Yes \\
\hline Time effects & Yes & Yes & Yes \\
\hline Observations & 1,528 & 1,546 & 1,546 \\
\hline R-squared & 0.351 & 0.357 & 0.998 \\
\hline
\end{tabular}

\section{CInternational Monetary Fund. Not for Redistribution}


Table B.7: GDP decomposition, sectoral trade, and emissions

(1)

(2)

(3)

\begin{tabular}{|c|c|c|c|}
\hline VARIABLE & $\Delta \mathrm{GHG}$ & GHG $^{\text {cycle }}$ & $\mathrm{GHG}^{\text {trend }}$ \\
\hline Real Hh. Cons. $\Delta /$ cycle $/$ trend $^{\text {che }}$ & $0.091^{* * *}(0.019)$ & $0.118^{* * *}(0.017)$ & $0.384^{* * *}(0.024)$ \\
\hline Real Cap. Spend. $(\mathrm{GCF}) \Delta /$ cycle / trend & $0.000 *(0.000)$ & $0.034^{* * *}(0.007)$ & $0.080^{* * *}(0.013)$ \\
\hline Real Gov. Cons. $\Delta /{ }^{\text {cycle } / \text { trend }}$ & $0.037^{* * *}(0.010)$ & $0.024^{* *}(0.009)$ & $0.210^{* * *}(0.015)$ \\
\hline Real Exports (Services) $\Delta /$ cycle / trend & $-0.000(0.001)$ & $0.069^{* * *}(0.012)$ & $0.131^{* * *}(0.014)$ \\
\hline Real Imports (Services) $\Delta /{ }^{\text {cycle }} /$ trend & $0.075^{* * *}(0.013)$ & $0.018(0.014)$ & $-0.285^{* * *}(0.020)$ \\
\hline Real Exports of Food $\Delta /$ cycle / trend & $-0.046(0.031)$ & $0.046^{* *}(0.018)$ & $0.131^{* * *}(0.014)$ \\
\hline Real Exports of Beverages and tobacco $\Delta /$ cycle / trend & $-0.229 *(0.133)$ & $0.025(0.041)$ & $0.132^{* * *}(0.015)$ \\
\hline Real Exports of Crude materials (exc. fuels) $\Delta /$ cycle / trend & $0.110^{* * *}(0.043)$ & $0.104^{* * *}(0.022)$ & $0.132^{* * *}(0.014)$ \\
\hline Real Exports of Mineral fuels $\Delta /{ }^{\text {cycle }} /$ trend & $-0.038^{* *}(0.016)$ & $0.058^{* * *}(0.012)$ & $0.131^{* * *}(0.014)$ \\
\hline Real Exports of Animal and vegetable oils $\Delta /$ cycle / trend & $-0.903 *(0.533)$ & $-0.324(0.293)$ & $0.125^{* * *}(0.015)$ \\
\hline Real Exports of Chemicals $\Delta /$ cycle / trend & $-0.079(0.059)$ & $0.064^{* *}(0.026)$ & $0.130^{* * *}(0.014)$ \\
\hline Real Exports of Manufactured goods $\Delta /{ }^{\text {cycle } / \text { trend }}$ & $-0.033(0.025)$ & $0.076^{* * *}(0.015)$ & $0.132^{* * *}(0.014)$ \\
\hline Real Exports of Machinery and transp. equip. $\Delta /$ cycle $/$ trend & $-0.031(0.025)$ & $0.089^{* * *}(0.025)$ & $0.131^{* * *}(0.014)$ \\
\hline Real Exports of Miscellaneous manufacturing $\Delta /$ cycle / trend & $-0.036(0.047)$ & $0.051^{* * *}(0.017)$ & $0.130^{* * *}(0.014)$ \\
\hline Real Exports of Commodities $\Delta /$ cycle/ trend & $0.002(0.026)$ & $0.070 * * *(0.018)$ & $0.131^{* * *}(0.014)$ \\
\hline Real Imports of Food $\Delta /$ cycle / trend & $0.071(0.044)$ & $0.050^{*}(0.029)$ & $-0.286^{* * *}(0.020)$ \\
\hline Real Imports of Beverages and tobacco $\Delta /$ cycle / trend & $-0.087(0.121)$ & $0.006(0.042)$ & $-0.285^{* * *}(0.020)$ \\
\hline Real Imports of Crude materials (exc. fuels) $\Delta /$ cycle / trend & $0.151(0.123)$ & $0.003(0.039)$ & $-0.283^{* * *}(0.020)$ \\
\hline Real Imports of Mineral fuels $\Delta /{ }^{\text {cycle } / \text { trend }}$ & $0.043(0.027)$ & $0.021(0.016)$ & $-0.285^{* * *}(0.020)$ \\
\hline Real Imports of Animal and vegetable oils $\Delta /$ cycle / trend & $-1.235^{* *}(0.578)$ & $-0.456^{*}(0.269)$ & $-0.294^{* * *}(0.020)$ \\
\hline Real Imports of Chemicals $\Delta /$ cycle / trend & $0.224^{* * *}(0.070)$ & $0.040(0.032)$ & $-0.286^{* * *}(0.020)$ \\
\hline Real Imports of Manufactured goods $\Delta /{ }^{\text {cycle }} /$ trend & $0.066(0.048)$ & $0.047(0.028)$ & $-0.283^{* * *}(0.020)$ \\
\hline Real Imports of Machinery and transp. equip. $\Delta /$ cycle / trend & $0.097 * *(0.041)$ & $0.004(0.020)$ & $-0.286 * * *(0.020)$ \\
\hline Real Imports of Miscellaneous manufacturing $\Delta /$ cycle / trend & $0.189^{* *}(0.087)$ & $-0.009(0.038)$ & $-0.283^{* * *}(0.020)$ \\
\hline Real Imports of Commodities $\Delta /{ }^{\text {cycle } / \text { trend }}$ & $0.072^{* * *}(0.024)$ & $0.015(0.017)$ & $-0.285^{* * *}(0.020)$ \\
\hline \multirow[t]{2}{*}{ Constant } & -0.001 & & $-6.633^{* * *}$ \\
\hline & $(0.014)$ & & $(0.588)$ \\
\hline Country effects & Yes & Yes & Yes \\
\hline Time effects & Yes & Yes & Yes \\
\hline Observations & 2,439 & 2,490 & 2,490 \\
\hline R-squared & 0.216 & 0.166 & 0.997 \\
\hline
\end{tabular}

Note: ${ }^{* * *} \mathrm{p}<0.01,{ }^{* *} \mathrm{p}<0.05,{ }^{*} \mathrm{p}<0.1$. Standard errors in parentheses. 
Table B.8: Augmented Dickey-Fuller test for unit root

\begin{tabular}{|c|c|c|c|c|c|}
\hline & \multicolumn{5}{|c|}{ Consumption-based Kuznets residuals (1990-2012) } \\
\hline & $(1)$ & $(2)$ & $(3)$ & $(4)$ & $(5)$ \\
\hline COUNTRY & $\mathrm{Z}(\mathrm{t})$ & $\hat{\varepsilon}_{t-1}^{\tau}$ & $\Delta \hat{\varepsilon}_{t-1}^{\tau}$ & $\Delta \hat{\varepsilon}_{t-2}^{\tau}$ & $\Delta \hat{\varepsilon}_{t-3}^{\tau}$ \\
\hline \multicolumn{6}{|c|}{ Advanced economies } \\
\hline Australia & $-1.641^{*}$ & -0.010 & $1.923^{* * *}$ & $-1.587^{* * *}$ & $0.644^{* * *}$ \\
\hline Canada & $-1.476^{*}$ & -0.006 & $2.660^{* * *}$ & $-2.552^{* * *}$ & $0.895^{* * *}$ \\
\hline France & $-1.522^{*}$ & -0.032 & $2.514^{* * *}$ & $-2.222^{* * *}$ & $0.757^{* *}$ \\
\hline Germany & 0.108 & 0.001 & $2.340^{* * *}$ & $-2.157^{* * *}$ & $0.740^{* * *}$ \\
\hline Italy & -0.459 & -0.013 & $2.247^{* * *}$ & $-1.643^{* *}$ & 0.333 \\
\hline Japan & $-2.851^{* * *}$ & $-0.024^{* *}$ & $2.189^{* * *}$ & $-2.081^{* * *}$ & $0.919 * * *$ \\
\hline Korea, Republic & $-2.961 * * *$ & $-0.113^{* *}$ & $1.366^{* * *}$ & $-0.778^{* *}$ & 0.343 \\
\hline U.K. & $-2.649 * * *$ & $-0.062^{* *}$ & $2.585^{* * *}$ & $-2.506^{* * *}$ & $1.106^{* * *}$ \\
\hline U.S.A. & $-4.918^{* * *}$ & $-0.020 * * *$ & $2.194^{* * *}$ & $-1.999^{* * *}$ & $0.864^{* * *}$ \\
\hline \multicolumn{6}{|c|}{ Emerging markets } \\
\hline Brazil & 3.851 & $0.028^{* * *}$ & $2.714^{* * *}$ & $-2.394^{* * *}$ & $0.625^{* * *}$ \\
\hline China & -0.545 & -0.002 & $2.532^{* * *}$ & $-2.235^{* * *}$ & $0.706^{* * *}$ \\
\hline India & $-2.474^{* *}$ & $-0.013^{* *}$ & $2.684^{* * *}$ & $-2.669 * * *$ & $1.029 * * *$ \\
\hline Indonesia & -1.321 & -0.008 & $2.179^{* * *}$ & $-1.970^{* * *}$ & $0.784^{* * *}$ \\
\hline Iran & $-2.815^{* * *}$ & $-0.014^{* *}$ & $2.285^{* * *}$ & $-1.831^{* * *}$ & $0.613^{* * *}$ \\
\hline Mexico & $-1.529^{*}$ & -0.041 & $2.464^{* * *}$ & $-2.299 * * *$ & $0.854^{* * *}$ \\
\hline Russia & -1.125 & -0.006 & $2.474^{* * *}$ & $-2.223^{* * *}$ & $0.723^{* * *}$ \\
\hline Saudi Arabia & -0.601 & -0.005 & $2.526^{* * *}$ & $-2.285^{* * *}$ & $0.802^{* * *}$ \\
\hline South Africa & $-2.263^{* *}$ & $-0.026^{* *}$ & $2.460 * * *$ & $-2.331^{* * *}$ & $0.887^{* * *}$ \\
\hline Turkey & $-3.708^{* * *}$ & $-0.074^{* * *}$ & $1.878^{* * *}$ & $-1.657^{* * *}$ & $0.711^{* * *}$ \\
\hline Ukraine & $-4.207 * * *$ & $-0.007 * * *$ & $2.300 * * *$ & $-2.115^{* * *}$ & $0.783^{* * *}$ \\
\hline
\end{tabular}

CInternational Monetary Fund. Not for Redistribution 
Table B.9: Economic structure and time-varying production-based Okun elasticities

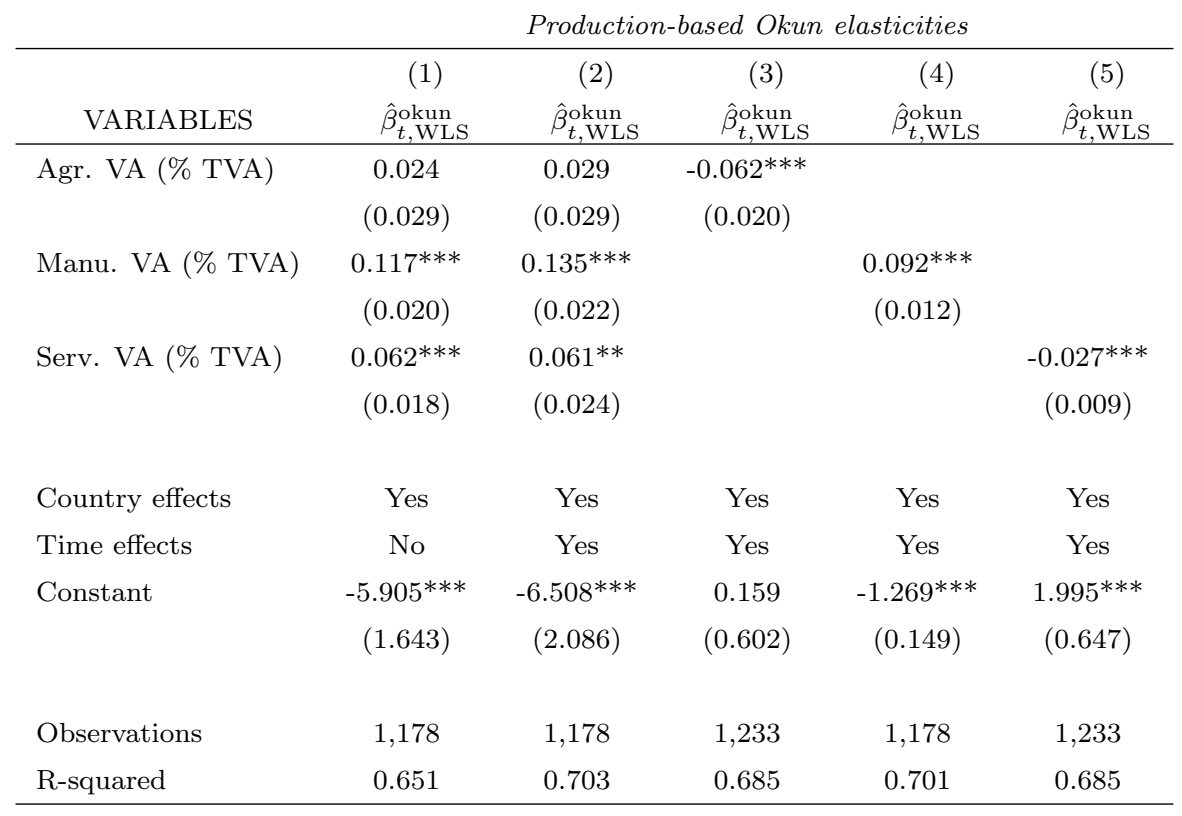

Note: $* * * \mathrm{p}<0.01, * * \mathrm{p}<0.05, * \mathrm{p}<0.1$. The results include the 20 largest world emitters and 37 other countries covered by the Germanwatch's CCPI.

Table B.10: Economic structure and time-varying consumption-based Okun elasticities

\begin{tabular}{lccccc}
\multicolumn{5}{c}{ Consumption-based Okun elasticities } \\
\hline \multicolumn{1}{c}{$(1)$} & $(2)$ & $(3)$ & $(4)$ & $(5)$ \\
VARIABLES & $\hat{\beta}_{t, \mathrm{WLS}}^{\text {okun }}$ & $\hat{\beta}_{t, \mathrm{WLS}}^{\text {okun }}$ & $\hat{\beta}_{t, \mathrm{WLS}}^{\text {okun }}$ & $\hat{\beta}_{t, \mathrm{WLS}}^{\text {okun }}$ & $\hat{\beta}_{t, \mathrm{WLS}}^{\text {okun }}$ \\
\hline Agr. VA (\% TVA) & $5.570^{* * *}$ & $2.709^{* * *}$ & $1.041^{* * *}$ & & \\
& $(0.344)$ & $(0.176)$ & $(0.182)$ & & \\
Manu. VA (\% TVA) & $3.073^{* * *}$ & $1.666^{* * *}$ & & $-0.273^{* * *}$ & \\
& $(0.202)$ & $(0.116)$ & & $(0.095)$ & \\
Serv. VA (\% TVA) & $4.178^{* * *}$ & $2.470^{* * *}$ & & & $0.778^{* * *}$ \\
& $(0.149)$ & $(0.116)$ & & & $(0.073)$ \\
Country effects & & & & & \\
Time effects & Yes & Yes & Yes & Yes & Yes \\
Constant & No & Yes & Yes & Yes & Yes \\
& $-369.676^{* * *}$ & $-212.113^{* * *}$ & -1.843 & $4.851^{* * *}$ & $-56.100^{* * *}$ \\
& $(13.633)$ & $(10.109)$ & $(1.393)$ & $(1.873)$ & $(5.507)$ \\
Observations & 998 & 998 & 1,051 & 998 & 1,051 \\
R-squared & 0.826 & 0.964 & 0.945 & 0.944 & 0.949 \\
\hline Note: *** $<<0.01, * *$
\end{tabular}

